ALINE DURRER PATELLI JULIANI

\title{
Análise do Campo Magnético de um Motor de Ímã Permanente no Rotor Utilizando o Método dos Elementos Finitos
}




\section{Análise do Campo Magnético de um Motor de Ímã Permanente no Rotor Utilizando o Método dos Elementos Finitos}

Dissertação apresentada à Escola de Engenharia de São Carlos, da Universidade de São Paulo, como parte dos requisitos para a obtenção do Título de Mestre em Engenharia Elétrica.

Área de Concentração: Sistemas Dinâmicos Orientador: Prof. Dr. Diógenes Pereira Gonzaga 


\section{Dedicatória:}

Aos meus pais, Fátima e Antonio, que sempre estiveram ao meu lado, incentivando e apoiando em todas as etapas da minha vida. Ao meu noivo, Alex, pelo amor e pela compreensão. 


\section{AGRADECIMENTOS}

Ao Prof. Dr. Diógenes Pereira Gonzaga pela sua excelente orientação e pela sua paciência no decorrer do mestrado.

Ao Prof. Dr. José Roberto Boffino de Almeida Monteiro pela assessoria em Eletrônica de Potência e pelas idéias sugeridas na execução deste trabalho.

Ao Prof. Dr. Naasson Pereira de Alcantara Junior pela formação da minha base em pesquisa científica e pelo incentivo para a realização do mestrado.

Ao Conselho Nacional de Desenvolvimento Científico e Tecnológico pela concessão da bolsa de estudo.

Ao Engenheiro e Mestre em Engenharia Elétrica Fernando Henrique Pisani Teixeira pelo projeto e construção do motor utilizado neste trabalho.

Ao Engenheiro e Mestre em Engenharia Elétrica Mário Celso Gonella pelo desenvolvimento do acionamento e do controle da máquina tratada neste projeto, e pela disponibilização de informações primordiais para a realização deste trabalho.

Aos amigos Wesley Fernando Usida, Danilo Hernane Spatti e Marcelo Suetake pela colaboração com sugestões.

Ao meu noivo, Alex, pelo esclarecimento de diversas dúvidas técnicas.

Ao meu irmão, Allan, pelo auxílio no desenho das figuras.

À minha mãe, Fátima, pela revisão gramatical deste texto e dos artigos científicos. 


\section{RESUMO}

JULIANI, A. D. P. Análise do Campo Magnético de um Motor de Ímã Permanente no Rotor Utilizando o Método dos Elementos Finitos. 2007. 115 f. Dissertação (Mestrado) - Escola de Engenharia de São Carlos, Universidade de São Paulo, São Carlos, 2007.

Neste trabalho é estudado um motor trifásico de ímã permanente no rotor, com fluxo não senoidal, através da análise do campo magnético. Essa máquina foi projetada utilizando-se a estrutura ferromagnética do estator de um motor de indução monofásico de 24 ranhuras o qual recebeu um novo enrolamento trifásico, e foi construído o rotor que é constituído de ímãs permanentes em sua superfície. Ela é aplicada em compressores herméticos de refrigeração, possibilitando o controle de velocidade e a melhoria da eficiência, quando comparada às demais máquinas utilizadas para a mesma aplicação. $\mathrm{O}$ estudo é realizado através da análise dos resultados obtidos utilizando-se um programa computacional baseado no Método dos Elementos Finitos, aplicado em grandezas como: tensão induzida, densidade de fluxo magnético, torque eletromagnético e perdas. São apresentados resultados numéricos comparativos para a máquina existente (protótipo) com as seguintes alterações: diminuição do tamanho do entreferro, troca dos ímãs de ferrita pelos de $\mathrm{NdFeB}$ (Bonded) e, juntamente com essas mudanças, o recálculo do número de espiras e do diâmetro do enrolamento do estator.

Palavras-chave: Máquinas Elétricas; Máquinas com Ímã Permanente; Método dos Elementos Finitos. 


\begin{abstract}
JULIANI, A. D. P. Finite Element Analysis of a Permanent Magnet Motor. 2007. 115 p. Dissertation (Master's Degree) - School of Engineering of São Carlos, University of São Paulo, São Carlos, 2007.

In this work is studied a three-phase permanent-magnet motor, with nonsinusoidal flux, through the analysis of magnetic field. This machine was designed to use the same stator of a 24 slots single-phase induction motor that received a new three-phase winding. The rotor consists of permanent-magnet on its surface. The main application of this machine is in hermetic compressor household refrigeration systems. It has speed control and better efficiency than other machines used for the same application. The study is made through the analysis of numerical results, obtained by a software joint in the finite element method. The results consist in electromagnetic quantity like, back-emf, magnetic flux density, electromagnetic torque and losses. Comparisons between the prototype with these changes are presented: fall in the size of airgap, exchange of ferrite magnets for $\mathrm{NdFeB}$ (Bonded) magnets and, together with these changes, the number of turns in each winding and the wire diameter are recalculated.
\end{abstract}

Keywords: Electrical Machines; Permanent Magnet Machine; Finite Element Method. 


\section{LISTA DE FIGURAS}

Figura 2.1 Motor CC convencional mostrando a posição do eixo de referência e do eixo da bobina (HENDERSHOT; MILLER, 1994)

Figura 2.2 Formas de onda do fluxo concatenado e da tensão induzida de um motor CC convencional

Figura 2.3 Diagrama de blocos do acionamento do MTIPR …............................. 28

Figura 2.4 Circuito de acionamento do MTIPR …................................................... 29

Figura 2.5 Sinais de comando dos transistores do circuito de acionamento do MTIPR

Figura 2.6 Tensão de saída do inversor trifásico do MTIPR

Figura 2.7 Estágios de excitação das bobinas (TEIXEIRA, 2006)

Figura 2.8 Modelo do MTIPR (GONELLA, 2006)

Figura 3.1 Rotor do tipo interior (HENDERSHOT; MILLER, 1994)

Figura 3.2 Rotor do tipo exterior (HENDERSHOT; MILLER, 1994)

Figura 3.3 Rotor do tipo disco (HENDERSHOT; MILLER, 1994)

Figura 3.4 Determinação do coeficiente de permeância através do segundo quadrante da curva de histerese

Figura 3.5

Dimensões para o cálculo da área da ranhura do estator

Figura 4.1

Dimensões do estator

Figura 4.2

Dimensões das ranhuras

Figura 4.3

Curva de magnetização da liga Fe-Si (MEEKER, 2006)...

Figura 4.4 Rotor dividido em regiões conforme a alimentação do enrolamento do estator

Figura 4.5 Dimensões do rotor

Figura 4.6

Curva de desmagnetização da ferrita (MEEKER, 2006)

Figura 4.7 Velocidade mecânica em relação ao tempo, mostrando o intervalo temporal selecionado para a análise estática do campo magnético .....

Figura 4.8 Nova divisão do rotor em regiões conforme a alimentação do enrolamento do estator

Figura 4.9 Velocidade mecânica

Figura 4.10 Torque de carga

Figura 4.11 Corrente elétrica

Figura 4.12 Comparação da tensão induzida obtida pelo software baseado no método dos elementos finitos com a obtida experimentalmente 
Figura 4.13 Comparação do torque eletromagnético obtido pelo software baseado no método dos elementos finitos com o obtido pela simulação temporal

Figura 4.14 Região central do entreferro em que são obtidas as curvas da densidade de fluxo magnético da componente normal

Figura 4.15 Densidade de fluxo magnético da componente normal: a) Posição $0,1^{\circ}$; b) Posição $33,9^{\circ}$

Figura 4.16 Densidade de fluxo magnético da componente normal: a) Posição $71,9^{\circ}$; b) Posição $101,4^{\circ}$

Figura 4.17 Densidade de fluxo magnético da componente normal: a) Posição $135,2^{\circ}$; b) Posição $169,0^{\circ}$

Figura 4.18 Densidade de fluxo magnético da componente normal: a) Posição $198,6^{\circ}$; b) Posição 228,20

Figura 4.19 Densidade de fluxo magnético da componente normal: a) Posição $257,8^{\circ}$; b) Posição $287,3^{\circ}$

Figura 4.20 Densidade de fluxo magnético da componente normal: a) Posição $316,8^{\circ}$; b) Posição $346,3^{\circ}$....

Figura 4.21 Densidade de fluxo magnético da posição $257,8^{\circ}$

Figura 4.22 Densidade de fluxo magnético da posição $287,3^{\circ}$

Figura 4.23 Densidade de fluxo magnético da posição $316,8^{\circ}$, com entreferro de $1,35 \mathrm{~mm}$ e ímãs de ferrita

Figura 4.24 Comparação da densidade de fluxo magnético da componente normal do protótipo (tamanho de entreferro igual a 1,35 $\mathrm{mm}$ ) com a do motor em projeto (tamanho de entreferro igual a $0,76 \mathrm{~mm}$ )

Figura 4.25 Densidade de fluxo magnético da posição $316,8^{\circ}$, com o tamanho do entreferro igual a $0,76 \mathrm{~mm}$ e ímãs de ferrita

Figura 4.26 Comparação da tensão induzida experimental, por fase, do protótipo (entreferro igual a $1,35 \mathrm{~mm}$ ) com a do motor em projeto (entreferro igual a $0,76 \mathrm{~mm}$ ) obtida com o software FEMM

Figura 4.27 Comparação do torque eletromagnético do protótipo (entreferro igual a $1,35 \mathrm{~mm}$ ) com o do motor em projeto (entreferro igual a $0,76 \mathrm{~mm}$ )

Figura 4.28 Comparação da densidade de fluxo magnético da componente normal do protótipo com a do motor constituído por ímãs de $\mathrm{NdFeB}$ (Bonded)

Figura 4.29 Densidade de fluxo magnético da posição $316,8^{\circ}$, com o tamanho do entreferro igual a $1,35 \mathrm{~mm}$ e ímãs de $\mathrm{NdFeB}$ (Bonded)

Figura 4.30 Comparação da tensão induzida experimental com a resultante da substituição dos ímãs de ferrita pelos de $\mathrm{NdFeB}$ (Bonded)

Figura 4.31 Comparação do torque eletromagnético do protótipo com o resultante da substituição dos ímãs de ferrita pelos de $\mathrm{NdFeB}$ (Bonded) 
Figura 4.32 Curvas do ímã NdFeB (Bonded), (NEOMAX, 2006)

Figura 4.33 Comparação da densidade de fluxo magnético da componente normal do protótipo com a do projeto refeito do MTIPR

Figura 4.34 Densidade de fluxo magnético da posição $316,8^{\circ}$, referente ao projeto refeito do MTIPR

Figura 4.35 Comparação da tensão induzida do protótipo com a do projeto refeito do MTIPR

Figura 4.36 Comparação do torque eletromagnético do protótipo com o do projeto refeito do MTIPR

Figura 4.37 Comparação das perdas resistivas do protótipo com as do projeto refeito do MTIPR

Figura 4.38 Estimativa das perdas no ferro referentes ao: 1) Protótipo; 2) Entreferro de tamanho igual a $0,76 \mathrm{~mm}$; 3) Rotor com ímãs de $\mathrm{NdFeB}$ (Bonded); 4) Projeto refeito

Figura A.1 Representação da estrutura dos domínios magnéticos dispostos aleatoriamente em um material policristalino. Neste caso cada grão monocristalino contém um único domínio magnético. Nesta condição o material está desmagnetizado, ou seja, não produz um campo magnético externo (FARIA, 2005)

Figura A.2 Representação ilustrativa das orientações dos momentos de dipolo magnético; (A) ferromagnetismo, (B) antiferromagnetismo e (C) ferrimagnetismo (FARIA, 2005)

Figura A.3 Ciclo de histerese

Figura A.5 Determinação do campo $H_{K}$ a partir de uma curva de desmagnetização intrínseca (FARIA, 2005)

Figura B.1 a) Circuito genérico percorrido pela corrente $i$; b) Conjunto de malhas (ALCANTARA, 1985)

Figura B.2 Representação de um campo magnético bidimensional

Figura B.3 Representação ilustrativa de um problema de campo magnetostático (ALCANTARA, 2003)

Figura B.4 Representação livre de um domínio subdividido em elementos triangulares (SYKULSKI, 1995)

Figura B.5 Elemento triangular

Figura C.1

Definição do problema

Figura C.2

Desenho da geometria

Figura C.3

Biblioteca dos materiais

Figura C.4

Definição das propriedades

Figura C.5 Edição das características de um dado material 
Figura C.6 Discretização da geometria em elementos triangulares de primeira

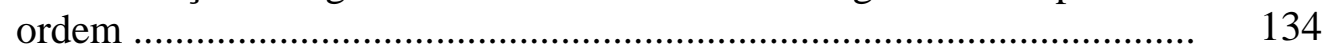

Figura C.7 Execução dos cálculos ........................................................................ 134

Figura C.8 Gráfico de linhas .......................................................................... 135

Figura C.9 Gráfico de cores ........................................................................ 135

Figura C.10 Gráfico da densidade de fluxo magnético da componente normal ........ 135 


\section{SUMÁRIO}

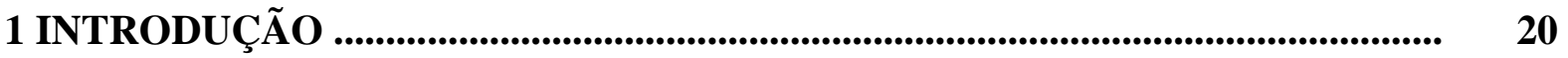

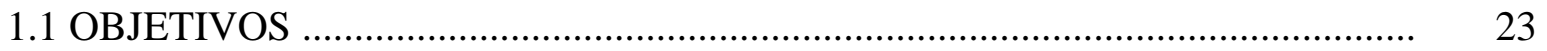

2 MOTOR SÍNCRONO DE ÍMÃ PERMANENTE NO ROTOR ................................ 24

2.1 FUNCIONAMENTO DO MTIPR .................................................................... 26

2.2 ACIONAMENTO ELÉTRICO DO MTIPR ….................................................. 28

2.2.1 Inversores Trifásicos ........................................................................... 29

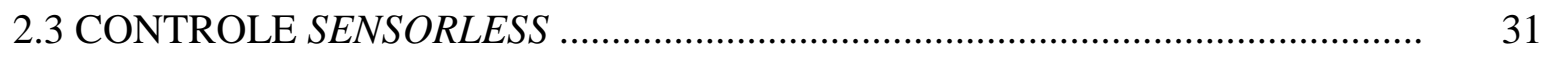

2.4 MODELAGEM MATEMÁTICA DO MTIPR ….............................................. 32

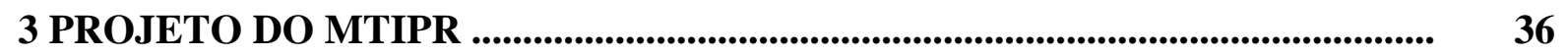

3.1 DETERMINAÇÃO DAS NECESSIDADES DA APLICAÇÃO ......................... 36

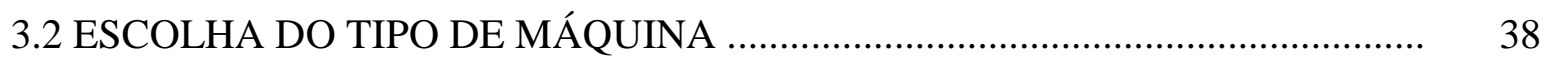

3.2.1 Máquina com Rotor do Tipo Interior ....................................................... 38

3.2.2 Máquina com Rotor do Tipo Exterior ......................................................... 39

3.2.3 Máquina com Rotor Tipo Disco .................................................................. 39

3.3 SELEÇÃO DO ÍMÃ PERMANENTE .............................................................. 40

3.4 ESCOLHA DO NÚMERO DE PÓLOS …......................................................

3.5 DETERMINAÇÃO DA GEOMETRIA, DAS DIMENSÕES E DO NÚMERO DE RANHURAS E DE FASE DO ESTATOR ..................................................... 42

3.6 DETERMINAÇÃO DO TAMANHO DO ENTREFERRO ................................. 42

3.7 CÁLCULO DO TAMANHO DO ROTOR ........................................................... 42

3.8 CÁlCULO DO FLUXO MAGNÉTICO POR PÓLO .......................................... 43

3.9 CÁlCULO DO NÚMERO DE CONDUTORES, DE ESPIRAS E DO DIÂMETRO DO ENROLAMENTO …......................................................... 43

3.10 VERIFICAÇÃO DAS CARACTERÍSTICAS DO MOTOR ….......................... 46

3.11 ESTIMATIVA DAS PERDAS MAGNÉTICAS …........................................ 47

4 RESULTADOS

4.1 CARACTERÍSTICAS CONSTRUTIVAS DO MTIPR ….................................. 52

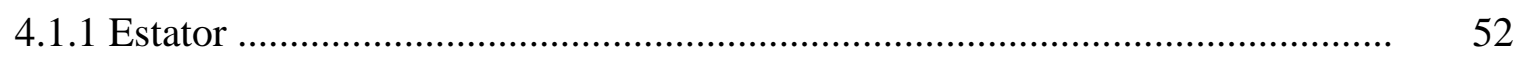


4.1.1.1 Alimentação do Estator .......................................................................... 54

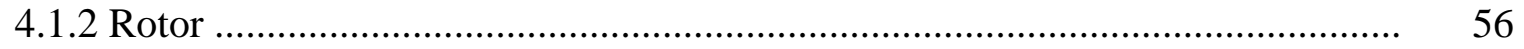

4.2 RESULTADOS DO PROGRAMA COMPUTACIONAL FEMM ...................... 57

4.2.1 Sem a Realização de Alterações do Projeto do MTIPR ................................... 60

4.2.2 Referentes a Dois Tamanhos de Entreferro ..................................................... 68

4.2.3 Referentes a Dois Tipos de Ímãs ....................................................................... 71

4.2.4 Projeto Refeito do MTIPR ……………..................................................... 73

4.2.4.1 Cálculos do Projeto Refeito do MTIPR ................................................. 74

4.2.4.2 Resultados Referentes ao Projeto Refeito do MTIPR …........................... 77

4.2.5 Estimativa das Perdas Magnéticas do MTIPR .................................................... 79

5 CONCLUSÕES E CONTINUIDADE DO TRABALHO ........................................ 82

REFERÊNCIAS BIBLIOGRÁFICAS ...................................................................... 86

APÊNDICE A - Materiais Magnéticos ............................................................................... 92

APÊNDICE B - Campos Magnéticos Estáticos e o Método dos Elementos Finitos • 108

APÊNDICE C - Descrição do Programa de Elementos Finitos FEMM ..................... 130 


\section{Capítulo 1}

\section{Introdução}

As máquinas elétricas são utilizadas em várias aplicações e estão inseridas em diversos ambientes. Tornaram-se elementos primordiais ao cotidiano do ser humano, o que foi possibilitado pelo desenvolvimento da tecnologia dos semicondutores de potência e dos microprocessadores, que melhoram o controle, as capacidades nominais e a velocidade de chaveamento dos dispositivos de potência.

Outros fatores que contribuíram para o avanço tecnológico das máquinas elétricas foram: o desenvolvimento de materiais, como os ímãs de ferrita e os de terras-raras, e a melhoria dos computadores que contribuíram para a realização de simulações espaciais e de projetos de motores, permitindo a utilização do Método dos Elementos Finitos, em programação nas linguagens bem conhecidas ou com softwares voltados para a análise do campo e de circuitos magnéticos.

A utilização dos ímãs permanentes, no rotor dos motores, exige o conhecimento das propriedades magnéticas do material ferromagnético que constitui a estrutura do estator. Isso é devido à limitação da densidade de fluxo magnético no ferro, que não deve exceder aproximadamente 1,6-1,7 T (HENDERSHOT; MILLER, 1994), faixa na qual ocorre o rápido decrescimento da permeabilidade magnética. 
Neste trabalho é feito um estudo do campo magnético, utilizando-se o Método dos Elementos Finitos, de um Motor Brushless DC (Brushless Direct Current Motor - BDCM) que é aplicado a compressores herméticos de refrigeração. Possui as principais vantagens, quando comparado aos motores de indução, que são os mais empregados para esse uso: controle de velocidade, maior eficiência e menor volume devido à baixa dissipação de energia no rotor, em consequência da ausência de enrolamento em sua construção.

Comumente, os aparelhos de refrigeração utilizam motores de indução monofásicos, em que o controle da velocidade é obtido com o uso de inversores de freqüência. No entanto, estes motores são projetados para trabalhar em velocidades e tensões pré-definidas, onde apresentam o máximo desempenho. Numa região de trabalho, fora deste ponto, o motor pode apresentar uma variação de eficiência de 55 a 65\% (ponto nominal) para 15 a 20\% (GUCKELBERGER, 2004).

Além das máquinas síncronas com ímã permanente no rotor (MSIP) apresentarem maior eficiência (em torno de 75\%) que os motores de indução monofásicos (GUCKELBERGER, 2004), elas possuem diversas vantagens em relação aos acionamentos convencionais de velocidade variável, que empregam motores de corrente contínua (CC): maior desempenho, ausência das escovas (brushless), o que propicia a eliminação de vários problemas relacionados a elas, como o centelhamento, a manutenção periódica, a restrição de utilização em áreas classificadas (ambientes que possam conter gases explosivos) e outros. 


\subsection{Objetivos}

Este trabalho tem como objetivo a análise do campo magnético no motor trifásico de ímã permanente no rotor (MTIPR), utilizando-se o método dos elementos finitos. Os resultados obtidos são usados para a realização de sugestões de melhorias de desempenho da máquina.

O projeto, a construção e o acionamento do motor de ímã permanente no rotor com controle sensorless estão disponíveis em (TEIXEIRA, 2006) e (GONELLA, 2006).

Essa máquina foi projetada e construída para ser aplicada em compressores herméticos de refrigeração, destacando-se pela possibilidade do controle de velocidade e pela melhoria da eficiência quando comparada aos demais tipos de máquinas utilizadas para a mesma aplicação. 


\section{Capítulo 2}

\section{Motor Síncrono de Ímã Permanente no Rotor}

O motor síncrono de ímã permanente no rotor (MSIP) é constituído por um estator formado por bobinas e por um rotor com ímãs permanentes em sua superfície.

Essas máquinas podem ser classificadas de acordo com a força contra-eletromotriz produzida pelo fluxo magnético incidindo no enrolamento do estator, que pode ser trapezoidal ou senoidal.

As máquinas que não possuem escovas e comutadores mecânicos, como são requeridos nos motores $\mathrm{CC}$ convencionais ou nas máquinas síncronas $\mathrm{CA}$ (corrente alternada), são denominadas de brushless (MILLER,1989; KENJO; NAGAMORI,1985). Vários motores enquadram-se nesta definição básica, como os motores de indução e os motores de passo (HENDERSHOT; MILLER, 1994).

Conforme o modo de operação da máquina síncrona, ela pode ser denominada brushless DC ou brushless AC.

Segundo (NASAR; BOLDEA; UNNEWEHR, 1993), a nomenclatura brushless DC deve-se à máquina síncrona com ímã permanente no rotor, com forma de onda não senoidal, ser comercializada juntamente com o seu conversor de potência. Esse conjunto comporta-se como uma máquina $\mathrm{CC}$, mas com um comutador eletrônico. 
Conforme (HENDERSHOT; MILLER, 1994), os motores brushless AC implicam em excitação senoidal e a tensão induzida, ideal, tem a mesma forma de onda da alimentação. Fisicamente o motor e o seu controle são similares ao brushless $D C$.

Essas máquinas são nomeadas síncronas devido ao fato do rotor girar à mesma velocidade angular que a onda do campo magnético girante, criado pelas correntes trifásicas do enrolamento do estator, ou seja, em sincronismo com a mesma.

O motor trifásico de ímã permanente no rotor (MTIPR), tratado neste trabalho, é uma máquina síncrona com alimentação trapezoidal. É empregado em sistemas de refrigeração, possuindo a mesma estrutura ferromagnética do estator de um motor de indução monofásico, que comumente é utilizado para esse tipo de aplicação. Com isso, modificações na linha de produção são evitadas.

Esta máquina não utiliza sensores para a detecção da posição do rotor, daí muitas vezes ser denominada de sensorless. A ausência desses componentes implica em uma maior facilidade para a construção do motor, possibilitando o seu emprego em ambientes hostis, pois estes poderiam prejudicar a operação dos sensores (HENDERSHOT; MILLER, 1994).

O funcionamento, o acionamento elétrico e o controle do MTIPR são detalhados nas seções seguintes.

\subsection{Funcionamento do MTIPR}

O processo de comutação dos motores brushless $D C$ é semelhante ao das máquinas CC convencionais. A figura 2.1 mostra o fluxo magnético produzido pelos ímãs permanentes e a posição do rotor $\left(\theta_{m}\right.$ [graus mecânicos]), que representa o deslocamento da bobina em relação ao eixo de referência, de um motor CC de dois pólos (HENDERSHOT; MILLER, 1994). 


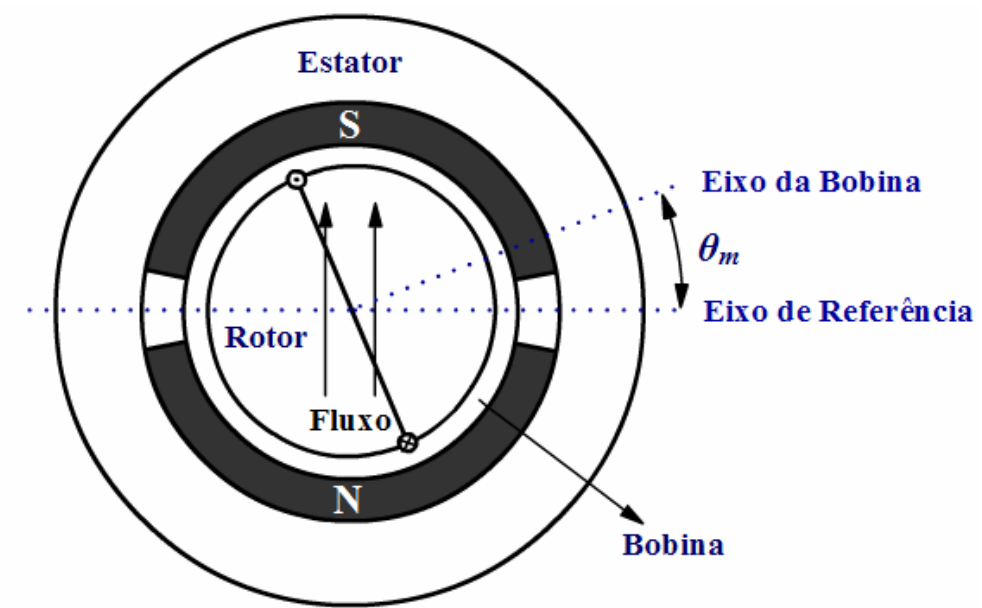

Figura 2.1. Motor CC convencional mostrando a posição do eixo de referência e do eixo da bobina (HENDERSHOT; MILLER, 1994).

Quando $\theta_{m}$ é igual a zero, o fluxo magnético produzido pelos ímãs não atravessa a bobina, com isso, o fluxo concatenado ( $\psi[\mathrm{Wb}])$ é nulo. À medida que $\theta_{m}$ aumenta, há o incremento do fluxo que atinge o seu valor máximo quando a posição do rotor fica entre $60^{\circ} \mathrm{e}$ $120^{\circ}$. Como há um espaço vazio entre os ímãs, ocorre a inversão do fluxo concatenado nesta posição.

Conhecendo-se a forma de onda do fluxo concatenado ( $\psi[\mathrm{Wb}])$, obtém-se a tensão induzida pelas bobinas $(e[\mathrm{~V}])$ por meio de sua derivada em relação ao tempo (Lei de Faraday):

$$
e=\frac{d \psi}{d t}=\frac{\partial \psi}{\partial \theta_{m}} \frac{d \theta_{m}}{d t}=\omega_{m} \frac{\partial \psi}{\partial \theta_{m}}
$$

Onde:

$\omega_{m}$ é a velocidade angular mecânica $[\mathrm{rad} / \mathrm{s}]$.

O torque eletromagnético $\left(T_{e l}[\mathrm{Nm}]\right)$ pode ser calculado através da equação (2).

$$
T_{e l}=\frac{e \cdot i}{\omega_{m}}
$$

Onde:

$i$ é a corrente elétrica [A]. 
As formas de onda do fluxo concatenado e da tensão induzida podem ser vistas na figura 2.2.

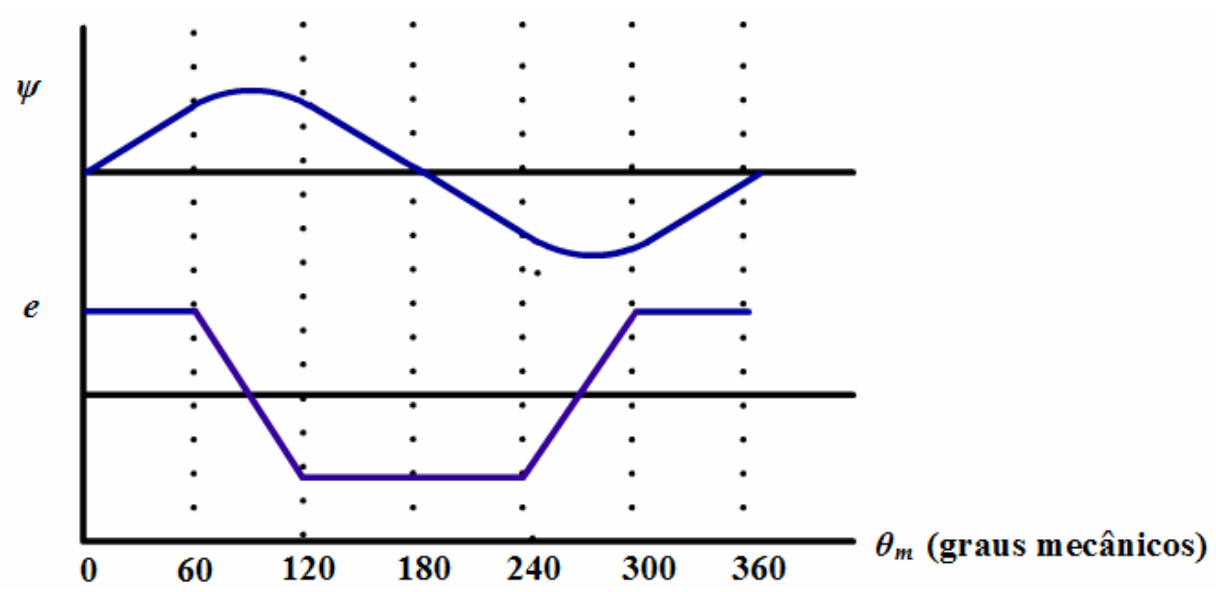

Figura 2.2. Formas de onda do fluxo concatenado e da tensão induzida de um motor CC convencional.

\subsection{Acionamento Elétrico do MTIPR}

O acionamento elétrico do MTIPR é representado pela figura 2.3 e é composto por cinco blocos: alimentação do sistema (fonte de tensão alternada), retificador, inversor trifásico, sistema de detecção da posição do rotor e controle do acionamento do inversor.

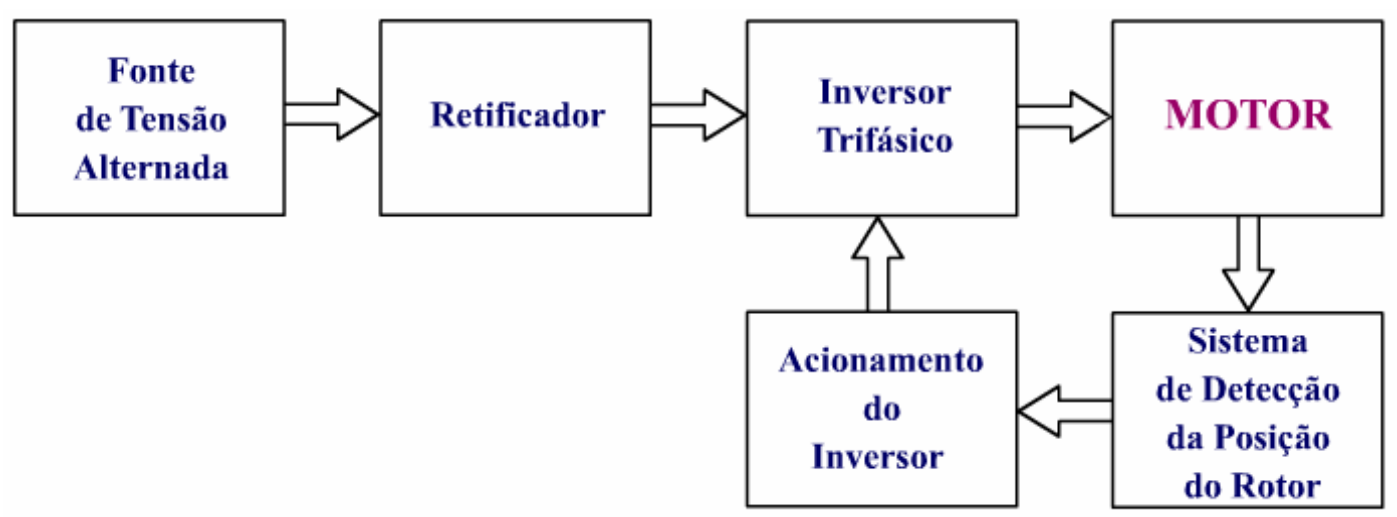

Figura 2.3. Diagrama de blocos do acionamento do MTIPR.

Nas subseções seguintes são detalhados o inversor trifásico, incluindo a sua lógica de acionamento e o sistema de detecção da posição do rotor. 


\subsubsection{Inversores Trifásicos}

Os inversores transformam uma tensão de entrada CC em uma tensão de saída CA simétrica em amplitude e de freqüência ajustável (RASHID, 1999).

De acordo com a aplicação, os inversores podem utilizar dispositivos com disparo ou bloqueio controlados, (MOSFETs e IGBTs), ou tiristores em comutação forçada.

O inversor trifásico é composto por três inversores monofásicos conectados em paralelo, como mostra a figura 2.4 .

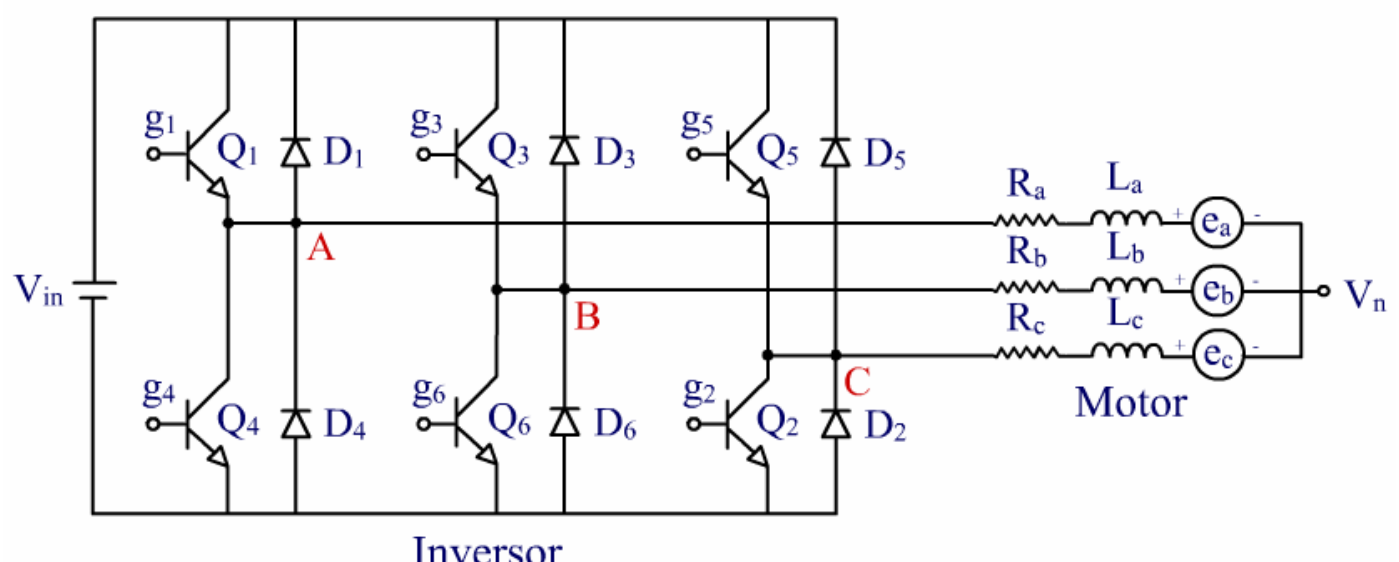

Figura 2.4. Circuito de acionamento do MTIPR.

Os transistores de potência do inversor devem receber comandos de condução de um sistema de controle, que é sincronizado com a posição do rotor ( $\theta_{r}$ [graus elétricos]).

Cada transistor conduz por $120^{\circ}$ elétricos. Apenas dois transistores estão conduzindo em qualquer instante de tempo, na seqüência (6-1), (1-2), (2-3), (3-4), (4-5) e (5-6), a partir de $30^{\circ}$. Os sinais de comando são mostrados na figura 2.5.

De acordo com o controle de cada transistor, obtém-se a tensão de alimentação da fase $a\left(v_{a}\right)$, da fase $b\left(v_{b}\right)$ e da fase $c\left(v_{c}\right)$ do motor, figura 2.6. Quando as duas chaves da fase correspondente estão desligadas ou abertas são as regiões de alta impedância. 
$\mathrm{g}_{1}$

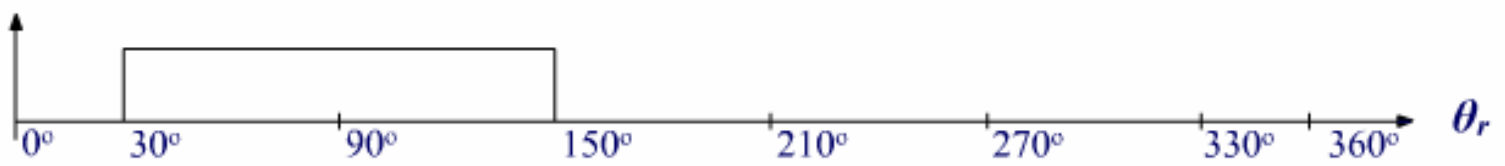

$\mathrm{g}_{2}$

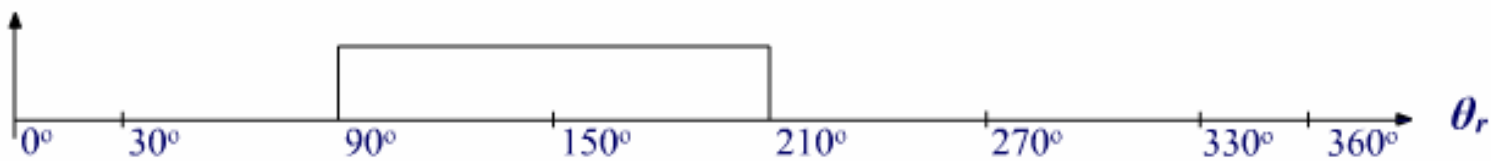

$\mathrm{g}_{3}$

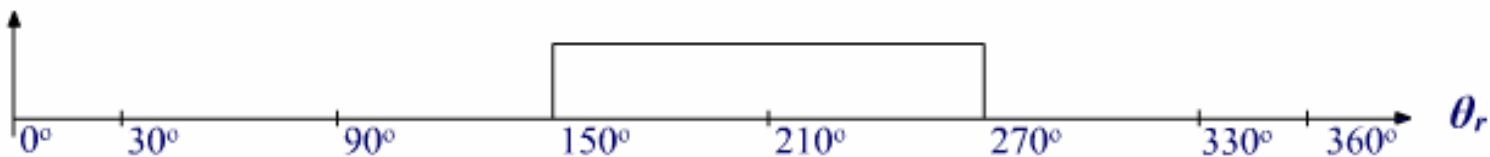

$\mathrm{g}_{4}$

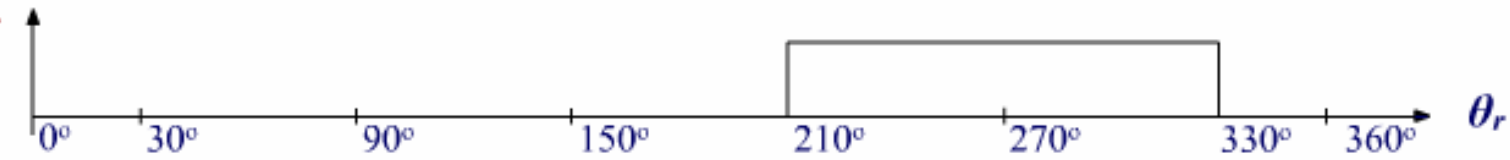

g5

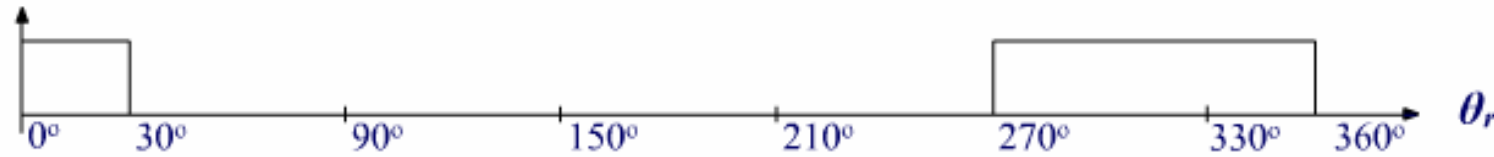

$\mathrm{g}_{6}$

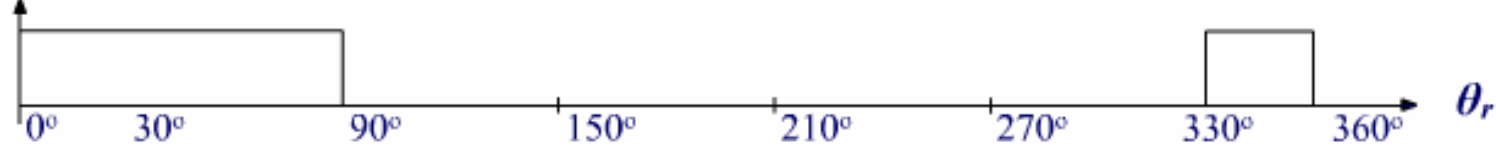

Figura 2.5. Sinais de comando dos transistores do circuito de acionamento do MTIPR.
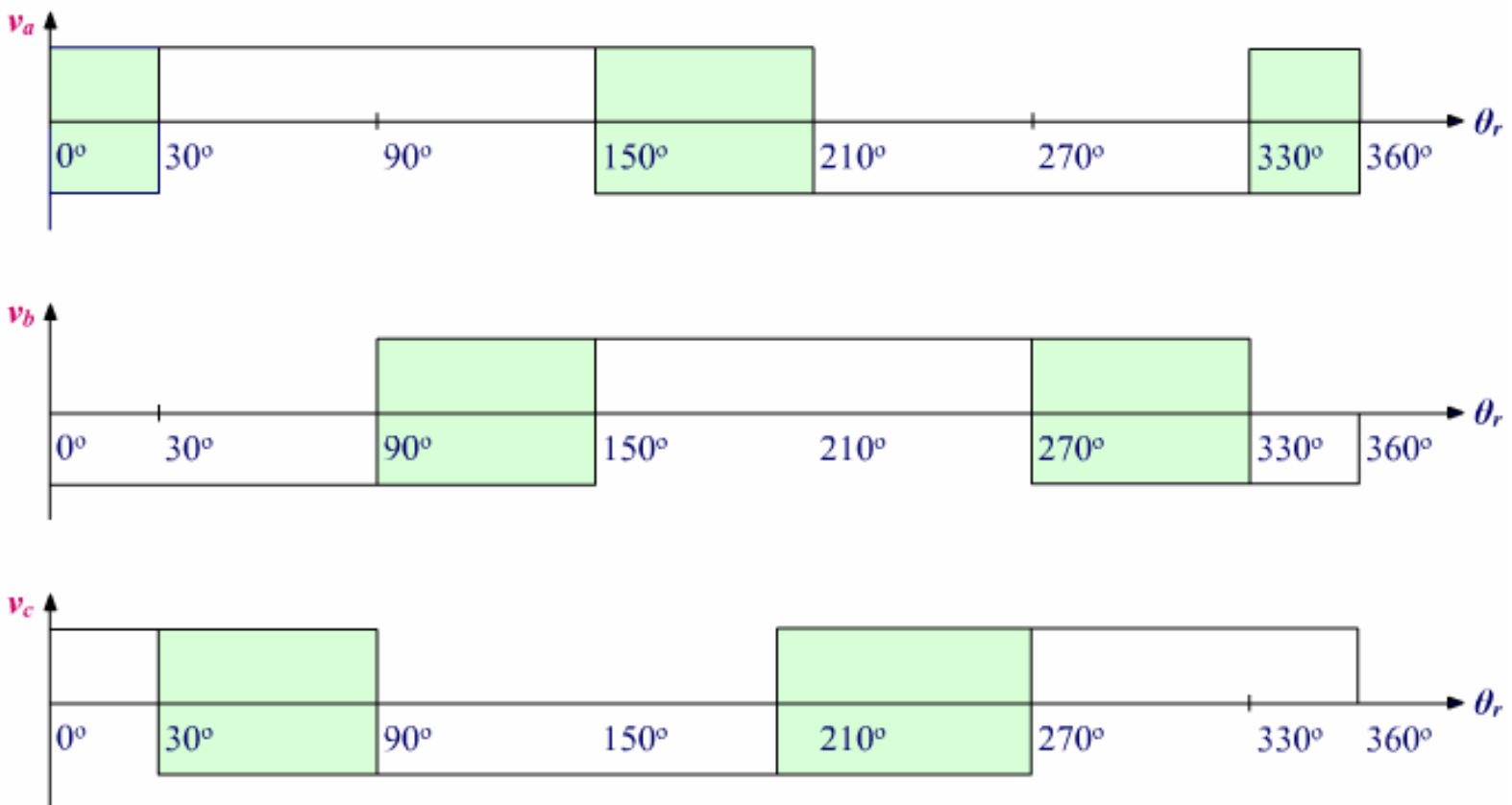

Regiões de alta impedância

Figura 2.6. Tensão de saída do inversor trifásico do MTIPR. 


\subsection{Controle Sensorless}

O controle do MTIPR é denominado de sensorless, devido à ausência de sensores de posição e de velocidade do rotor. Normalmente, esse tipo de controle, utiliza sensores de corrente e de tensão.

Algumas razões para a eliminação dos sensores de posição são: confiabilidade do sistema e hostilidade do ambiente (GIERAS; WING, 2002).

O controle sensorless para motores síncronos de ímã permanente, com tensões induzidas senoidais, diferencia-se do controle para motores com tensões induzidas trapezoidais. No primeiro caso, as três fases são energizadas ao mesmo tempo, enquanto no segundo, apenas duas fases são energizadas simultaneamente (figura 2.7). A estratégia mais simples para a detecção da posição do rotor é através da forma de onda da tensão induzida na fase desenergizada (GIERAS; WING, 2002), que é a utilizada pelo controle do MTIPR.

As técnicas para a detecção da posição do rotor em motores brushless $D C$ são detalhadas em (TEIXEIRA, 2006) e (GONELLA, 2006). As principais são:

- Detecção da tensão induzida (ponto de cruzamento pelo zero da tensão na bobina que está desenergizada);

- Detecção da terceira harmônica;

- Detecção do intervalo de condução dos diodos de retorno do inversor trifásico. 

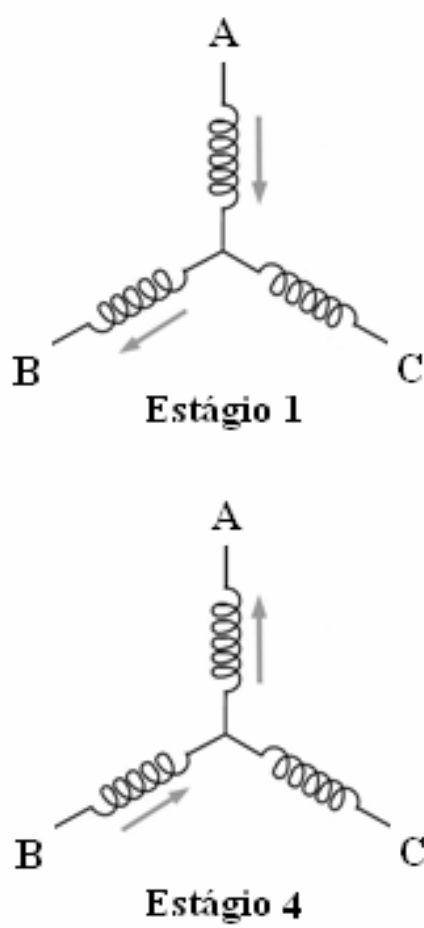
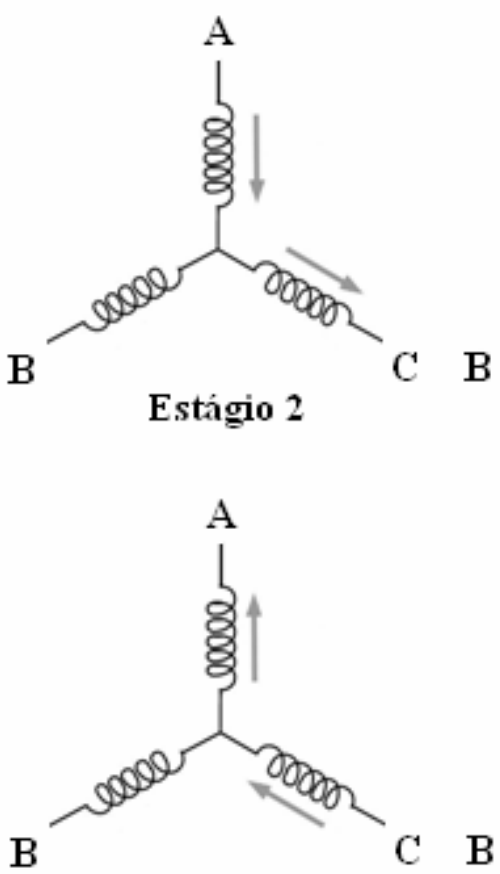

Estágio 5

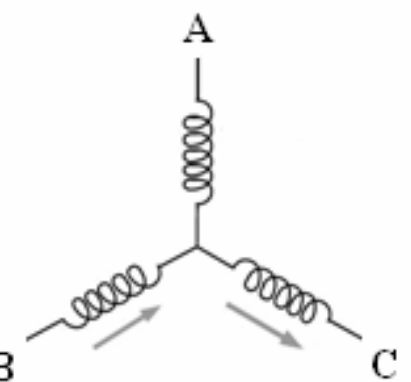

Estágio 3

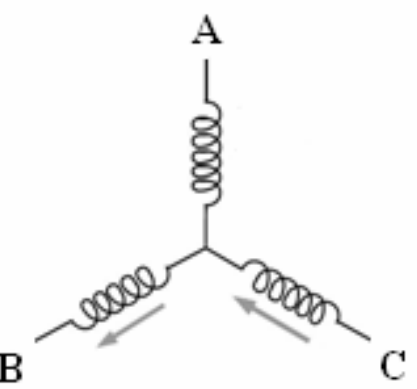

Estágio 6

Figura 2.7. Estágios de excitação das bobinas (TEIXEIRA, 2006).

\subsection{Modelagem Matemática do MTIPR}

O modelo por fase da máquina é utilizado para a realização da modelagem matemática do MTIPR, que é representado por um circuito série contendo um resistor, um indutor e uma fonte de tensão representando a força contra-eletromotriz (figura 2.8), conectados em "Y".

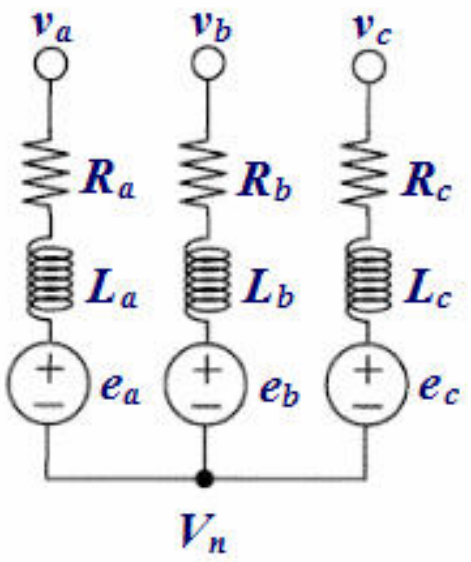

Figura 2.8. Modelo do MTIPR (GONELLA, 2006). 
Desconsiderando-se as correntes induzidas no rotor pelos campos harmônicos do estator e as perdas de dispersão no núcleo de ferro, tem-se o equacionamento do circuito representado pela figura 2.8 (KRISHNAN, 2001):

$$
\left[\begin{array}{l}
v_{a} \\
v_{b} \\
v_{c}
\end{array}\right]=\left[\begin{array}{ccc}
R_{a} & 0 & 0 \\
0 & R_{b} & 0 \\
0 & 0 & R_{c}
\end{array}\right] \cdot\left[\begin{array}{l}
i_{a} \\
i_{b} \\
i_{c}
\end{array}\right]+\frac{d}{d t}\left[\begin{array}{ccc}
L_{a} & M_{a b} & M_{a c} \\
M_{b a} & L_{b} & M_{b c} \\
M_{c a} & M_{c b} & L_{c}
\end{array}\right] \cdot\left[\begin{array}{l}
i_{a} \\
i_{b} \\
i_{c}
\end{array}\right]+\left[\begin{array}{c}
e_{a} \\
e_{b} \\
e_{c}
\end{array}\right]-\left[\begin{array}{c}
V_{n} \\
V_{n} \\
V_{n}
\end{array}\right]
$$

Onde:

$L_{a}, L_{b}$ e $L_{c}$ são as indutâncias do estator da fase $a, b$ e $c[\mathrm{H}]$

$M_{a b}, M_{a c}, M_{b a}, M_{b c}, M_{c a}$ e $M_{c b}$ são as indutâncias mútuas [H];

$R_{a}, R_{b}$ e $R_{c}$ são as resistências do estator da fase $a, b$ e $c[\Omega]$;

$V_{n}$ é a tensão do terminal neutro [V].

Assumindo-se que as três fases são simétricas e equilibradas, e o rotor de pólos lisos, tem-se:

$$
\begin{gathered}
M_{a b}=M_{a c}=M_{b a}=M_{b c}=M_{c a}=M_{c b}=M \\
L_{a}=L_{b}=L_{c}=L
\end{gathered}
$$

Substituindo-se as equações 4 e 5 em 3:

$$
\left[\begin{array}{l}
v_{a} \\
v_{b} \\
v_{c}
\end{array}\right]=\left[\begin{array}{ccc}
R_{a} & 0 & 0 \\
0 & R_{b} & 0 \\
0 & 0 & R_{c}
\end{array}\right] \cdot\left[\begin{array}{l}
i_{a} \\
i_{b} \\
i_{c}
\end{array}\right]+\frac{d}{d t}\left[\begin{array}{ccc}
L & M & M \\
M & L & M \\
M & M & L
\end{array}\right] \cdot\left[\begin{array}{l}
i_{a} \\
i_{b} \\
i_{c}
\end{array}\right]+\left[\begin{array}{l}
e_{a} \\
e_{b} \\
e_{c}
\end{array}\right]-\left[\begin{array}{l}
V_{n} \\
V_{n} \\
V_{n}
\end{array}\right]
$$


A soma das correntes por fase é nula e considerando-se o terminal neutro isolado, a equação (6) torna-se:

$$
\left[\begin{array}{l}
v_{a} \\
v_{b} \\
v_{c}
\end{array}\right]=\left[\begin{array}{ccc}
R_{a} & 0 & 0 \\
0 & R_{b} & 0 \\
0 & 0 & R_{c}
\end{array}\right] \cdot\left[\begin{array}{c}
i_{a} \\
i_{b} \\
i_{c}
\end{array}\right]+\frac{d}{d t}\left[\begin{array}{ccc}
L-M & 0 & 0 \\
0 & L-M & 0 \\
0 & 0 & L-M
\end{array}\right] \cdot\left[\begin{array}{c}
i_{a} \\
i_{b} \\
i_{c}
\end{array}\right]+\left[\begin{array}{c}
e_{a} \\
e_{b} \\
e_{c}
\end{array}\right]-\left[\begin{array}{c}
V_{n} \\
V_{n} \\
V_{n}
\end{array}\right]
$$

As tensões induzidas de cada fase são expressas pela equação (8).

$$
e_{f}=f_{f}\left(\theta_{r}\right) \cdot k_{e} \cdot \omega_{r}
$$

Onde:

$f_{f}\left(\theta_{r}\right)$ é uma função normalizada que representa a forma de onda da força contraeletromotriz de cada fase em função da posição do rotor;

$k_{e}$ é a constante da força contra-eletromotriz [Vs $\left.\cdot \mathrm{rad}^{-1}\right]$.

A equação dinâmica de um sistema rotativo é expressa pela equação (9).

$$
J \cdot \frac{d\left(\omega_{m}\right)}{d t}+D \cdot \omega_{m}=T_{e l}-T_{c}
$$

Onde:

$D$ é o coeficiente de atrito viscoso do eixo da máquina $[\mathrm{Nms}] ;$

$J$ é o coeficiente do momento de inércia $\left[\mathrm{Kg} \cdot \mathrm{m}^{2}\right]$;

$T_{c}$ é o torque aplicado ao eixo pela carga $[\mathrm{Nm}]$. 
A velocidade angular mecânica é dada por:

$$
\omega_{m}=\frac{2}{P} \omega_{r}
$$

Onde:

$P$ é o número de pólos;

$\omega_{r}$ é a velocidade angular do rotor $\left[\mathrm{rad} \cdot \mathrm{s}^{-1}\right]$.

Através da equação (10), a velocidade angular do rotor pode ser expressa por:

$$
\omega_{r}=\frac{d \theta_{r}}{d t}=\frac{P}{2} \omega_{m}
$$

Isolando-se os termos diferenciais das equações (7), (9) e (11), tem-se:

$$
\left[\begin{array}{c}
\dot{i}_{a} \\
\dot{i_{b}} \\
\dot{i}_{c} \\
\dot{\omega}_{m} \\
\dot{\theta}_{r}
\end{array}\right]=\left[\begin{array}{ccccc}
\frac{-R_{a}}{L-M} & 0 & 0 & 0 & 0 \\
0 & \frac{-R_{b}}{L-M} & 0 & 0 & 0 \\
0 & 0 & \frac{-R_{c}}{L-M} & 0 & 0 \\
0 & 0 & 0 & \frac{-D}{J} & 0 \\
0 & 0 & 0 & \frac{P}{2} & 0
\end{array}\right] \cdot\left[\begin{array}{c}
i_{a} \\
i_{b} \\
i_{c} \\
\omega_{m} \\
\theta_{r}
\end{array}\right]+\left[\begin{array}{ccccc}
\frac{1}{L-M} & 0 & 0 & 0 & 0 \\
0 & \frac{1}{L-M} & 0 & 0 & 0 \\
0 & 0 & 0 & \frac{1}{J} & 0 \\
0 & 0 & 0 & 0 & 0
\end{array}\right]\left[\begin{array}{c}
v_{a}-e_{a}+V_{n} \\
v_{b}-e_{b}+V_{n} \\
1
\end{array}\right] \cdot\left[\begin{array}{c}
T_{c}-e_{c}+V_{n} \\
T_{e l}-T_{c} \\
0
\end{array}\right]
$$

Para a resolução do sistema de equações diferenciais ordinárias (equação 12), utilizase um método de integração numérica, como o de Runge-Kutta, para a obtenção das variáveis desejadas $\left(i_{a}, i_{b}, i_{c}, \omega_{m}\right.$ e $\left.\theta_{r}\right)$

A partir dos valores das correntes elétricas por fase e do posicionamento do rotor, obtidos com a simulação temporal, pode-se utilizá-los em um programa de elementos finitos para a obtenção de grandezas eletromagnéticas, que não são obtidas pela solução do sistema de equações diferenciais, como, por exemplo, o campo magnético. 


\section{Capítulo 3}

\section{Projeto do MTIPR}

Devido aos diferentes tipos de motores brushless e dos diversos materiais magnéticos, importantes especificações devem ser realizadas antes do projeto do motor ser iniciado. Conforme (HENDERSHOT; MILLER, 1994), os passos de um projeto de uma máquina brushless DC são detalhados a seguir. Também é apresentada uma breve descrição do projeto do MTIPR, de acordo com (TEIXEIRA, 2006).

\subsection{Determinação das Necessidades da Aplicação}

As necessidades da aplicação a serem supridas pela máquina devem ser determinadas, pois a partir delas é que as principais características do motor são especificadas.

Uma importante definição das máquinas utilizadas em compressores herméticos é o número de terminais disponíveis para a alimentação. Como normalmente são empregados motores de indução, para essa aplicação, e já existe um projeto da carcaça, são disponibilizados três terminais.

Os compressores também possuem um determinado espaço para a alocação do motor. 
Nos sistemas de refrigeração uma baixa inércia é exigida, a temperatura de operação é de $60^{\circ} \mathrm{C}$ e a velocidade máxima de operação é igual a 471,24 $\mathrm{rad} \cdot \mathrm{s}^{-1}, 4500 \mathrm{rpm}$ (TEIXEIRA, 2006).

\subsection{Escolha do Tipo de Máquina}

A seguir são apresentados os tipos de máquinas segundo (HENDERSHOT; MILLER, 1994). A escolha de um deles é feita de acordo com as necessidades da aplicação.

\subsubsection{Máquina com Rotor do Tipo Interior}

Um motor com rotor interior (figura 3.1) possui o estator semelhante ao dos motores de indução. As principais vantagens dessa configuração são a baixa inércia e o elevado torque. No entanto, possui as desvantagens em relação aos cuidados necessários da fixação dos ímãs na superfície do rotor, para que não se desloquem da posição original (descolem) com o movimento do rotor (HENDERSHOT; MILLER, 1994).

O estator e o rotor são constituídos por lâminas de um material ferromagnético (HENDERSHOT; MILLER, 1994).

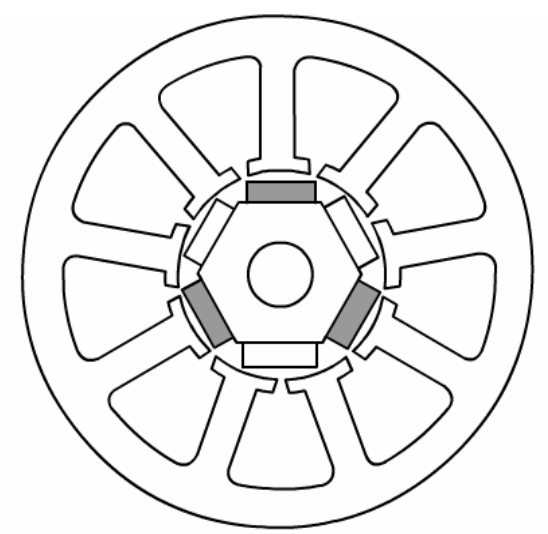

Figura 3.1. Rotor do tipo interior (HENDERSHOT; MILLER, 1994). 


\subsubsection{Máquina com Rotor do Tipo Exterior}

Normalmente, os motores brushless, com rotor do tipo exterior (figura 3.2), são usados em aplicações que necessitam de velocidade constante e alta rotação. Possui popularidade devido ao seu baixo custo e da sua facilidade de fabricação (HENDERSHOT; MILLER, 1994).

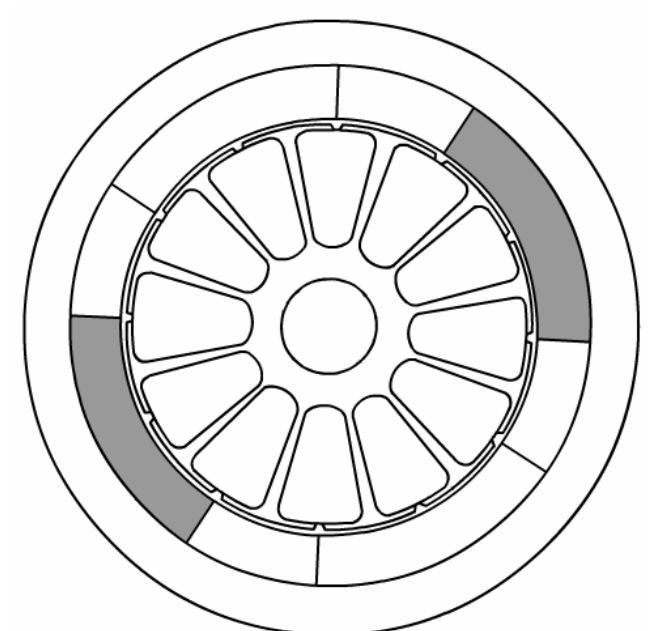

Figura 3.2. Rotor do tipo exterior (HENDERSHOT; MILLER, 1994).

\subsubsection{Máquina com Rotor Tipo Disco}

As principais vantagens dos motores com rotor tipo disco (figura 3.3) são: baixo custo, a forma plana e ausência dos torques de relutância e de borda (conseqüência da inexistência de ranhuras). Possui entreferro axial e o seu tamanho, entre os ímãs e o enrolamento do estator, é muito grande resultando uma alta dispersão do fluxo magnético. Embora isso implique em uma configuração ineficiente do circuito magnético, não impede que ele seja utilizado em aplicações que necessitem de baixo torque e de velocidade em torno de 1000 rpm. Esses motores são empregados normalmente em unidades de disquete, videocassetes, etc (HENDERSHOT; MILLER, 1994). 


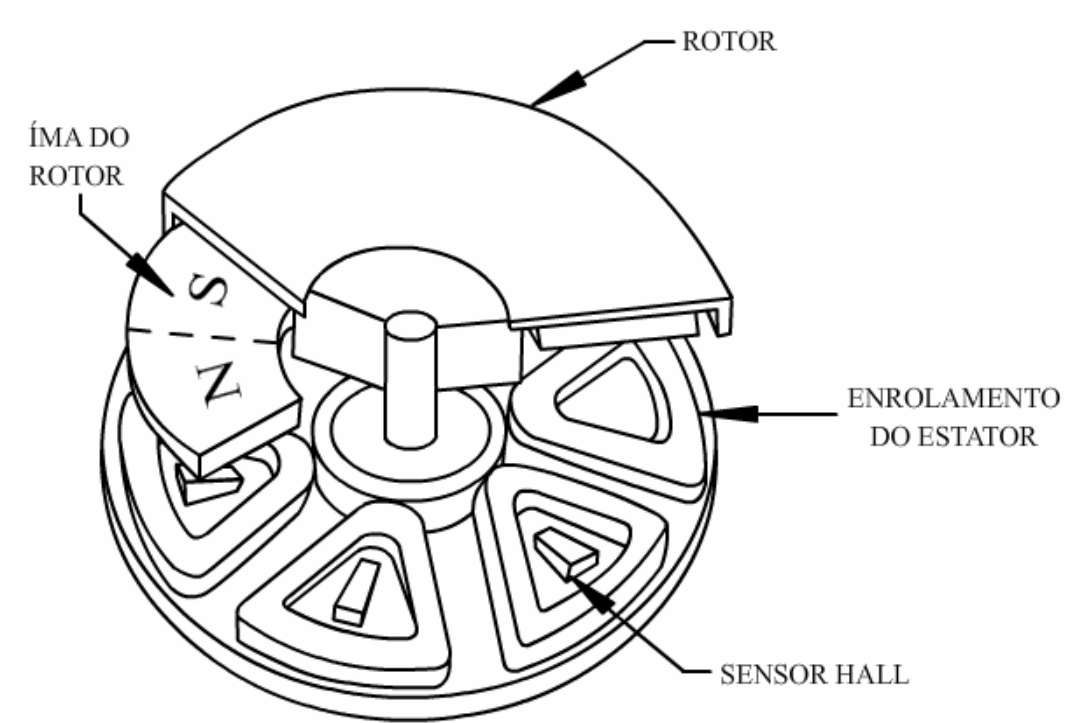

Figura 3.3. Rotor do tipo disco (HENDERSHOT; MILLER, 1994).

Neste trabalho, foi selecionado o rotor do tipo interior, pois essa configuração assemelha-se à dos motores de indução, apresentando baixa inércia.

\subsection{Seleção do Ímã Permanente}

O ímã de ferrita, em forma de arco, foi selecionado para a confecção do rotor. Essa escolha foi feita devido a sua baixa energia, evitando-se a saturação do material ferromagnético da máquina, e as suas vantagens econômicas, quando comparado aos ímãs de terras-raras.

O coeficiente de permeância $(P C)$ deve ser determinado para o prosseguimento dos cálculos, na qual caracteriza a operação do ímã no circuito magnético formado pela geometria do motor. Um campo estático de desmagnetização é aplicado no ímã pelo entreferro, causando a sua operação abaixo da densidade residual $\left(\mathrm{B}_{\mathrm{r}}[\mathrm{T}]\right)$. Em circuito aberto, o coeficiente de permeância é em torno de $(0,7-0,95) \cdot \mathrm{B}_{\mathrm{r}}$. A linha que une a origem a esse ponto de operação é chamada de linha de carga (HENDERSHOT; MILLER, 1994), que pode ser visualizada na figura 3.4 . 


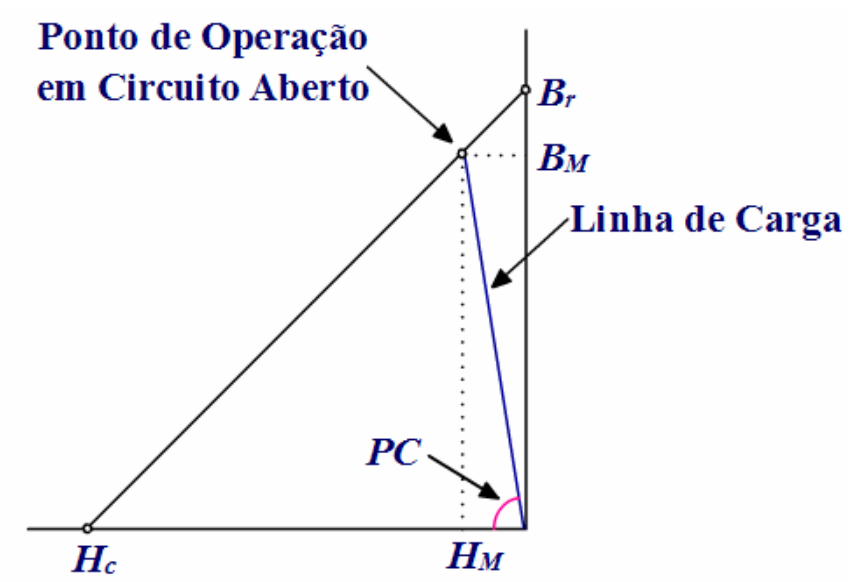

Figura 3.4. Determinação do coeficiente de permeância através do segundo quadrante da curva de histerese.

Através da figura 3.4, determina-se o coeficiente de permeância e a espessura do ímã $\left(L_{m}[\mathrm{~mm}]\right)$ que será empregado no motor.

$$
P C=\frac{B_{M}}{\mu_{0} \cdot H_{M}}=\frac{L_{m}}{g}
$$

Onde:

$B_{M}$ é a densidade de fluxo magnético no ponto de operação em circuito aberto [T];

$g$ é o tamanho do entreferro [mm];

$H_{M}$ é a intensidade de campo magnético no ponto de operação em circuito aberto $\left[\mathrm{A} \cdot \mathrm{m}^{-1}\right]$.

Os materiais magnéticos, incluindo-se os ímãs permanentes, estão detalhados no apêndice $\mathrm{A}$.

\subsection{Escolha do Número de Pólos}

A escolha do número de pólos depende de vários fatores, tais como: material e categoria do ímã, configuração do rotor, montagem mecânica do rotor e dos ímãs, velocidade de rotação e inércia requerida (HENDERSHOT; MILLER, 1994). 
De acordo com as características citadas anteriormente, foi determinado o número de quatro pólos para o MTIPR.

3.5 Determinação da Geometria, das Dimensões e do Número de Ranhuras e de Fase do Estator

Pelo motivo do estator ser proveniente de um motor de indução monofásico, ele é composto por 24 ranhuras. A sua geometria e as suas dimensões são detalhadas no Capítulo 4. Por causa da disposição de três terminais de alimentação, o motor é trifásico.

\subsection{Determinação do Tamanho do Entreferro}

Segundo (HENDERSHOT; MILLER, 1994), o tamanho do entreferro dever ser entre 0,13-0,25 mm para motores de baixa potência, 0,38-0,51 $\mathrm{mm}$ para motores médios e $\quad$ 0,640,89 mm para as máquinas de alta potência.

\subsection{Cálculo do Tamanho do Rotor}

O diâmetro do rotor $\left(D_{r}[\mathrm{~mm}]\right)$, sem os ímãs em sua superfície, é calculado pela equação (14).

$$
D_{r}=D_{i_{-} e}-2 \cdot g-2 \cdot L_{m}
$$

Onde:

$D_{i_{-} e}$ é o diâmetro interno do estator [mm]. 


\subsection{Cálculo do Fluxo Magnético por Pólo}

O fluxo magnético por pólo $\left(\phi_{\text {Pólo }}[\mathrm{Wb}]\right)$ é calculado através da multiplicação da área magnética do pólo $\left(A_{m}\left[\mathrm{~m}^{2}\right]\right)$ pela densidade de fluxo magnético do ponto de operação $\left(\mathrm{B}_{\mathrm{M}}\right.$ $[\mathrm{T}])$.

$$
\phi_{\text {Pólo }}=A_{m} \cdot B_{M}
$$

Sendo:

$$
A_{m}=\frac{\pi \cdot D_{r} \cdot T_{P a \cot e}}{P}
$$

Onde:

$T_{\text {Pacote }}$ é a altura do pacote de lâminas do estator [m].

\subsection{Cálculo do Número de Condutores, de Espiras e do Diâmetro do Enrolamento}

Considerando a velocidade máxima de operação $\left(\omega_{\text {máx }}\right)$ de 471,24 [ $\mathrm{rad} \cdot \mathrm{s}^{-1}$ ], a velocidade sem carga é $20 \%$ maior para os ímãs de ferrita e $10 \%$ maior para os ímãs de terras-raras (HENDERSHOT; MILLER, 1994). Com isso, a constante da força contraeletromotriz $\left(k_{e}\left[\mathrm{Vs} \cdot \mathrm{rad}^{-1}\right]\right)$ pode ser calculada pela equação (17).

$$
k_{e}=\frac{V_{c c}}{n \cdot \omega_{\text {máx }}}
$$


Onde:

$n$ é igual a 1,250 se os ímãs do rotor forem de ferrita ou 1,111 se forem de terras-raras;

$V c c$ é a tensão de barramento.

O número total de condutores ( $Z$ ) é determinado pela equação (18).

$$
Z=1,5 \frac{1}{C} \frac{\pi \cdot k_{e}}{\phi_{P o l o} \cdot P}
$$

Onde $C$ é fator da distribuição do fluxo no enrolamento do estator, podendo ser estimado em torno de 90\% na região de comutação (HENDERSHOT; MILLER, 1994).

O número de espiras de cada bobina $\left(N_{\text {espiras }}\right)$ é determinado pela equação (19).

$$
N_{\text {espiras }}=\frac{Z}{N_{\text {BobinasFase }} \cdot N_{a}}
$$

Onde:

$N_{a}$ é igual a 1, 2 ou 3, dependendo se o motor é monofásico, bifásico ou trifásico, respectivamente;

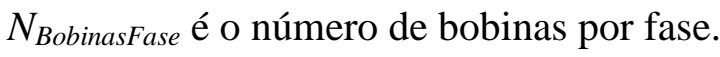

Para a determinação do diâmetro do enrolamento é necessário fazer um cálculo aproximado da área de cada ranhura do estator $\left(A_{\text {Ranhura }}\left[\mathrm{mm}^{2}\right]\right)$. As dimensões são mostradas na figura 3.5 e a equação (20) expressa esse cálculo. 


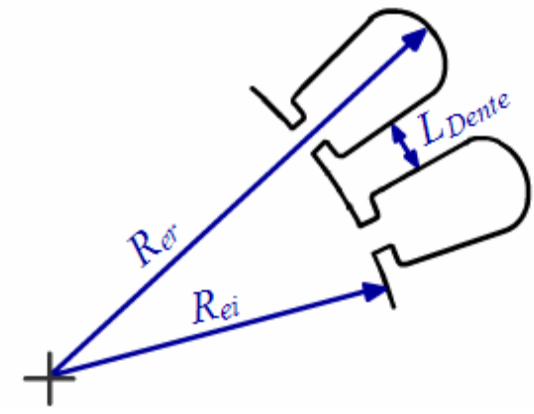

Figura 3.5. Dimensões para o cálculo da área da ranhura do estator.

$$
A_{\text {Ranhura }}=\frac{\left(R_{e r}{ }^{2}-R_{e i}{ }^{2}\right) \cdot \pi-\left(R_{e r}-R_{e i}\right) \cdot L_{\text {Dente }} \cdot N_{\text {Ranhura }}}{N_{\text {Ranhura }}}
$$

Onde:

$L_{\text {Dente }}$ é a distância entre as ranhuras [mm];

$N_{\text {Ranhura }}$ é o número total de ranhuras;

$R_{e r}$ é o raio do estator referente às ranhuras $[\mathrm{mm}]$;

$R_{e i}$ é o raio interno do estator [mm].

O diâmetro do fio $\left(D_{F i o}[\mathrm{~mm}]\right)$ é calculado através da equação $(21)$, sendo o seu valor consultado em uma tabela para selecionar-se a bitola correspondente. Neste trabalho, é utilizado o sistema AWG (American Wire Gauge).

$$
D_{\text {Fio }}=\sqrt{\frac{A_{\text {Ranhura }} \cdot F_{P}}{N_{\text {Espiras }}}}
$$

Onde $F_{P}$ é o fator de preenchimento, assumindo o valor em torno de $0,3-0,35$, no caso de camada dupla, e 0,65-0,7, no caso de camada simples (HENDERSHOT; MILLER, 1994). 


\subsection{Verificação das Características do Motor}

Uma importante informação, que deve ser conferida antes da implementação da máquina, é o máximo valor da corrente de alimentação do estator, que não desmagnetize os ímãs, podendo ser calculado através da equação (22).

$$
I_{\text {desmag }}=2,02 \frac{4 \cdot P \cdot a \cdot\left(L_{m}+g\right) \cdot H_{d}}{Z}
$$

Onde:

$a$ é o número de caminhos paralelos da bobina;

$H_{d}$ é a máxima intensidade de campo magnético, de valor contrário, que pode ser aplicada no ímã, sem desmagnetizá-lo.

Outras características da máquina projetada devem ser conferidas em relação às necessidades da aplicação. Alguns exemplos são: estimativa das perdas resistivas e do torque eletromagnético.

Esses e outros cálculos podem ser realizados através das equações citadas anteriormente. Um software baseado no método dos elementos finitos, além de possibilitar a análise do campo magnético para a verificação da existência de saturação no material ferromagnético, também calcula essas grandezas eletromagnéticas.

As perdas dos materiais ferromagnéticos são decorrentes do campo magnético e da frequência a que estão expostos, são normalmente calculadas por programas computacionais que baseiam-se na análise temporal. Como este trabalho realiza um estudo estático, as perdas magnéticas no ferro são estimadas através da equação de Steinmetz, que é detalhada na subseção seguinte. 


\subsection{Estimativa das Perdas Magnéticas}

Depois das perdas resistivas (equação 23), as perdas no ferro são as maiores responsáveis pela diminuição da eficiência dos motores brushless (HENDERSHOT; MILLER, 1994).

$$
P_{r}=R \cdot I^{2}
$$

Onde:

I é a corrente elétrica $[\mathrm{A}]$;

$P_{r}$ é a perda resistiva $[\mathrm{W}]$;

$R$ é resistência elétrica $[\Omega]$.

As perdas magnéticas surgem da variação da densidade de fluxo magnético no ferro, que são dividadas em dois tipos: perdas por histerese e perdas por correntes de Foucault.

A primeira resulta da "resistência" do aço em mudar de estado magnético. Como a indução magnética varia ciclicamente, o estado magnético descreve uma localidade no diagrama $\mathrm{B} / \mathrm{H}$ (detalhado no apêndice $\mathrm{A})$ : a perda de energia por ciclo é proporcional à área fechada, então a perda por histerese é proporcional à variação da freqüência no campo magnético (HENDERSHOT; MILLER, 1994).

As correntes de Foucault também são causadas pela variação da densidade de fluxo magnético, que induzem a circulação de corrente no ferro na mesma frequência da variação do campo magnético. Essa perda é proporcional ao quadrado da frequiência e ao quadrado do pico da indução magnética (HENDERSHOT; MILLER, 1994).

As perdas no ferro $\left(W_{F e}\left[\mathrm{~W} \cdot \mathrm{Kg}^{-1}\right]\right)$, decorrentes de excitação senoidal, são usualmente descritas pela equação de Steinmetz, sendo que o primeiro termo da soma expressa a perda por histerese e o segundo a perda por correntes de Foucault: 


$$
W_{F e}=C_{h} \cdot f \cdot B_{p}{ }^{n\left(B_{p}\right)}+C_{e} \cdot B_{p}{ }^{2} \cdot f^{2}
$$

Onde:

$B_{p}$ é o valor de pico da indução magnética quando o fluxo é senoidal [T];

$C_{e}, C_{h}$ e $n$ são os coeficientes de perda do material, sendo que $n$ é dependente de $B_{p}$;

$f$ é a freqüência do campo magnético externo [Hz].

A equação de Steinmetz foi modificada por (SLEMON; LIU, 1990) para que a estimativa de perdas em materiais ferromagnéticos fosse feita, decorrentes de campos magnéticos com a forma de onda não senoidal:

$$
W_{F e}=C_{h} \cdot f \cdot B_{p}^{n\left(B_{p}\right)}+\frac{C_{e}}{2 \pi^{2}}\left[\frac{d B}{d t}\right]^{2}
$$

Os coeficientes de perda do material podem ser obtidos através do gráfico de perda magnética versus a freqüência (disponibilizados pelo fabricante), (HENDERSHOT; MILLER, 1994). O primeiro passo para a obtenção de $C_{h}$ e $n$ é a divisão da equação (24) pela freqüência:

$$
\frac{W_{F e}}{f}=C_{h} \cdot B_{p}{ }^{a+b \cdot B_{p}}+C_{e} \cdot f \cdot B_{p}{ }^{2}
$$

A equação (26) pode ser escrita como:

$$
\frac{W_{F e}}{f}=D+E \cdot f
$$


Sendo:

$$
D=C_{h} \cdot B_{p}^{a+b \cdot B_{p}}
$$

Aplicando-se a função logaritmo em ambos os membros da equação (28), tem-se:

$$
\log D=\log C_{h}+\left(a+b \cdot B_{p}\right) \cdot \log B_{p}
$$

Selecionando-se três valores de indução magnética do gráfico de perdas, como por exemplo, 1,0 T, 1,2 T e 1,5 T para as frequências de $60 \mathrm{~Hz}, 100 \mathrm{~Hz}$ e $500 \mathrm{~Hz}$, tem-se a respectiva perda magnética para cada ponto. Com isso, as curvas de $W_{F e} / f$ versus $f$ podem ser traçadas. A partir delas, determinam-se os três valores de $D\left(W_{F e} / f\right)$, que correspondem ao ponto em que cada reta intercepta o eixo y. Substituindo-se esses dados na equação (29), obtém-se um sistema de três equações com o mesmo número de incógnitas, sendo que a sua solução resulta nos coeficientes de perda do material, $C_{h}$ e $n$.

Através do cálculo do coeficiente angular $(m)$ de cada reta (do gráfico de perdas), obtém-se o valor de $C_{e}$ (equação 30 ), que pode ser o maior dos três valores encontrados (HENDERSHOT; MILLER, 1994).

$$
C_{e}=\frac{m}{B_{p}{ }^{2}}
$$




\section{Capítulo 4}

\section{Resultados}

Neste capítulo são apresentados os cálculos realizados, utilizando-se um programa computacional baseado no método dos elementos finitos (detalhado no apêndice C), referentes ao MTIPR. Essa máquina tem a potência nominal aproximadamente de 1/4 CV. Possui quatro pólos e foi projetada para funcionar continuamente até $4500 \mathrm{rpm}$, sem desligar, diferentemente dos outros motores utilizados em sistemas de refrigeração.

Para utilizar-se o software de elementos finitos (FEMM), definiu-se as propriedades magnéticas dos materiais do motor, conforme as características construtivas especificadas por (TEIXEIRA, 2006). Em seu projeto inicial, calculou-se o tamanho do entreferro de ar de 0,76 mm, porém devido à dificuldade de encontrar-se o tamanho especificado dos ímãs do rotor, utilizaram-se os existentes no mercado, obtendo-se um entreferro de 1,35 mm.

A alimentação do estator é realizada de acordo com os resultados da simulação temporal de (GONELLA, 2006). 


\subsection{Características Construtivas do MTIPR}

São apresentadas as geometrias e as características elétricas e magnéticas do estator e do rotor.

\subsubsection{Estator}

A chapa de aço do estator possui espessura de $0,5 \mathrm{~mm}$ e a altura do pacote é de $47 \mathrm{~mm}$ (TEIXEIRA, 2006). As dimensões do estator e das ranhuras são mostradas na figura 4.1 e 4.2, respectivamente. A distribuição, em camada simples, das três fases do enrolamento de 4 pólos nas ranhuras do estator também é mostrada pela figura 4.1.

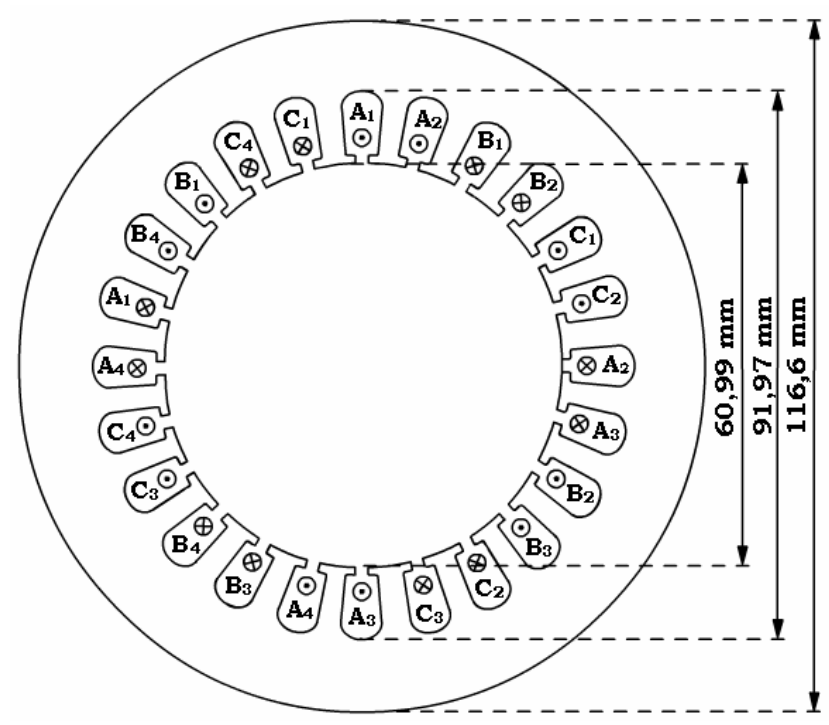

Figura 4.1. Dimensões do estator.

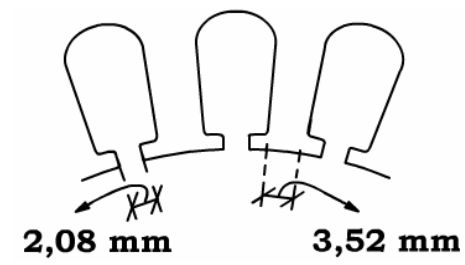

Figura 4.2. Dimensões das ranhuras. 
O estator possui 24 ranhuras e 12 bobinas. Devido ao motor ser trifásico, tem-se quatro bobinas por fase e o número de espiras de cada uma é igual a 105. A bitola do enrolamento utilizado é a 21 AWG, que possui o diâmetro igual a 0,7229 mm.

O estator é constituído pela liga Fe-Si, sendo a sua curva de magnetização mostrada na figura 4.3.

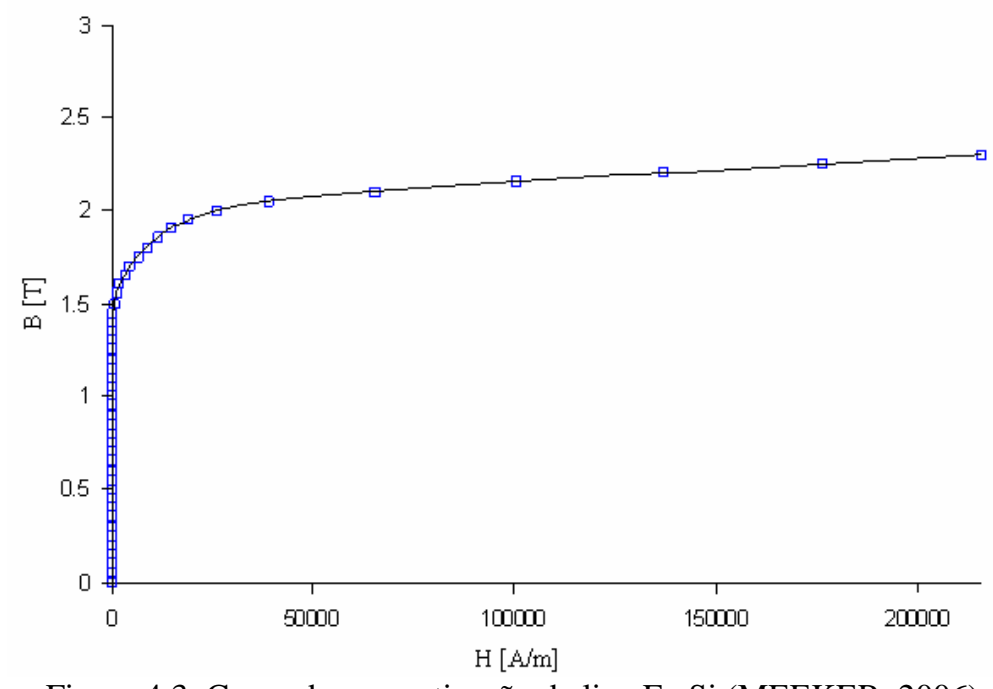

Figura 4.3. Curva de magnetização da liga Fe-Si (MEEKER, 2006).

Para o cálculo das perdas magnéticas desse material, deve-se determinar os coeficientes de perda, que são obtidos através da teoria e do equacionamento apresentados no capítulo 3. A partir disso, selecionaram-se três valores de indução magnética $\left(B_{p}\right)$ com diferentes valores de freqüência $(f)$ e suas respectivas perdas $\left(W_{F e}\left[\mathrm{~W} \mathrm{Kg}^{-1}\right]\right)$, retirados do catálogo do fabricante (USS; 1978). As curvas $W_{F e} / f$ versus $f$ foram traçadas e determinou-se o ponto de cruzamento de cada reta no eixo $y(D)$ :

1) $B_{p l}=0,5 \mathrm{~T}, D_{l}=1,40 \mathrm{~W} \cdot \mathrm{Kg}^{-1} \cdot \mathrm{Hz}$;

2) $B_{p 2}=0,7 \mathrm{~T}, D_{2}=1,08 \mathrm{~W} \cdot \mathrm{Kg}^{-1} \cdot \mathrm{Hz}$;

3) $B_{p 3}=1,0 \mathrm{~T}, D_{3}=1,44 \mathrm{~W} \cdot \mathrm{Kg}^{-1} \cdot \mathrm{Hz}$. 
Substituindo-se os valores citados anteriormente na equação (29) e resolvendo-a, tem-se: $C_{h}=1,44$ e $n=2,27$.

Através do cálculo dos coeficientes angulares de cada reta, determinou-se o maior valor do coeficiente $C_{e}: 0,035$.

\subsubsection{Alimentação do Estator}

Devido à ausência de sensores de posicionamento do rotor, necessita-se fazer a associação da alimentação do enrolamento do estator com o posicionamento do rotor. Para isso, adotou-se uma posição inicial (figura 4.4), e apartir dela movimentou-se o rotor de 5 em $5^{\circ}$ mecânicos no sentido anti-horário, calculando-se em cada posição o torque eletromagnético através do programa computacional FEMM. Para facilitar a realização das simulações, utilizou-se a linguagem Lua Scripting para automatizá-las.

A tabela 4.1 apresenta um resumo da figura 2.6, que consiste na saída do inversor trifásico, ou seja, os seis estados da alimentação do enrolamento do estator.

Tabela 4.1 - Estados da alimentação do enrolamento do estator associados com os valores de pico das tensões.

\begin{tabular}{cccc}
\hline Tipo de & Fase A & Fase B & Fase C \\
Alimentação & & & \\
\hline Alimentação 1 & 0 & $-\mathrm{V}_{\mathrm{b}}$ & $+\mathrm{V}_{\mathrm{c}}$ \\
Alimentação 2 & $+\mathrm{V}_{\mathrm{a}}$ & $-\mathrm{V}_{\mathrm{b}}$ & 0 \\
Alimentação 3 & $+\mathrm{V}_{\mathrm{a}}$ & 0 & $-\mathrm{V}_{\mathrm{c}}$ \\
Alimentação 4 & 0 & $+\mathrm{V}_{\mathrm{b}}$ & $-\mathrm{V}_{\mathrm{c}}$ \\
Alimentação 5 & $-\mathrm{V}_{\mathrm{a}}$ & $+\mathrm{V}_{\mathrm{b}}$ & 0 \\
Alimentação 6 & $-\mathrm{V}_{\mathrm{a}}$ & 0 & $+\mathrm{V}_{\mathrm{c}}$ \\
\hline
\end{tabular}

Considerou-se que a máquina estava funcionando em vazio, por isso a magnitude da corrente adotada por fase é constante. 
Para cada posição do rotor, calculou-se o torque eletromagético para todos os estados da alimentação. Como trata-se de um motor de quatro pólos, são necessários dois ciclos elétricos completos para completar uma revolução mecânica, com isso, a cada $30^{\circ}$ mecânicos tem-se a associação de um tipo de alimentação.

Analisando-se os resultados, obteve-se o torque máximo durante $25^{\circ}$ mecânicos, tornando-se necessário o cálculo do conjugado em um intervalo menor nas regiões em que houve a mudança da alimentação. Realizando-se esse procedimento, chegou-se à associação da posição do rotor com a alimentação do enrolamento do estator, mostrada na tabela 4.2.

Tabela 4.2 - Alimentação do enrolamento do estator associada com o posicionamento do rotor.

\begin{tabular}{ccc}
\hline Tipo de Alimentação & $\begin{array}{c}\text { Posição do Rotor no Primeiro } \\
\text { Ciclo Elétrico }\end{array}$ & $\begin{array}{c}\text { Posição do Rotor no Segundo } \\
\text { Ciclo Elétrico }\end{array}$ \\
\hline Alimentação 1 & $22,2^{\circ} \leq 52,2^{\circ}$ & $202,2^{\circ} \leq 232,2^{\circ}$ \\
Alimentação 2 & $52,2^{\circ} \leq 82,2^{\circ}$ & $232,2^{\circ} \leq 262,2^{\circ}$ \\
Alimentação 3 & $82,2^{\circ} \leq 112,2^{\circ}$ & $262,2^{\circ} \leq 292,2^{\circ}$ \\
Alimentação 4 & $112,2^{\circ} \leq 142,2^{\circ}$ & $292,2^{\circ} \leq 322,2^{\circ}$ \\
Alimentação 5 & $142,2^{\circ} \leq 172,2^{\circ}$ & $322,2^{\circ} \leq 352,2^{\circ}$ \\
Alimentação 6 & $172,2^{\circ} \leq 202,2^{\circ}$ & $352,2^{\circ} \leq 22,2^{\circ}$ \\
\hline
\end{tabular}

A figura 4.4 ilustra o rotor dividido em regiões conforme os estados da alimentação do enrolamento do estator, que são expressos pelos números próximos ao centro.

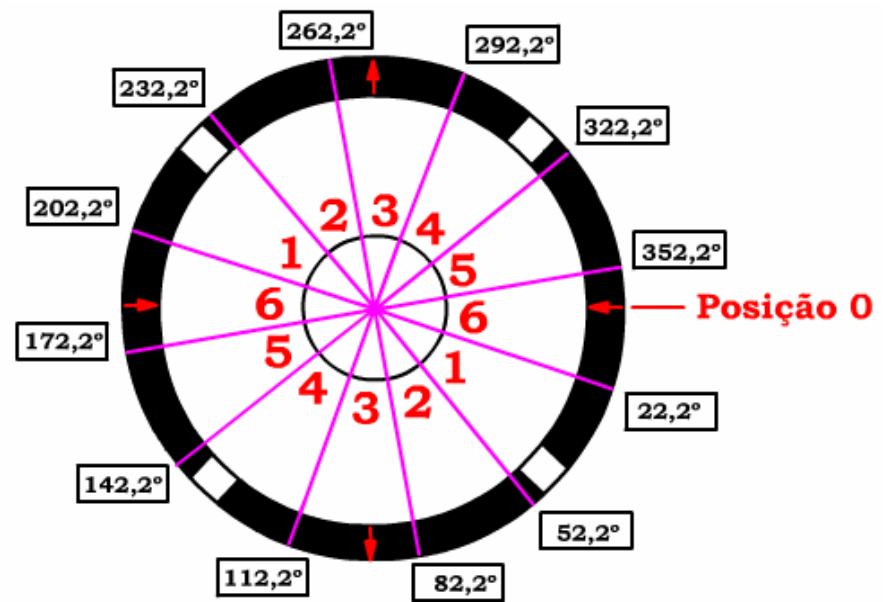

Figura 4.4. Rotor dividido em regiões conforme a alimentação do enrolamento do estator. 


\subsubsection{Rotor}

O rotor é constituído por lâminas de Fe-Si e suas dimensões são mostradas na figura 4.5. Possui quatro ímãs em sua superfície, com orientação radial.

Os resultados deste trabalho referem-se a dois tipos de ímãs permanentes, ferrita e de $\mathrm{NdFeB}$ (Bonded), sendo as suas propriedades magnéticas apresentadas na tabela 4.3. O ímã de terras-raras possui a curva $\mathrm{BH}$ linear, com permeabilidade magnética relativa igual a 1,2. A curva de desmagnetização da ferrita é mostrada na figura 4.6.

Tabela 4.3 - Propriedades Magnéticas

\begin{tabular}{ccc}
\hline Ímãs & $\begin{array}{c}\text { Produto de Energia } \\
\text { Máximo }\left(\mathbf{B H}_{\mathbf{m a x}}\right) \\
\mathbf{k J / \mathbf { m } ^ { 3 }}\end{array}$ & $\begin{array}{c}\text { Coercividade Normal }\left(\mathbf{H}_{\mathbf{C B}}\right) \\
\mathbf{k A} / \mathbf{m}\end{array}$ \\
\hline Ferrita & 30 & 260 \\
$\mathrm{NdFeB}$ (Bonded) & 79 & 478 \\
\hline
\end{tabular}

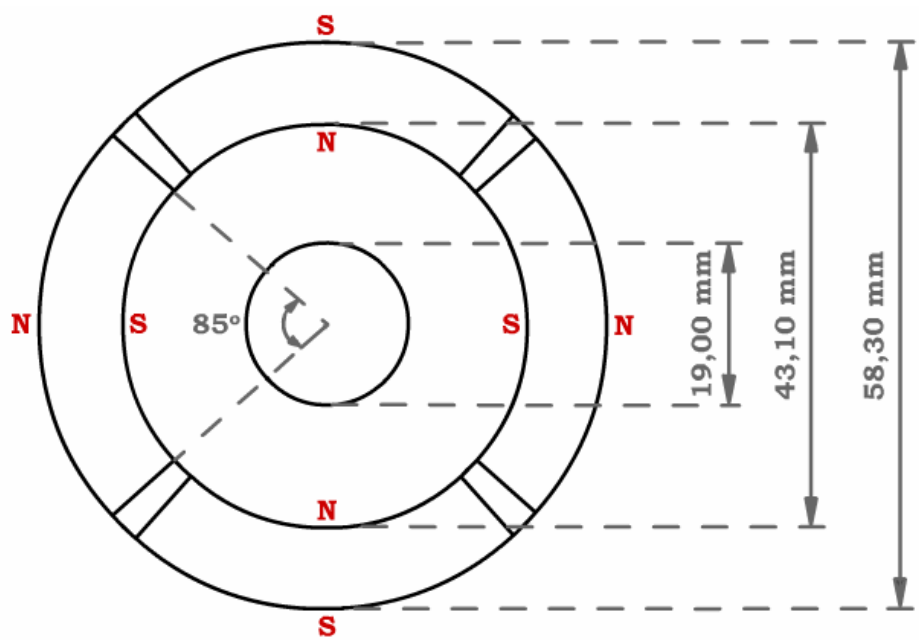

Figura 4.5. Dimensões do rotor. 


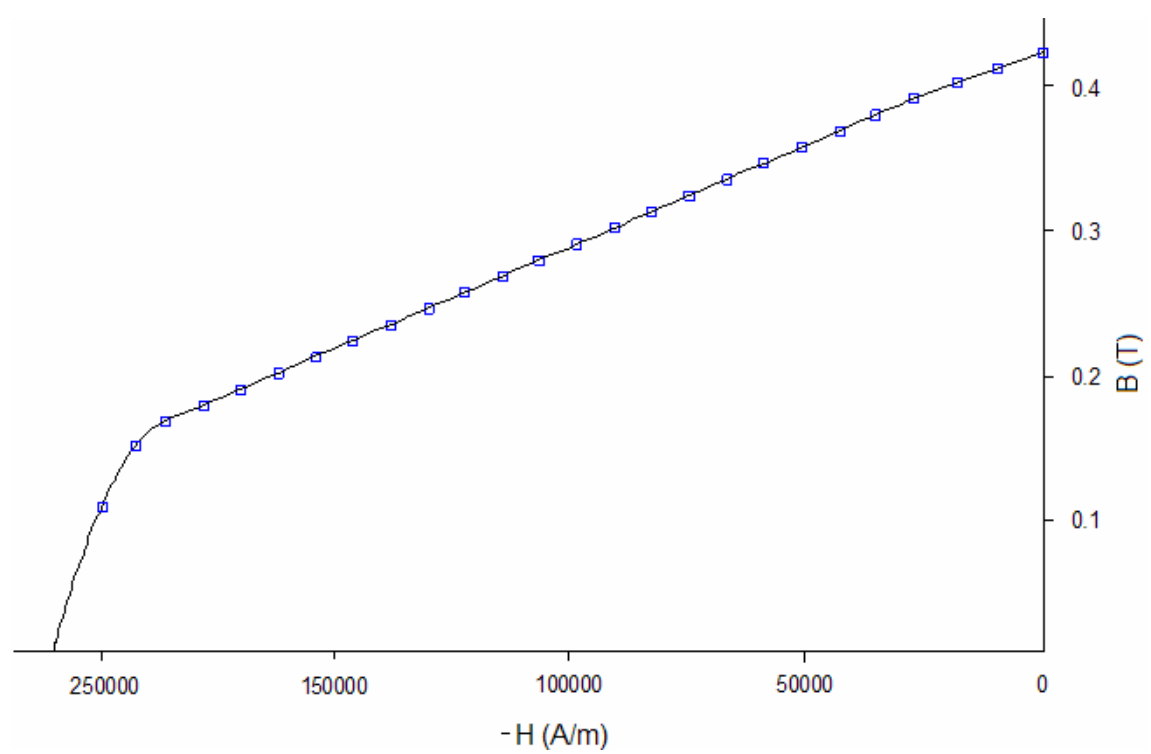

Figura 4.6. Curva de desmagnetização da ferrita (MEEKER, 2006).

\subsection{Resultados do Programa Computacional FEMM}

Nesta seção são apresentados os resultados obtidos pelo programa FEMM. Foram utilizados os dados das correntes elétricas por fase e da velocidade mecânica, variáveis obtidas por (GONELLA, 2006) através da simulação temporal para alimentar-se o enrolamento do estator e para calcularem-se as tensões induzidas por fase, respectivamente.

A figura 4.7 mostra o intervalo temporal selecionado para a análise estática do campo magnético, utilizando-se o método dos elementos finitos (MEF), que é detalhado no apêndice B. Este período foi escolhido porque abrange a velocidade média de operação do motor para o tipo da aplicação estudada. São apresentados os resultados referentes a uma revolução mecânica. 


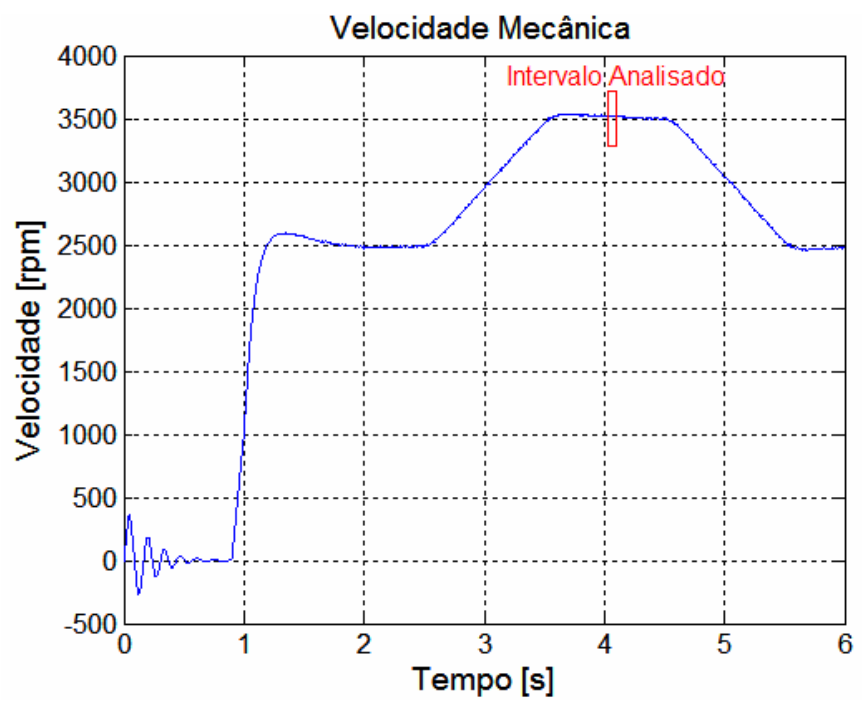

Figura 4.7. Velocidade mecânica em relação ao tempo, mostrando o intervalo temporal selecionado para a análise estática do campo magnético.

O movimento do rotor foi realizado em passos em torno de $3^{\circ}$ mecânicos até completarem-se $360^{\circ}$ mecânicos. Esse valor é aproximado, pois para cada intervalo há um número diferente de pontos (em torno de 400, armazenados em um arquivo de extensão txt) contendo os resultados temporais, e estes não possuem um espaçamento fixo entre si.

Selecionou-se em torno de 120 pontos, sendo que cada um corresponde a uma determinada posição, que é nomeada de acordo ao ângulo rotacionado no sentido anti-horário em relação a posição zero (figura 4.8).

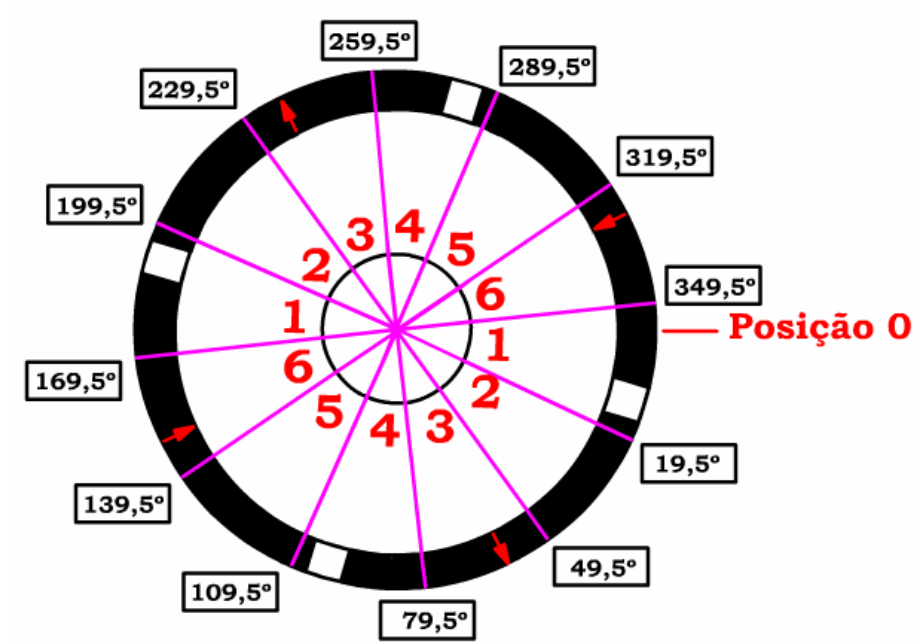

Figura 4.8. Nova divisão do rotor em regiões conforme a alimentação do enrolamento do estator. 
A figura 4.4 diferencia-se da figura 4.8 , pois a primeira está $32,7^{\circ}$ adiantada em relação a segunda (sentido anti-horário), devido à readequação do referencial zero adotado anteriormente em relação à posição nula utilizada na simulação temporal.

A nova associação da alimentação do enrolamento do estator com o posicionamento do rotor é mostrada na tabela 4.4 .

Tabela 4.4 - Nova alimentação do enrolamento do estator associada com o posicionamento do rotor.

\begin{tabular}{ccc}
\hline Tipo de Alimentação & $\begin{array}{c}\text { Posição do Rotor no Primeiro } \\
\text { Ciclo Elétrico }\end{array}$ & $\begin{array}{c}\text { Posição do Rotor no Segundo } \\
\text { Ciclo Elétrico }\end{array}$ \\
\hline Alimentação 1 & $349,5^{\circ} \leq 19,5^{\circ}$ & $169,5^{\circ} \leq 199,5^{\circ}$ \\
Alimentação 2 & $19,5^{\circ} \leq 49,5^{\circ}$ & $199,5^{\circ} \leq 229,5^{\circ}$ \\
Alimentação 3 & $49,5^{\circ} \leq 79,5^{\circ}$ & $229,5^{\circ} \leq 259,5^{\circ}$ \\
Alimentação 4 & $79,5^{\circ} \leq 109,5^{\circ}$ & $259,5^{\circ} \leq 289,5^{\circ}$ \\
Alimentação 5 & $109,5^{\circ} \leq 139,5^{\circ}$ & $289,5^{\circ} \leq 319,5^{\circ}$ \\
Alimentação 6 & $139,5^{\circ} \leq 169,5^{\circ}$ & $319,5^{\circ} \leq 349,5^{\circ}$ \\
\hline
\end{tabular}

Nas subseções seguintes são apresentados os resultados referentes ao intervalo selecionado que é de 4,00255 s até 4,01955 s.

Primeiramente são apresentados os resultados da simulação temporal, utilizados para a análise estática no programa computacional baseado no método dos elementos finitos.

São mostrados os resultados comparativos para a máquina existente (protótipo) com o tamanho do entreferro de $1,35 \mathrm{~mm}$ e outra em projeto com o tamanho igual a $0,76 \mathrm{~mm}$.

Os gráficos apresentados correspondem à velocidade mecânica, ao torque de carga, à corrente elétrica, à tensão induzida, ao torque eletromagnético e às perdas resisitivas e magnéticas. Todos esses resultados são expostos em relação à posição angular do rotor, com exceção das perdas no ferro que são em relação ao tipo do projeto correspondente. 
Também são apresentadas as curvas referentes à densidade de fluxo magnético da componente normal e gráficos de cores da densidade de fluxo magnético. Esses dados são importantes para a análise do comportamento magnético dos materiais ferromagnéticos e dos ímãs permanentes na máquina projetada. Através disso, sugestões de melhorias de desempenho são propostas, como por exemplo, a substituição de materiais.

São apresentados resultados referentes à alteração dos ímãs de ferrita pelos de $\mathrm{NdFeB}$ (Bonded).

Também é mostrado um novo cálculo de projeto do MTIPR, fornecendo um torque eletromagnético próximo ao do oferecido pelo protótipo, porém usando ímãs de terras-raras no rotor. As especificações do enrolamento do estator, como número de espiras e tamanho do diâmetro, são modificadas, visando uma diminuição das perdas resistivas.

Todos esses resultados são provenientes do programa FEMM, utilizando-se linguagem Lua Scripting para a automação dos cálculos. Foram armazenados em arquivos no formato txt e são apresentados em forma de gráficos, que foram obtidos através do software Matlab ${ }^{\circledR}$.

\subsubsection{Sem a Realização de Alterações do Projeto do MTIPR}

Nesta subseção são apresentados os resultados obtidos pela simulação temporal realizada por (GONELLA, 2006), que são dados essenciais para a realização de todos os cálculos deste trabalho.

São mostrados os resultados obtidos pelo programa computacional FEMM, inicialmente, sem constar nenhuma alteração de projeto do MTIPR. É através da análise desses resultados que melhorias de desempenho são propostas. 
Também é apresentada a comparação da tensão induzida obtida experimentalmente, por (TEIXEIRA, 2006), com a calculada pelo software FEMM. Essa medida é importante para a verificação se a configuração, da geometria e dos materiais, está feita corretamente no programa computacional, baseado no método dos elementos finitos.

A figura 4.9 ilustra a velocidade mecânica em relação à posição angular do intervalo selecionado, obtida pela simulação temporal.

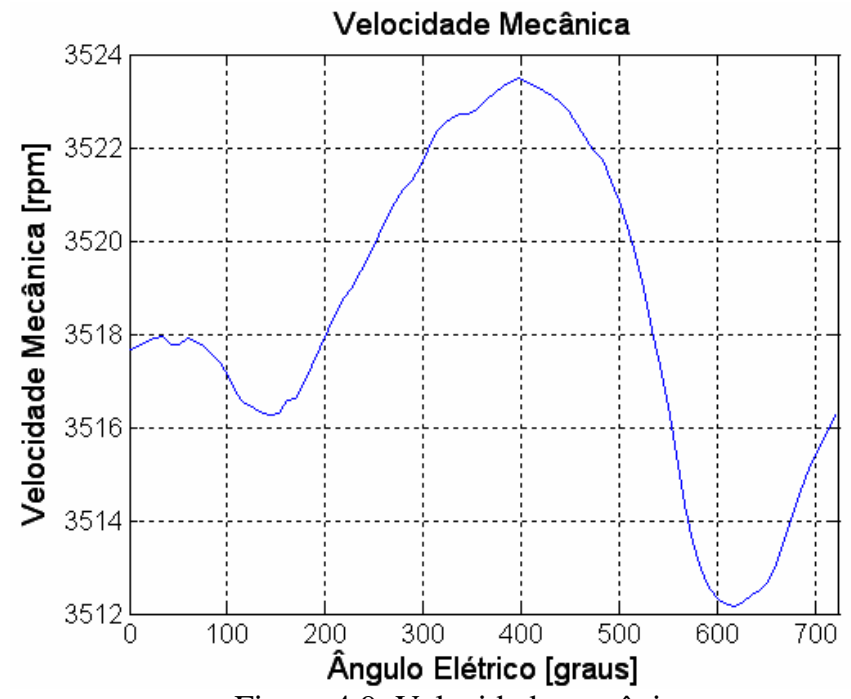

Figura 4.9. Velocidade mecânica.

A figura 4.10 é o torque de carga, mostrando a compressão e a sucção do pistão do sistema de refrigeração, em uma revolução mecânica.

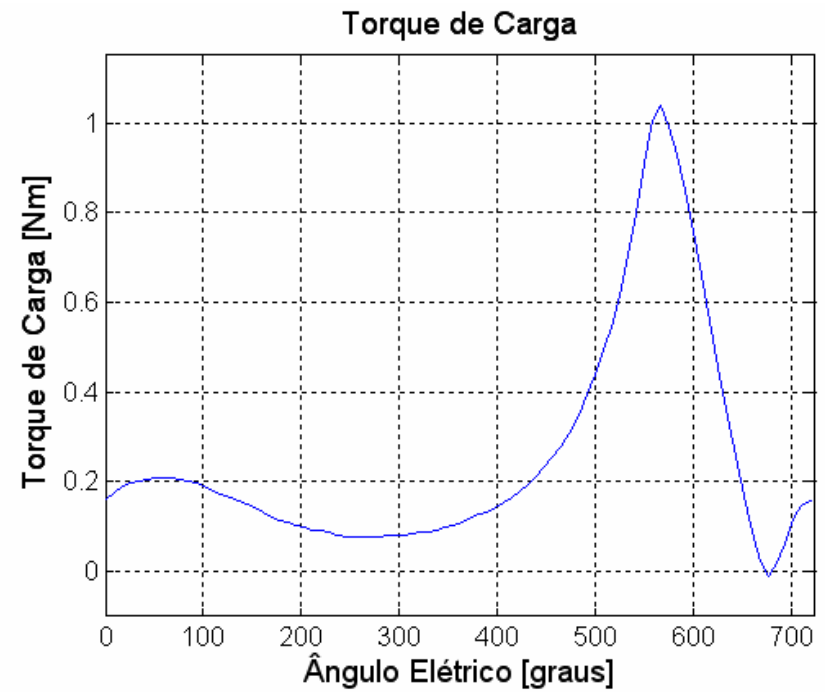

Figura 4.10. Torque de carga. 
A corrente elétrica, por fase, obtida pela simulação temporal realizada por (GONELLA, 2006) é mostrada na figura 4.11. Ela é utilizada para realizar a alimentação do enrolamento do estator, no programa computacional FEMM. Todos os resultados apresentados neste trabalho são conseqüências dessa alimentação.

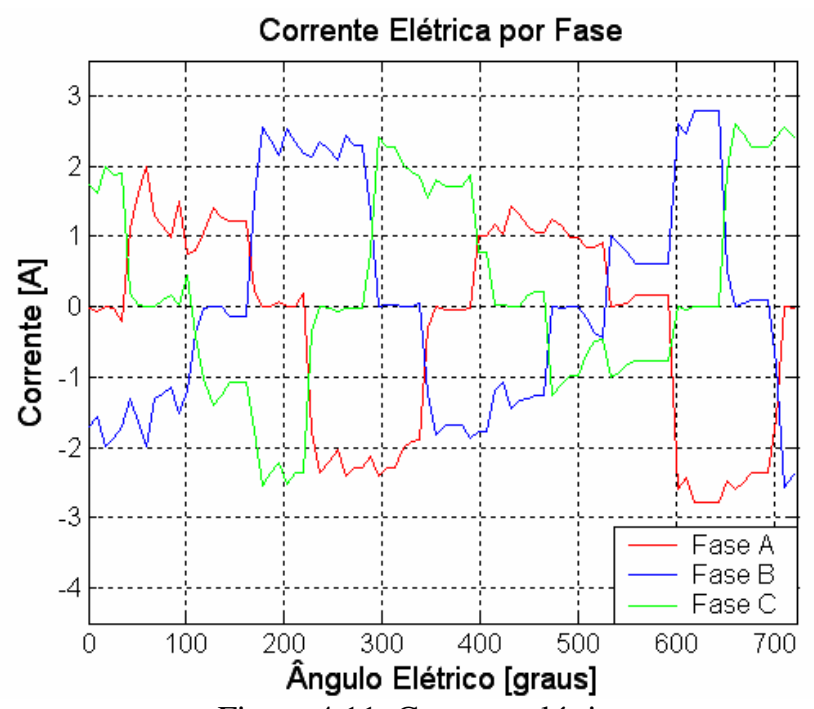

Figura 4.11. Corrente elétrica.

Na figura 4.12 é ilustrada a comparação entre a tensão induzida obtida pelo software baseado no método dos elementos finitos e a obtida experimentalmente por (TEIXEIRA, 2006). Ambas possuem a mesma forma de onda e o valor eficaz da força contra-eletromotriz calculada é inferior em torno de $3 \%$. 


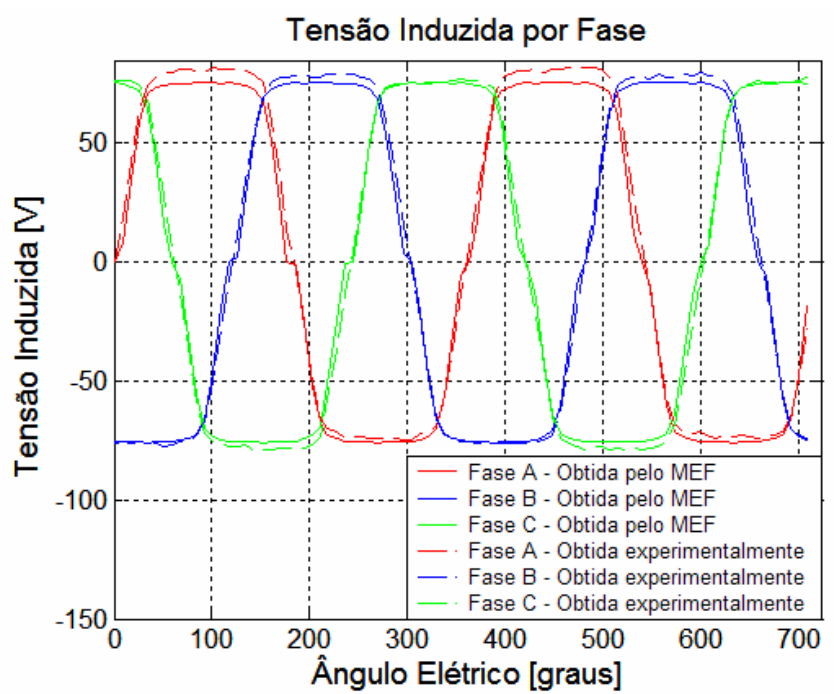

Figura 4.12. Comparação da tensão induzida obtida pelo software baseado no método dos elementos finitos com a obtida experimentalmente.

A figura 4.13 mostra o torque eletromagnético obtido pela simulação temporal e o obtido pelo software FEMM. Ambas as curvas possuem a forma de onda semelhante, e devese ressaltar que esses resultados foram obtidos por abordagens diferentes.

O valor eficaz do torque, obtido pela simulação temporal, é em torno de $2,6 \%$ maior que o obtido pelo programa computacional FEMM. Observa-se que a sua maior magnitude refere-se à posição $633,6^{\circ}$ elétricos.

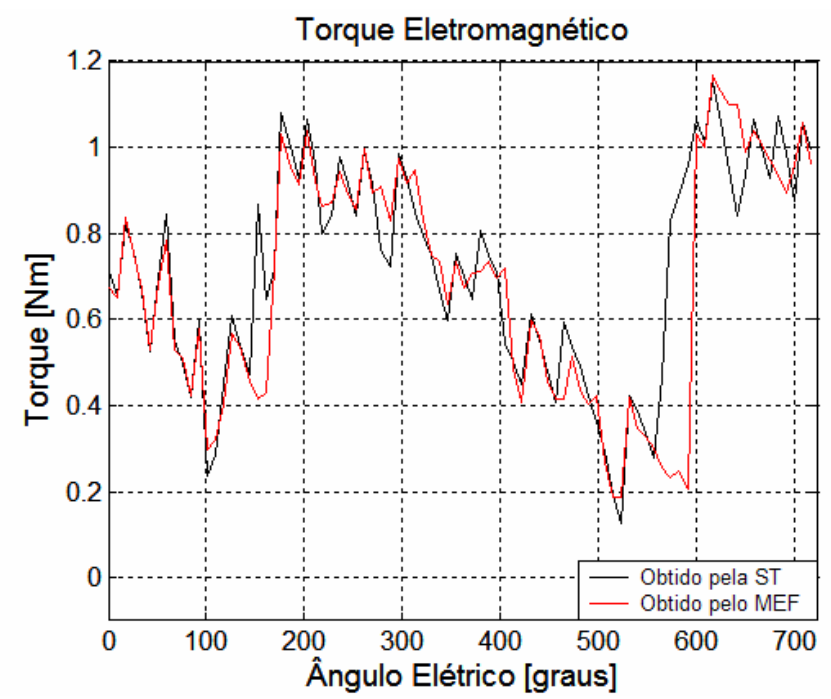

Figura 4.13. Comparação do torque eletromagnético obtido pelo software baseado no método dos elementos finitos com o obtido pela simulação temporal. 
A densidade de fluxo magnético da componente normal, da região central do entreferro (figura 4.14), é mostrada nas figuras 4.15 - 4.20. Cada curva representa um estado da alimentação, abrangendo os dois ciclos elétricos, durante uma revolução mecânica.

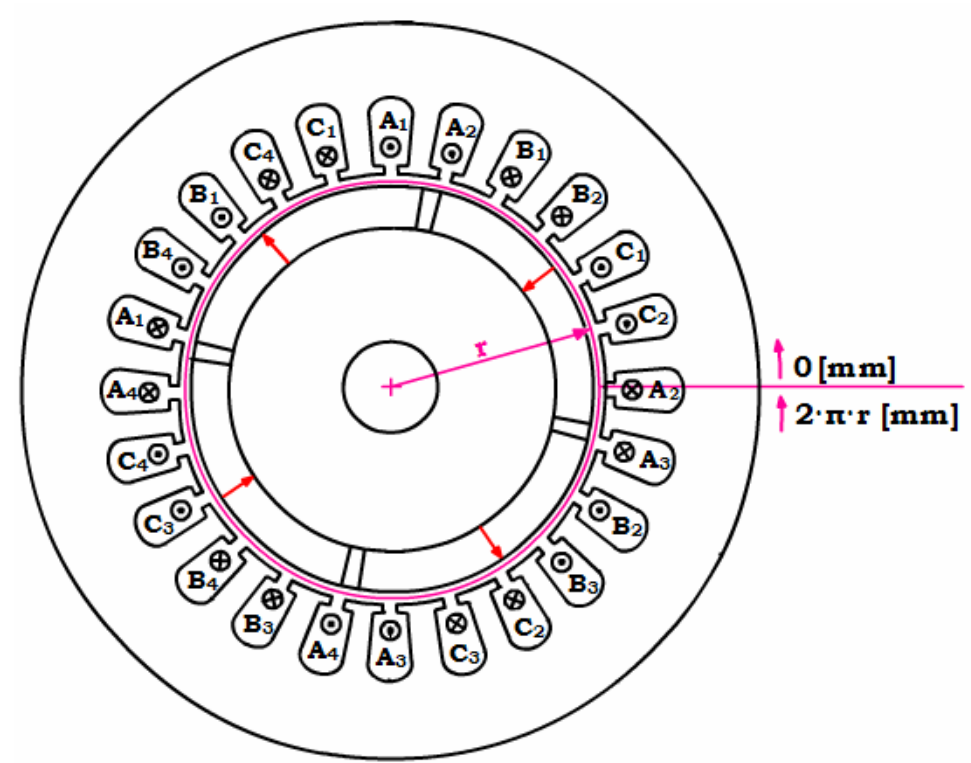

Figura 4.14. Região central do entreferro em que são obtidas as curvas da densidade de fluxo magnético da componente normal.

A figura 4.15.a é a densidade de fluxo magnético da componente normal com o rotor na posição $0,1^{\circ}$ mecânicos e a 4.15 .b na posição $33.9^{\circ}$ mecânicos.

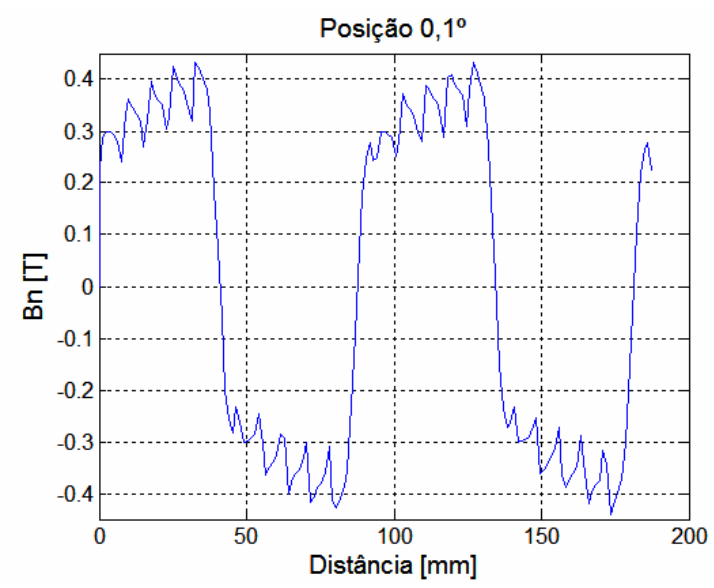

a)

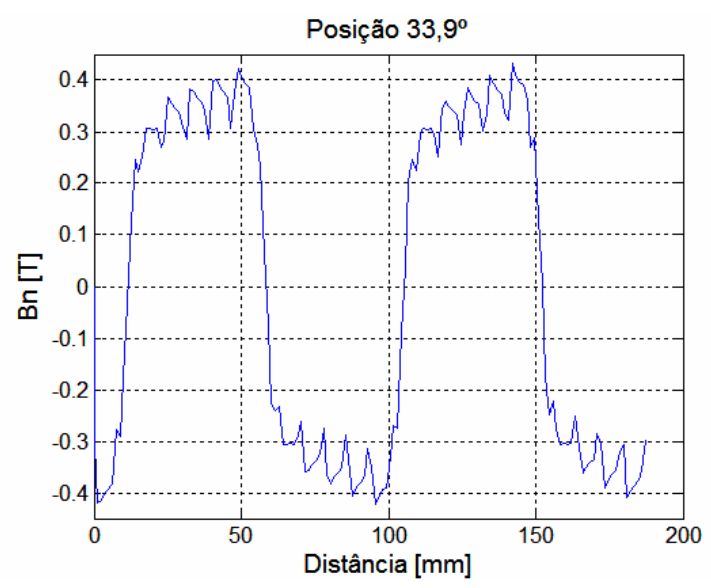

b)

Figura 4.15. Densidade de fluxo magnético da componente normal: a) Posição 0,1º b) Posição 33,9. 


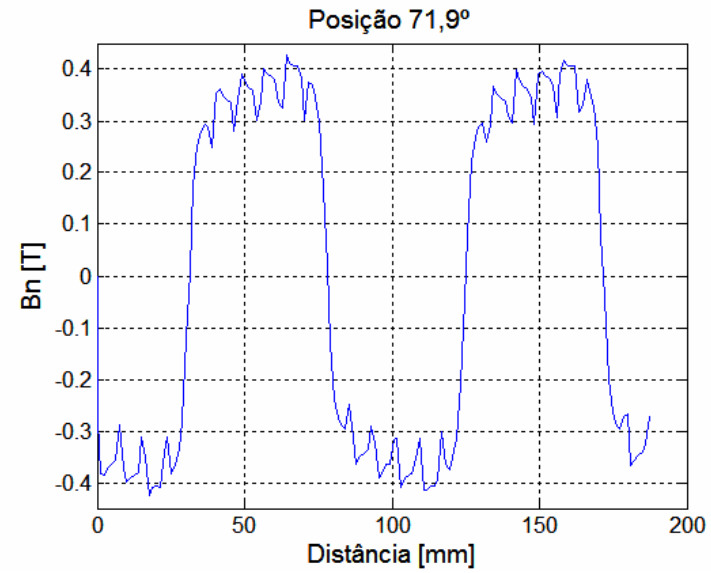

a)

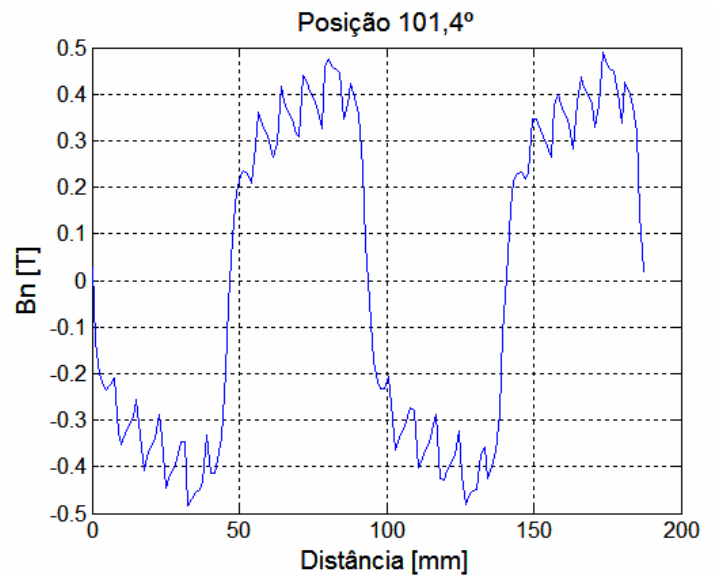

b)

Figura 4.16. Densidade de fluxo magnético da componente normal: a) Posição $71,9^{\circ}$; b) Posição $101,4^{\circ}$.

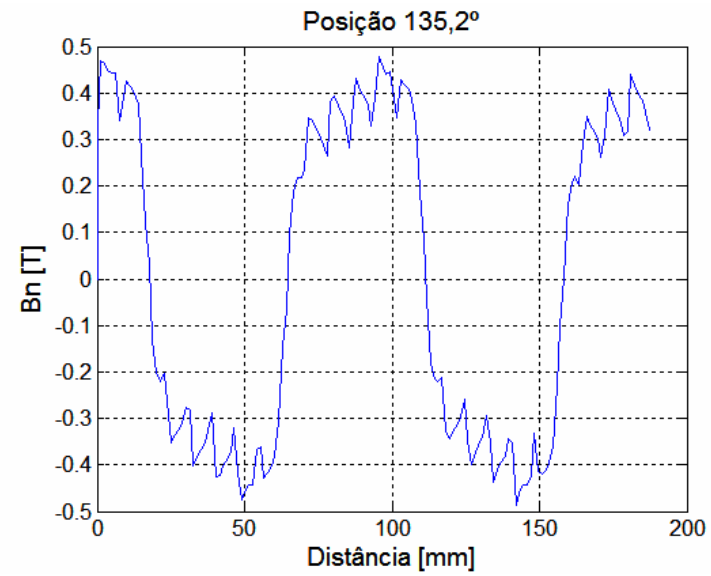

a)

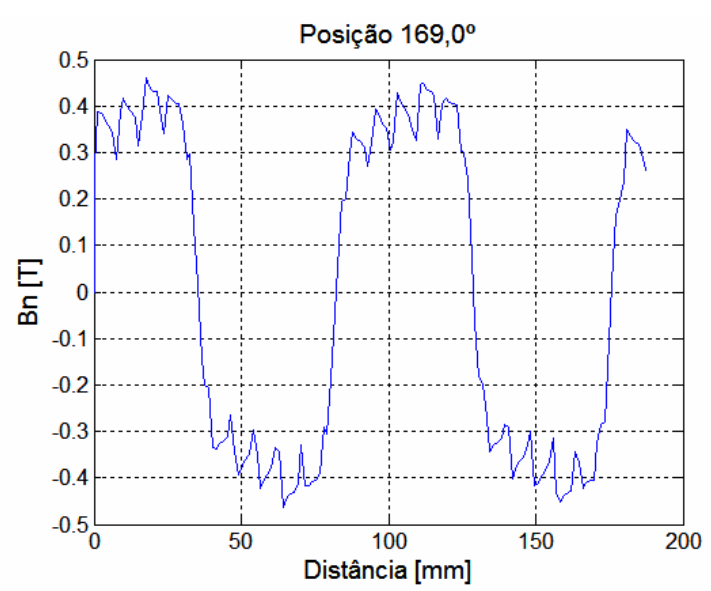

b)

Figura 4.17. Densidade de fluxo magnético da componente normal: a) Posição 135,2; b) Posição $169,0^{\circ}$.

Observa-se que as magnitudes da indução magnética estão de acordo com a disposição dos ímãs e que que as formas de onda das curvas são semelhantes. Além disso, os valores da densidade de fluxo magnético, nos espaços vazios entre os ímãs, são próximos a zero e exatamente nulos na região central dessas localidades. 


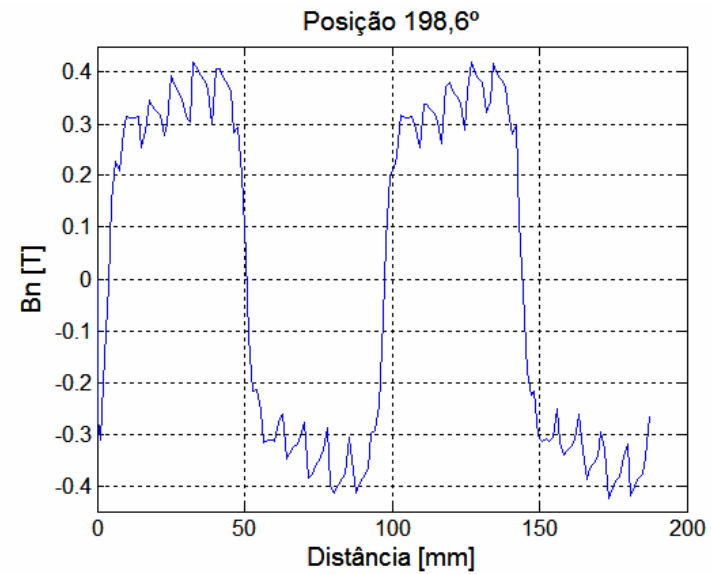

a)

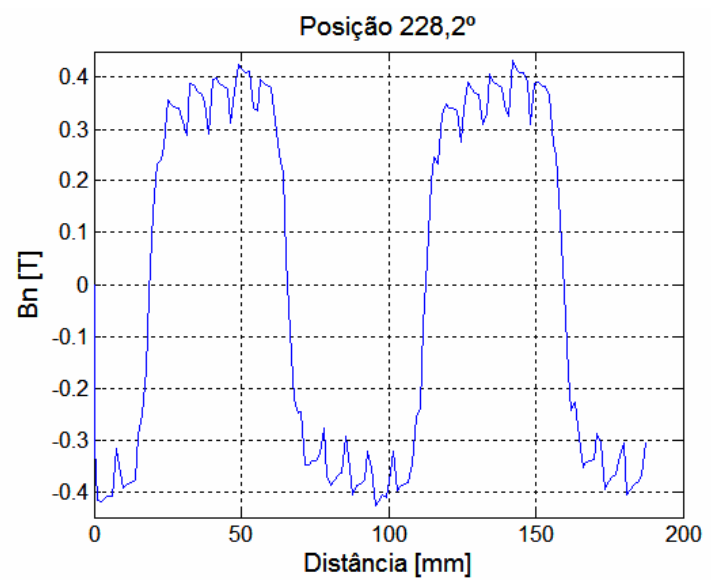

b)

Figura 4.18. Densidade de fluxo magnético da componente normal: a) Posição 198,6º b) Posição 228, $2^{\circ}$.

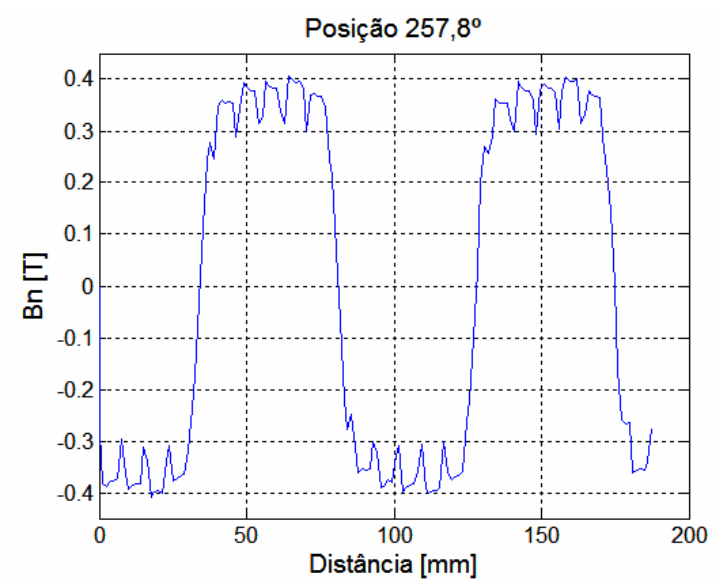

a)

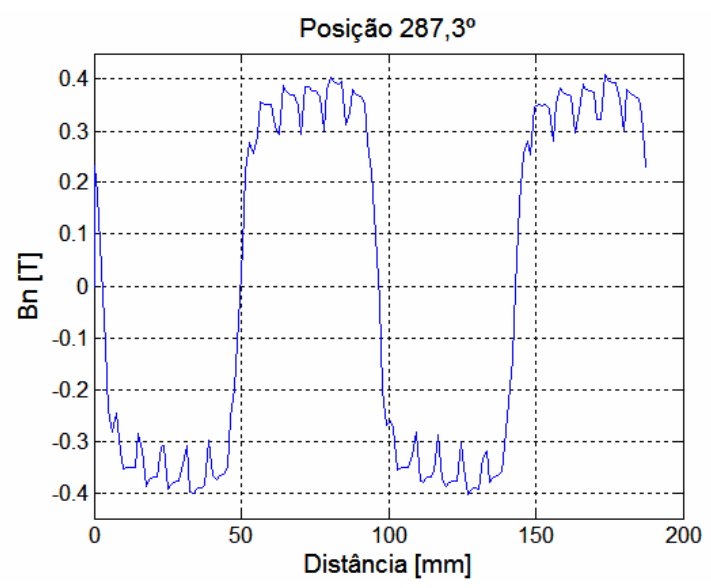

b)

Figura 4.19. Densidade de fluxo magnético da componente normal: a) Posição 257, $8^{\circ}$; b) Posição $287,3^{\circ}$.

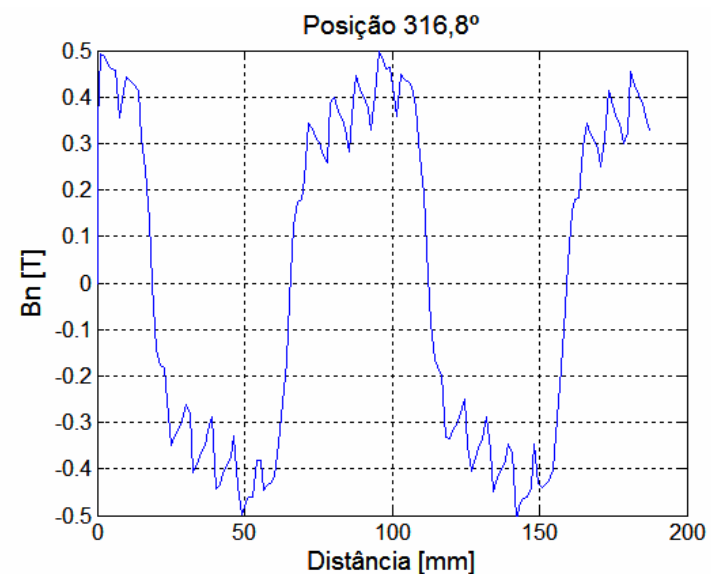

a)

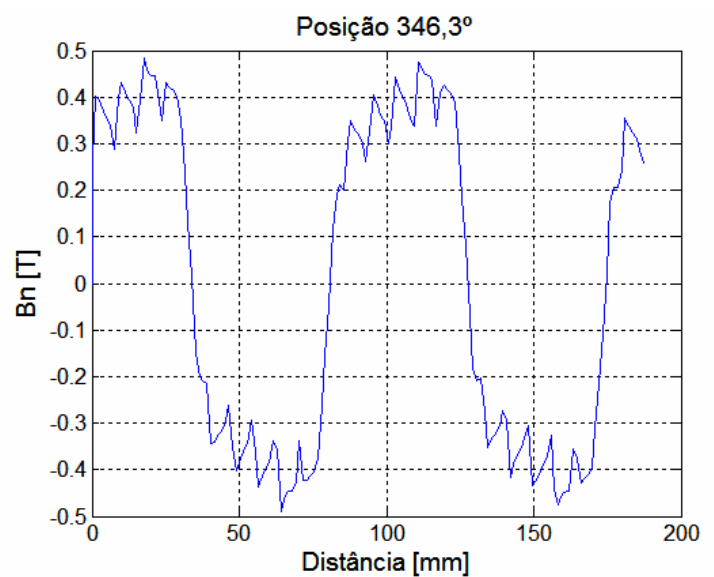

b)

Figura 4.20. Densidade de fluxo magnético da componente normal: a) Posição 316,8 ; b) Posição 346,3 .

As figuras 4.19.a e 4.19.b referem-se às posições em que a densidade de fluxo magnético atravessa a região central do ímãs, ocorrendo uma redução das ondulações. 
A observação realizada anteriormente pode ser mais bem entendida analisando-se os gráficos de cores da densidade de fluxo magnético correspondentes às posições $257,8^{\circ} \mathrm{e}$ $287,3^{\circ}$, mostrados nas figuras 4.21 e 4.22 .
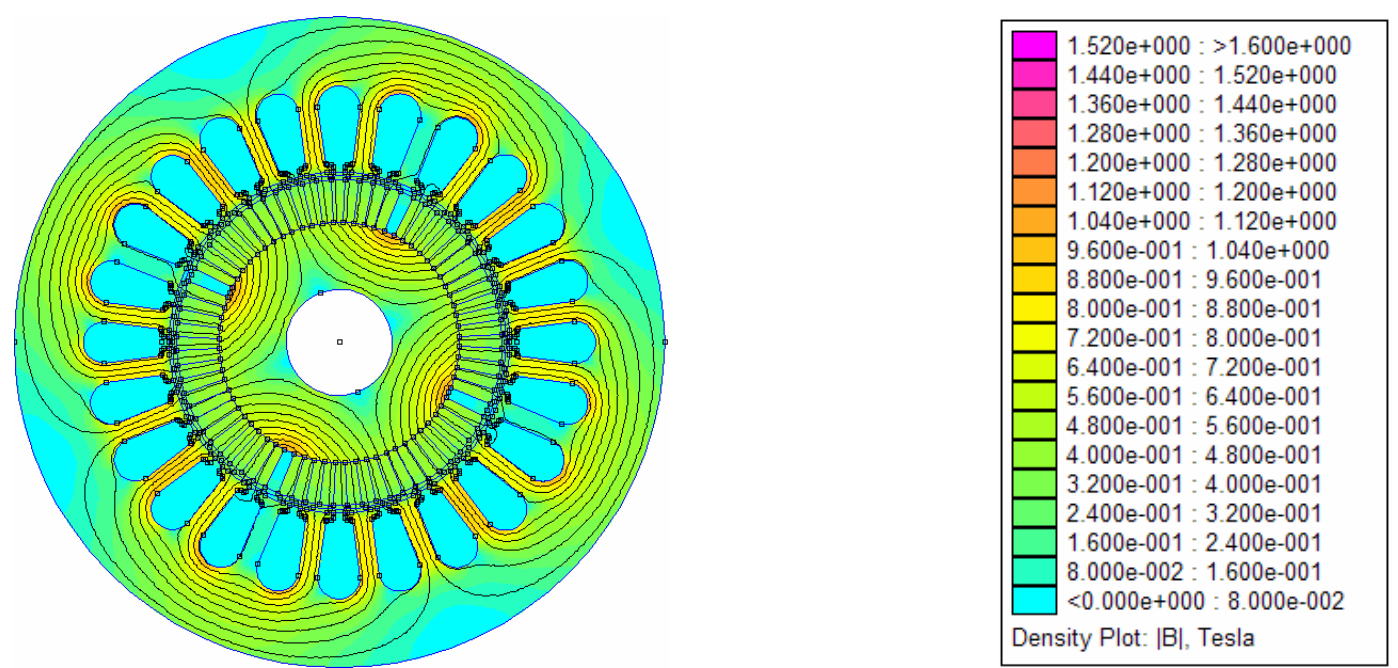

Figura 4.21. Densidade de fluxo magnético da posição $257,8^{\circ}$.
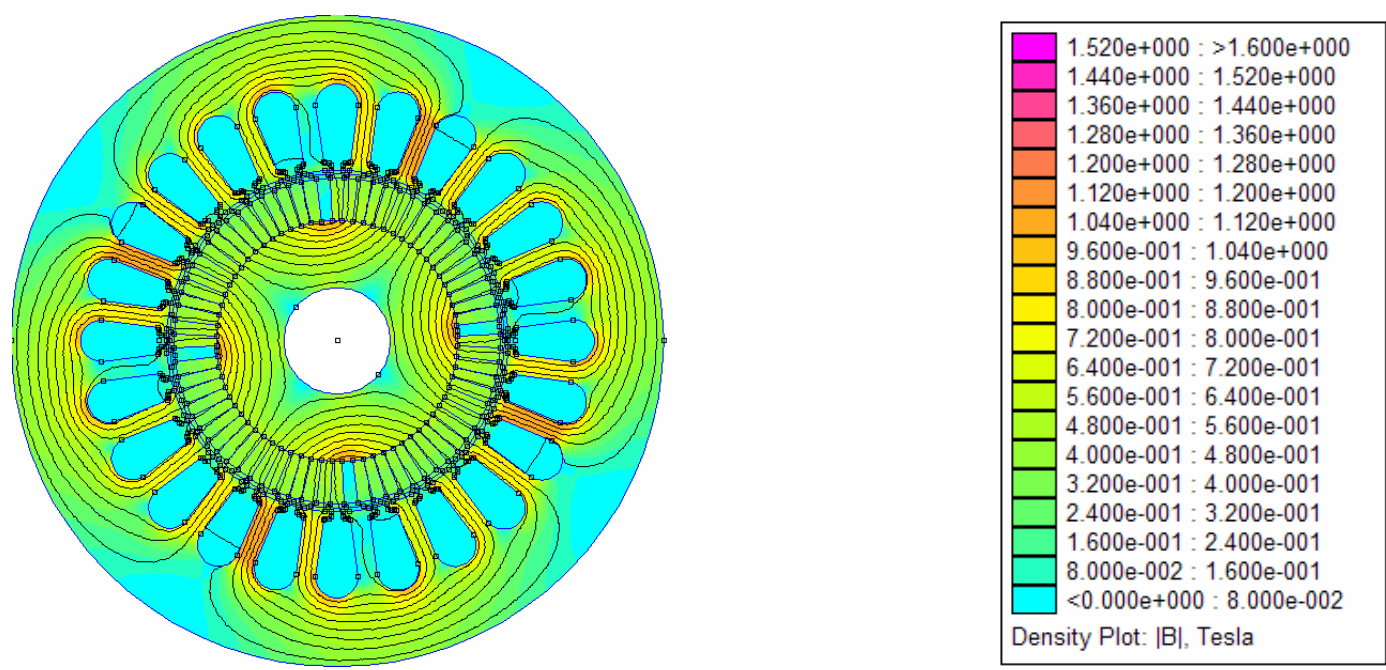

Figura 4.22. Densidade de fluxo magnético da posição $287,3^{\circ}$.

A figura 4.23 mostra o rotor na posição $316,8^{\circ}$ mecânicos, que apresentou as maiores magnitudes de densidade de fluxo magnético e conseqüentemente o maior valor de torque eletromagnético. Nas demais subseções os gráficos de cores e da densidade de fluxo magnético da componente normal são apresentados para essa posição do rotor. 

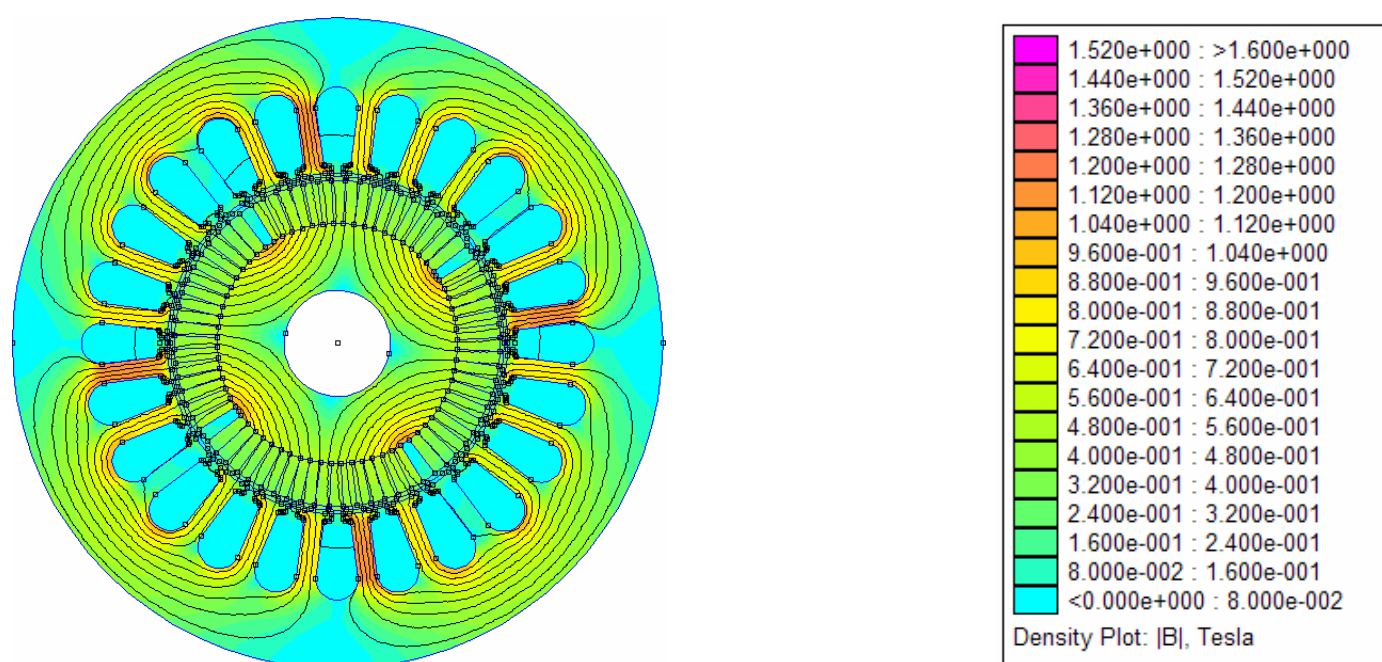

Figura 4.23. Densidade de fluxo magnético da posição $316,8^{\circ}$, com entreferro de 1,35 mm e ímãs de ferrita.

Observando-se a figura 4.23, nota-se que a densidade de fluxo magnético entre as ranhuras não ultrapassa 1,2 T. Isso possibilita a alteração do material dos ímãs, desde que os limites de saturação do material ferromagnético sejam respeitados.

\subsubsection{Referentes a Dois Tamanhos de Entreferro}

Nesta subseção são apresentados resultados comparativos entre o protótipo existente e outro em projeto, em que o primeiro possui tamanho de entreferro igual a $1,35 \mathrm{~mm}$ e o segundo $0,76 \mathrm{~mm}$. Essa alteração foi feita porque trata-se do tamanho do entreferro calculado inicialmente, pois devido à dificuldade de se encontrar ímãs que satisfizessem essa medida utilizou-se os existentes no mercado.

Essa mudança interfere diretamente nos valores da densidade de fluxo magnético no entreferro (figura 4.24) e no material ferromagnético (figura 4.25). 


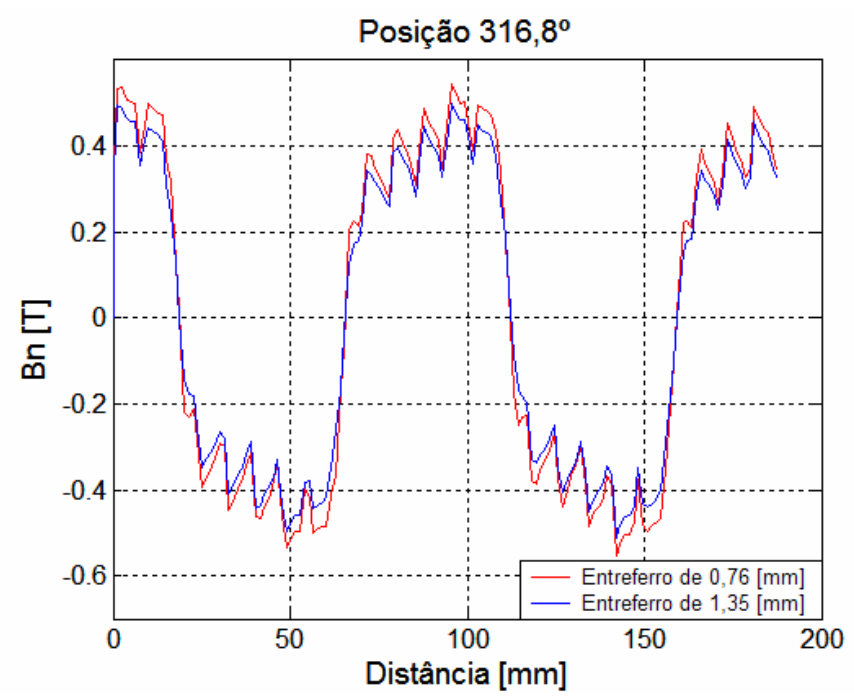

Figura 4.24. Comparação da densidade de fluxo magnético da componente normal do protótipo (tamanho de entreferro igual a $1,35 \mathrm{~mm}$ ) com a do motor em projeto (tamanho de entreferro igual a $0,76 \mathrm{~mm}$ ).

O valor eficaz da indução magnética do protótipo é em torno de $9 \%$ menor que o do motor em projeto. Essa diferença pode ser observada através da figura 4.24, em que o rotor está na posição de $316,8^{\circ}$ mecânicos.

A densidade de fluxo magnético nos dentes também não ultrapassa 1,2 T, figura 4.25.
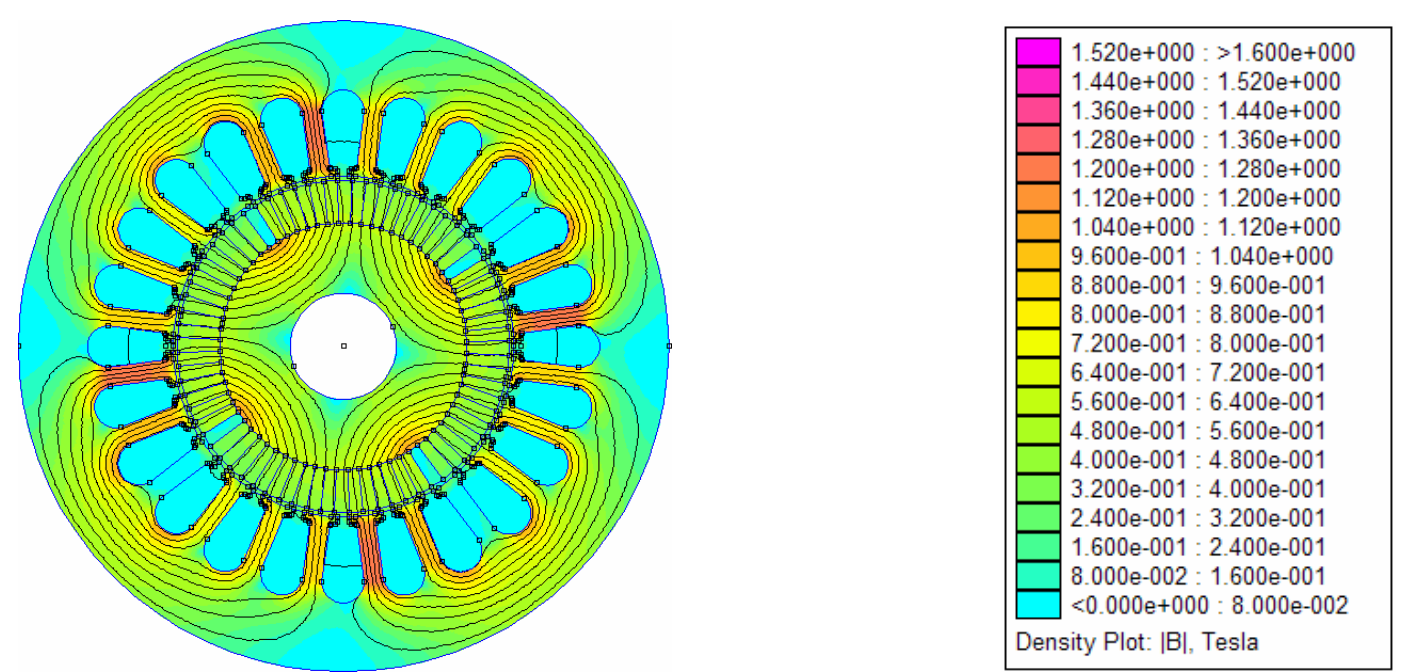

Figura 4.25. Densidade de fluxo magnético da posição $316,8^{\circ}$, com o tamanho do entreferro igual a $0,76 \mathrm{~mm}$ e ímãs de ferrita. 
A alteração da indução magnética tem como consequiência a alteração da força contraelemotriz. A figura 4.26 mostra a comparação da tensão induzida por fase do protótipo (entreferro igual a $1,35 \mathrm{~mm}$ ) com o motor em projeto (entreferro igual a $0,76 \mathrm{~mm}$ ). O valor eficaz da primeira é em torno de $9 \%$ menor que o da segunda.

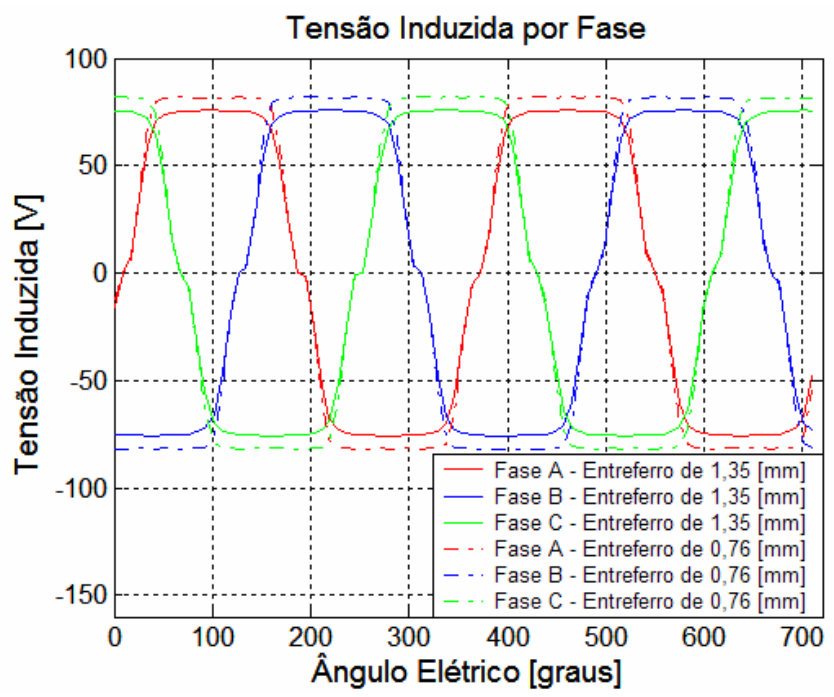

Figura 4.26. Comparação da tensão induzida experimental, por fase, do protótipo (entreferro igual a 1,35 mm) com a do motor em projeto (entreferro igual a $0,76 \mathrm{~mm}$ ) obtida com o software FEMM.

A mudança da força contra-elemotriz resulta na alteração do torque eletromagnético. A figura 4.27 o compara para os dois tamanhos de entreferro. A magnitude do torque, referente ao motor com menor entreferro, é em torno de $9 \%$ superior em relação ao maior.

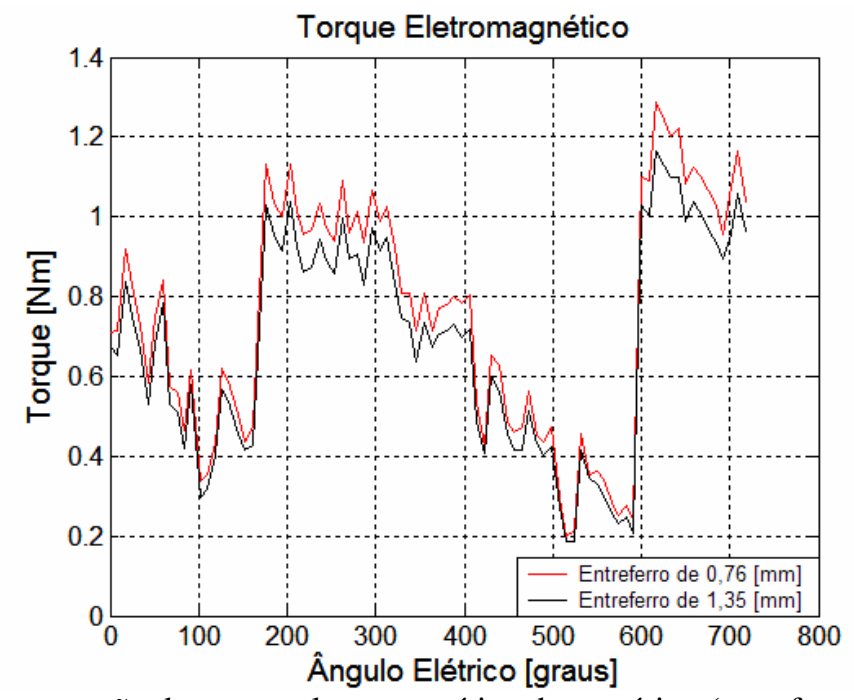

Figura 4.27. Comparação do torque eletromagnético do protótipo (entreferro igual a 1,35 mm) com o do motor em projeto (entreferro igual a $0,76 \mathrm{~mm}$ ). 


\subsubsection{Referentes a Dois Tipos de Ímãs}

Após comprovar-se que a densidade de fluxo magnético não ultrapassa 1,2 T entre os dentes, trocou-se os ímãs de ferrita pelos de NdFeB (Bonded). Nesta subseção, os resultados referem-se a essa única alteração do projeto do MTIPR, mantendo-se o entreferro de 1,35 $\mathrm{mm}$.

A figura 4.28 compara a densidade de fluxo magnético da componente normal do protótipo com a do motor em projeto. O valor eficaz da indução magnética do primeiro é em torno de $25 \%$ menor que o do segundo.

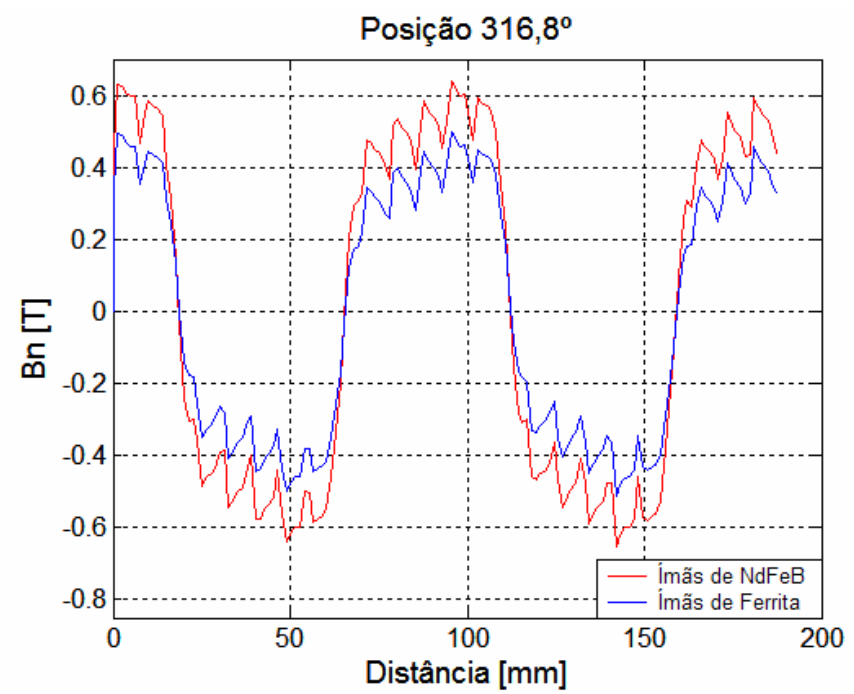

Figura 4.28. Comparação da densidade de fluxo magnético da componente normal do protótipo com a do motor constituído por ímãs de $\mathrm{NdFeB}$ (Bonded).

A figura 4.29 mostra a densidade de fluxo magnético, também na posição $316,8^{\circ}$ mecânicos, que não ultrapassa 1,5 T entre os dentes. 

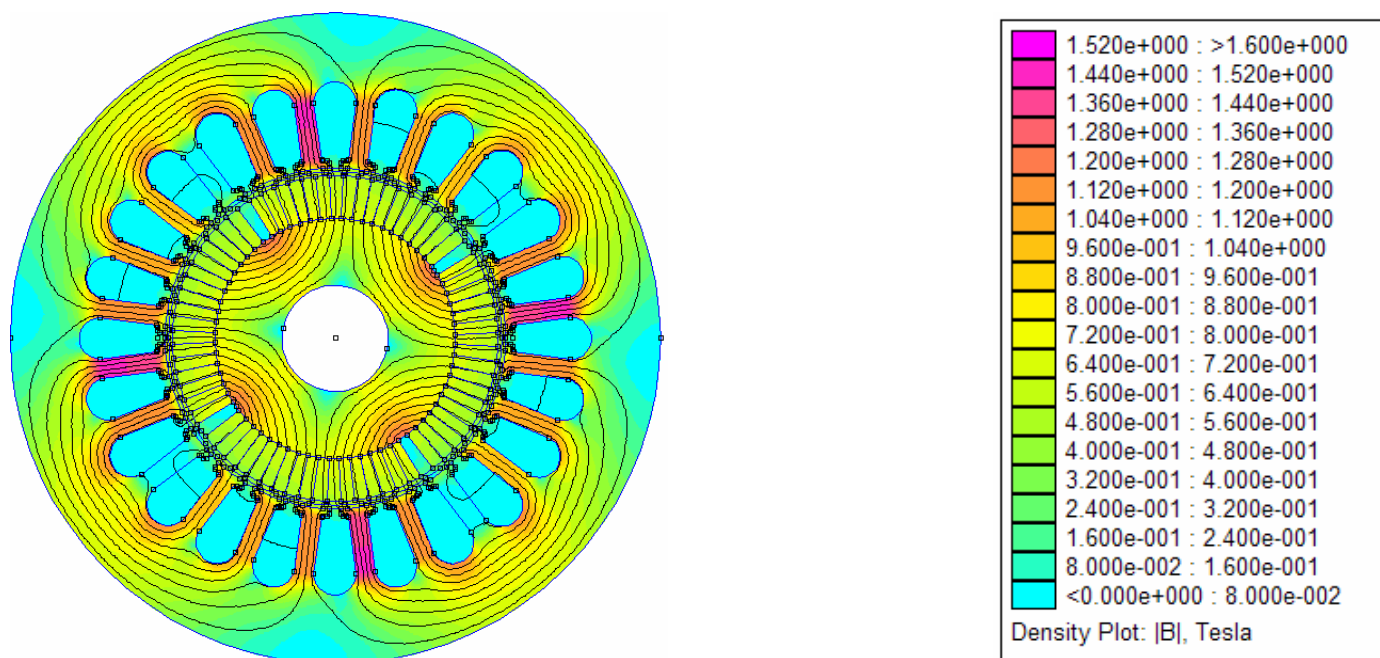

Figura 4.29. Densidade de fluxo magnético da posição $316,8^{\circ}$, com o tamanho do entreferro igual a $1,35 \mathrm{~mm}$ e ímãs de NdFeB (Bonded).

A comparação da tensão induzida, obtida com a substituição dos ímãs de ferrita pelos de $\mathrm{NdFeB}$ (Bonded), é feita pela figura 4.30. O valor eficaz da força contra-eletromotriz, referente ao motor com ímas de terras-raras, é aproximadamente 38\% maior que o da máquina com ímãs de ferrita.

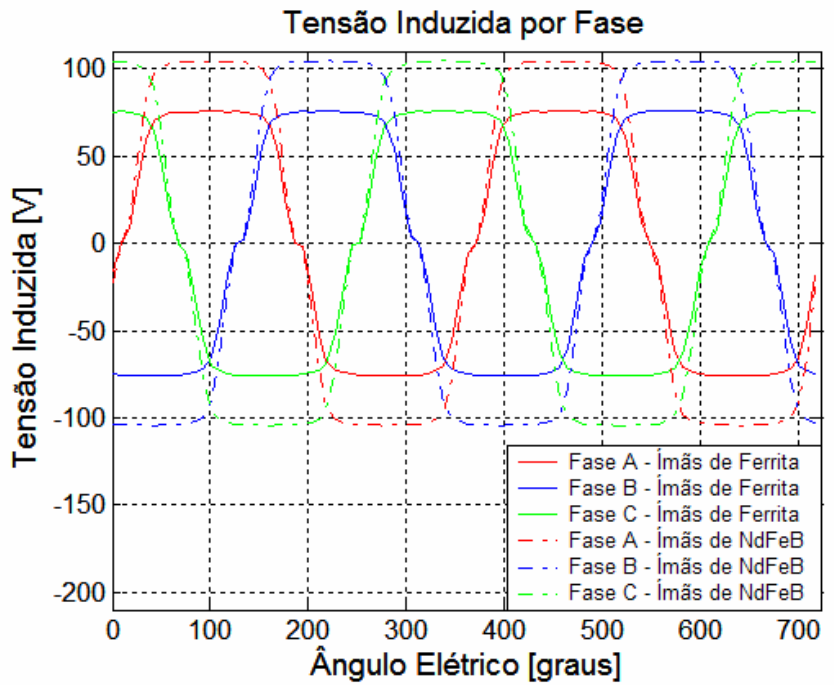

Figura 4.30. Comparação da tensão induzida experimental com a resultante da substituição dos ímãs de ferrita pelos de NdFeB (Bonded). 
A figura 4.31 apresenta a comparação do torque eletromagnético obtido com a substituição do ímãs de ferrita pelos de NdFeB (Bonded). O valor eficaz do torque, referente ao motor com ímas de terras-raras, é cerca de $38 \%$ maior que o da máquina com ímãs de ferrita.

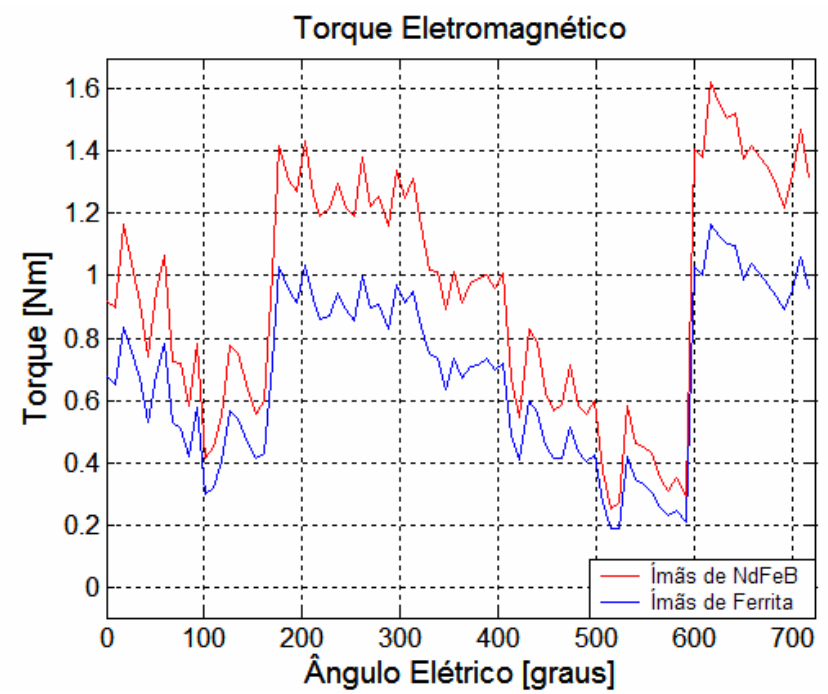

Figura 4.31. Comparação do torque eletromagnético do protótipo com o resultante da substituição dos ímãs de ferrita pelos de NdFeB (Bonded).

\subsubsection{Projeto Refeito do MTIPR}

Na subseção anterior foram apresentados os resultados referentes à substituição dos ímãs de ferrita pelos de NdFeB (Bonded). Através da análise da densidade de fluxo magnético nos dentes do estator, observou-se que a indução magnética não ultrapassou 1,5 T.

Portanto, um novo projeto do MTIPR poderia ser feito, conservando-se a alteração dos ímãs permanentes e recalculando-se a bitola do fio e o número de espiras do enrolamento, mantendo-se o valor eficaz do torque eletromagnético próximo ao do fornecido pelo protótipo. Com isso, um estudo da redução das perdas no cobre pode ser realizado.

A seguir são apresentados os cálculos do projeto refeito do motor, baseados nas teorias e nas equações apresentadas no capítulo 3. 


\subsubsection{Cálculos do Projeto Refeito do MTIPR}

Para a realização dos cálculos, referentes ao enrolamento e à geometria do rotor, algumas especificações técnicas são definidas de acordo com (TEIXEIRA, 2006), alterandose o material dos ímãs permanentes e o tamanho do entreferro:

- Motor trifásico;

- Número de pólos igual a 4;

- Tamanho de entreferro igual a 0,76 mm;

- Estator oriundo de um motor de indução monofásico;

- Temperatura de operação igual a $60^{\circ} \mathrm{C}$;

- Ímãs de $\mathrm{NdFeB}$ (Bonded);

- A velocidade mecânica máxima é de $471,24 \mathrm{rad} \cdot \mathrm{s}^{-1}$;

- Área magnética do pólo igual a $1,604 \cdot 10^{-3} \mathrm{~m}^{2}$;

- Área aproximada de cada ranhura é de $100,6 \mathrm{~mm}^{2}$;

- Tensão de barramento igual a $300 \mathrm{~V}$.

Para o cálculo da espessura dos ímãs de terras-raras, o coeficiente de permeância foi definido igual a 10:

$$
L_{m}=g \cdot P C=0,76 \cdot 10=7,6 \mathrm{~mm}
$$

O valor do arco do ímã manteve-se em $85^{\circ}$ mecânicos, facilitando-se a montagem do rotor e objetivando-se a mínima dispersão de fluxo entre os ímãs.

Para o prosseguimento dos cálculos é necessária a determinação da densidade de fluxo magnético, no ponto de operação em circuito aberto, que é obtida através da figura 4.32. 


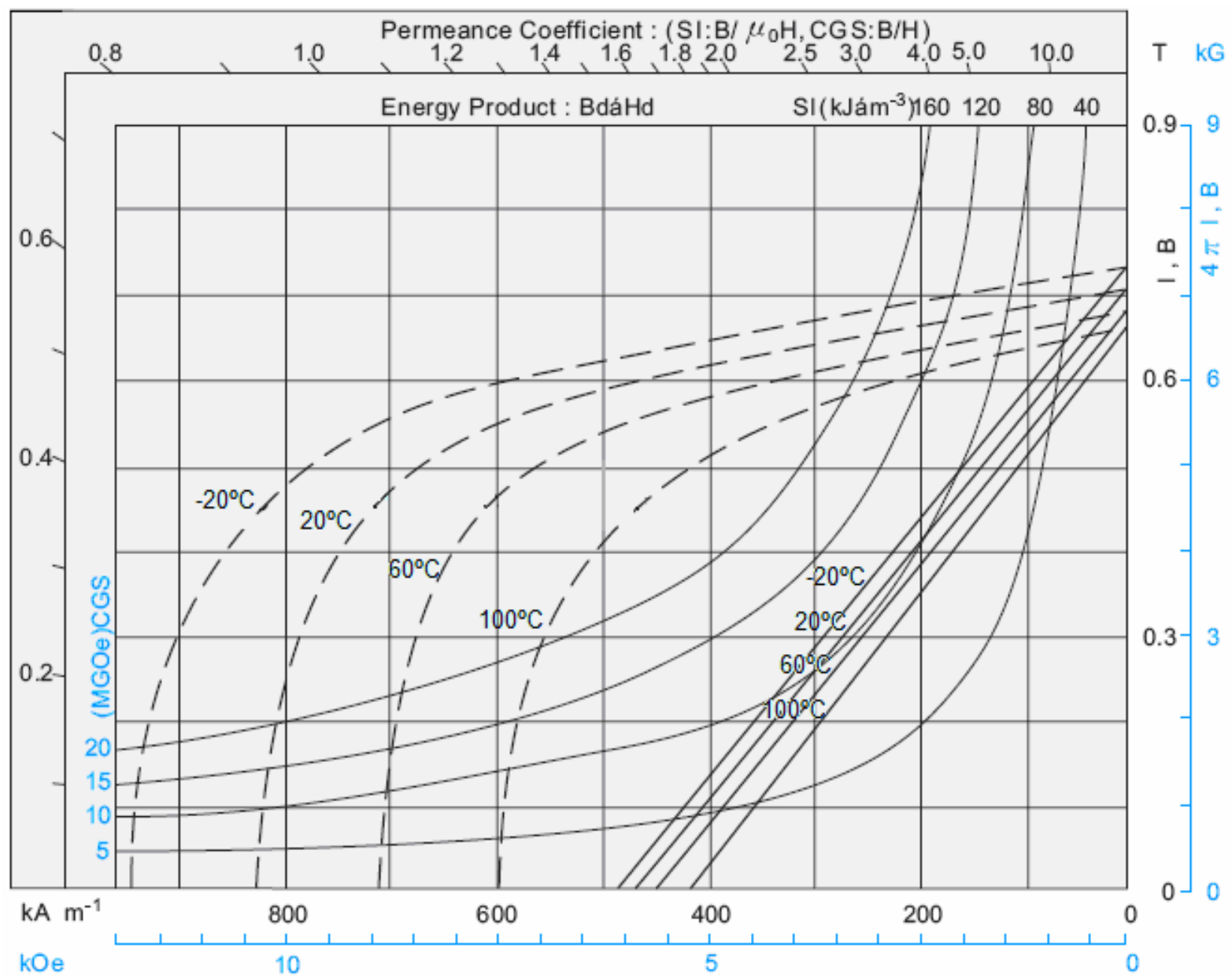

Figura 4.32. Curvas do ímã NdFeB (Bonded), (NEOMAX, 2006).

Observando-se a figura 4.32 define-se $B_{M}$ igual a $0,6 \mathrm{~T}$, para o coeficiente de permeância igual a 10 e temperatura de operação de $60^{\circ} \mathrm{C}$.

O diâmetro do rotor, sem os ímãs em sua superfície, é calculado pela equação (32).

$$
D_{r}=D_{i_{-} e}-2 \cdot g-2 \cdot L_{m}=60,99-2 \cdot 0,76-2 \cdot 7,6=44,27 \mathrm{~mm}
$$

O fluxo magnético por pólo é calculado através da equação (33).

$$
\phi_{\text {Pólo }}=A_{m} \cdot B_{M}=1,604 \cdot 10^{-3} \cdot 0,6=9,546 \cdot 10^{-4} \mathrm{~Wb}
$$


A constante da força contra-eletromotriz é obtida pela equação (34).

$$
k_{e}=\frac{V_{c c}}{n \cdot \omega_{\text {max }}}=\frac{300}{1,111 \cdot 471,24}=0,573 \mathrm{Vs} \mathrm{rad}^{-1}
$$

O número total de condutores $(Z)$ é determinado pela equação (35).

$$
Z=1,5 \frac{1}{C} \frac{\pi \cdot k_{e}}{\phi_{\text {Pólo }} \cdot P}=1,5 \frac{1}{0,9} \frac{\pi \cdot 0,573}{9,546 \cdot 10^{-4} \cdot 4}=785,7
$$

O número de espiras de cada bobina $\left(N_{\text {espiras }}\right)$ é determinado pela equação (36).

$$
N_{\text {espiras }}=\frac{Z}{N_{\text {BobinasFase }} \cdot N_{a}}=\frac{785,7}{4 \cdot 3}=65,4
$$

O diâmetro do fio é calculado através da equação (37).

$$
D_{\text {Fio }}=\sqrt{\frac{A_{\text {Ranhura }} \cdot F_{P}}{N_{\text {Espiras }}}}=\sqrt{\frac{100,6 \cdot 0,7}{65}}=1,04 \mathrm{~mm}
$$

O diâmetro de 1,04 mm corresponde à bitola 17 (AWG). 


\subsubsection{Resultados Referentes ao Projeto Refeito do MTIPR}

São apresentados os resultados referentes ao projeto refeito do MTIPR.

A comparação da densidade de fluxo magnético da componente normal do protótipo com a do projeto refeito da máquina é mostrada pela figura 4.33 .

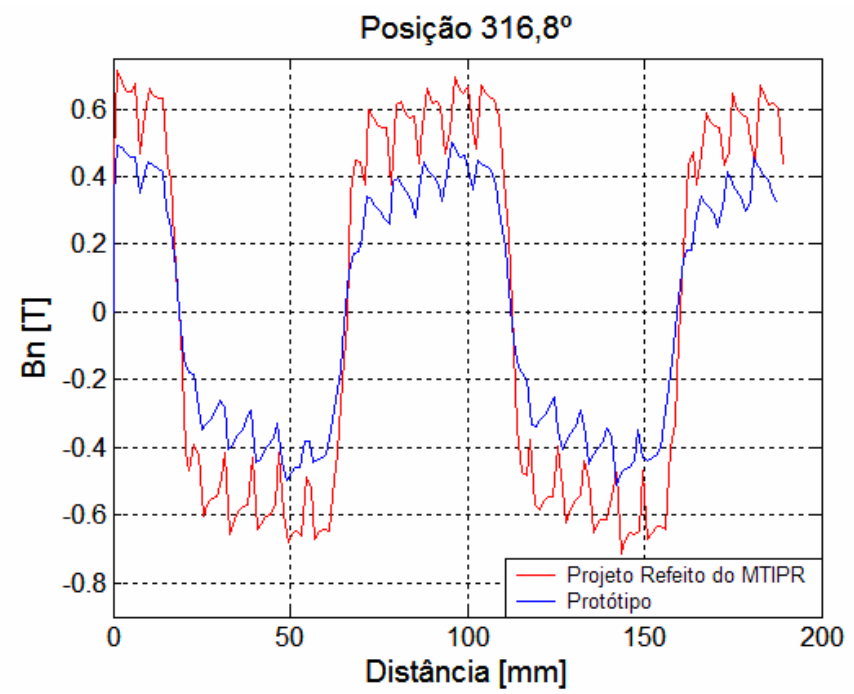

Figura 4.33. Comparação da densidade de fluxo magnético da componente normal do protótipo com a do projeto refeito do MTIPR.

O valor eficaz da indução magnética do projeto refeito do MTIPR é aproximadamente $35 \%$ maior que o do protótipo.

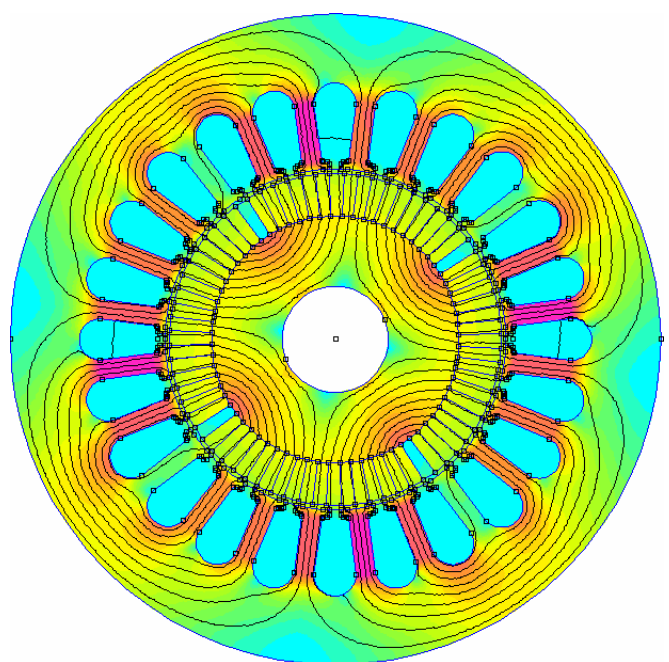

$1.520 \mathrm{e}+000:>1.600 \mathrm{e}+000$ $1.440 \mathrm{e}+000: 1.520 \mathrm{e}+000$ $1.360 \mathrm{e}+000: 1.440 \mathrm{e}+000$

$1.280 \mathrm{e}+000: 1.360 \mathrm{e}+000$

$1.200 \mathrm{e}+000: 1.280 \mathrm{e}+000$

$1.120 \mathrm{e}+000: 1.200 \mathrm{e}+000$

$1.040 \mathrm{e}+000: 1.120 \mathrm{e}+000$

$9.600 \mathrm{e}-001: 1.040 \mathrm{e}+000$

$8.800 \mathrm{e}-001: 9.600 \mathrm{e}-001$

$8.000 \mathrm{e}-001: 8.800 \mathrm{e}-001$

$7.200 \mathrm{e}-001: 8.000 \mathrm{e}-001$

$6.400 \mathrm{e}-001: 7.200 \mathrm{e}-001$

$5.600 \mathrm{e}-001: 6.400 \mathrm{e}-001$

$4.800 \mathrm{e}-001: 5.600 \mathrm{e}-001$

$4.000 \mathrm{e}-001: 4.800 \mathrm{e}-001$

$3.200 \mathrm{e}-001: 4.000 \mathrm{e}-001$

$2.400 \mathrm{e}-001: 3.200 \mathrm{e}-001$

$1.600 \mathrm{e}-001: 2.400 \mathrm{e}-001$

$8.000 \mathrm{e}-002: 1.600 \mathrm{e}-001$

$<0.000 \mathrm{e}+000: 8.000 \mathrm{e}-002$

Density Plot: $|\mathrm{B}|$, Tesla

Figura 4.34. Densidade de fluxo magnético da posição $316,8^{\circ}$, referente ao projeto refeito do MTIPR. 
A figura 4.34 é o gráfico de cores da densidade de fluxo magnético da posição $316,8^{\circ}$ mecânicos, referente ao projeto refeito do MTIPR. A indução magnética não ultrapassa $1,5 \mathrm{~T}$ entre os dentes.

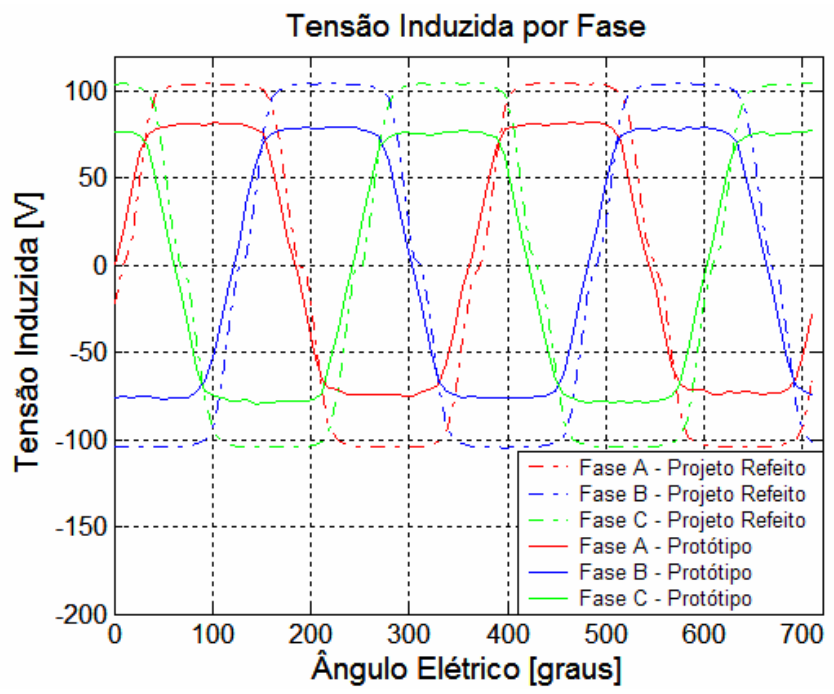

Figura 4.35. Comparação da tensão induzida do protótipo com a do projeto refeito do MTIPR .

A figura 4.35 mostra a comparação da tensão induzida, por fase, do protótipo com a do projeto refeito do motor. O valor eficaz da primeira é cerca de $25 \%$ menor que o da segunda.

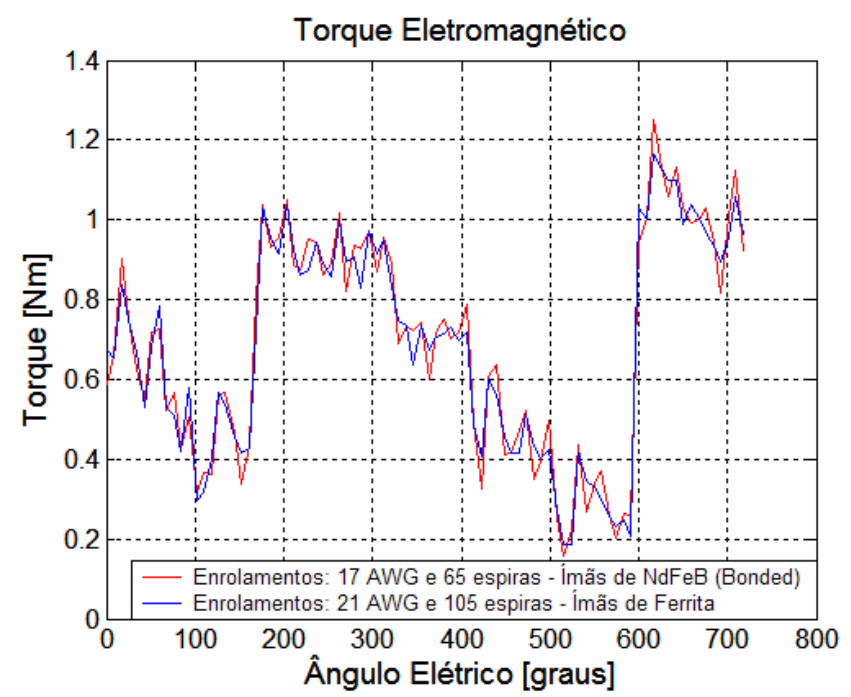

Figura 4.36. Comparação do torque eletromagnético do protótipo com o do projeto refeito do MTIPR.

O valor eficaz do torque eletromagnético, do projeto refeito da máquina, é em torno de 0,84\% maior que o do protótipo. 
A figura 4.37 compara as perdas no cobre do protótipo com as do projeto refeito do MTIPR, diferenciando-se cerca de 292,36\%.

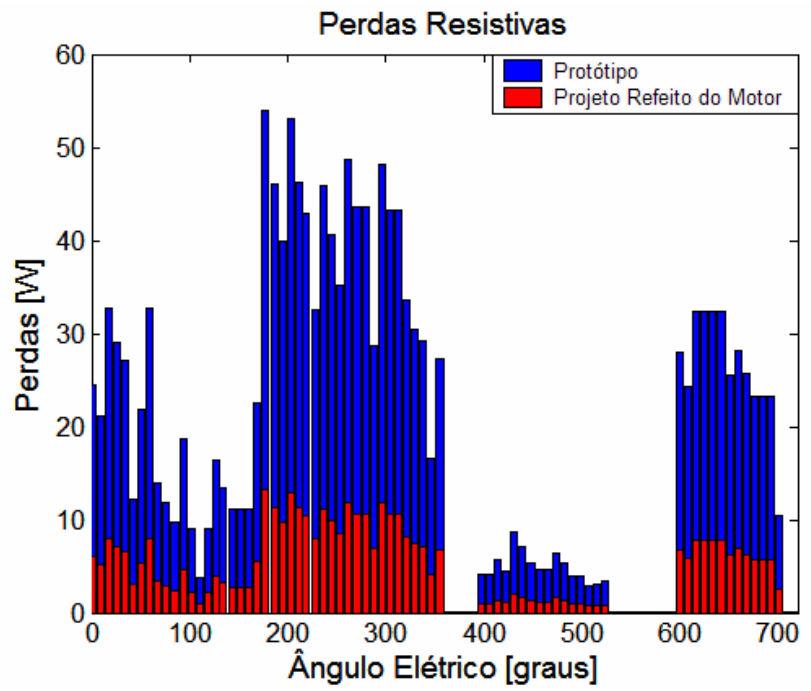

Figura 4.37. Comparação das perdas resistivas do protótipo com as do projeto refeito do MTIPR.

\subsubsection{Estimativa das Perdas Magnéticas do MTIPR}

A estimativa das perdas no ferro é mostrada na figura 4.38, comparando-se o resultado do protótipo (representado pelo número 1) com a alteração do tamanho do entreferro (2), com a mudança de ímãs (3) e com o projeto refeito (4). São apresentadas as perdas por histerese, por correntes de Foucault e a soma de ambas, que foram obtidas através da equação de Steinmetz. 


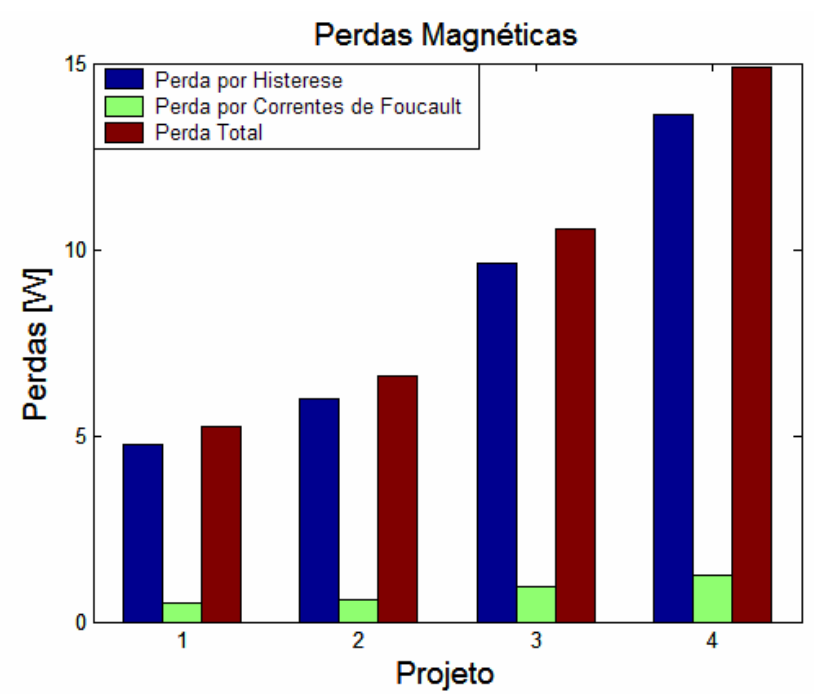

Figura 4.38. Estimativa das perdas no ferro referentes ao: 1) Protótipo; 2) Entreferro de tamanho igual a $0,76 \mathrm{~mm}$; 3) Rotor com ímãs de $\mathrm{NdFeB}$ (Bonded); 4) Projeto refeito.

Comparando-se as perdas totais calculadas em relação ao protótipo, tem-se: que a obtida referente ao motor com o tamanho de entreferro igual a $0,76 \mathrm{~mm}$ é cerca de $25,39 \%$ maior, a do motor com ímãs de $\mathrm{NdFeB}$ (Bonded) é em torno de 100,56\% superior e a do projeto refeito é aproximadamente $183,09 \%$ maior.

Através das perdas calculadas, pode-se fazer uma estimativa da soma das perdas elétricas e magnéticas das máquinas estudadas neste trabalho:

1) Protótipo: perda resistiva + perda magnética $=27,36 \mathrm{~W}+5,26 \mathrm{~W}=32,62 \mathrm{~W}$;

2) Motor com tamanho de entreferro igual a $0,76 \mathrm{~mm}: 27,36 \mathrm{~W}+6,59 \mathrm{~W}=33,92 \mathrm{~W}$;

3) Máquina com ímãs de NdFeB: 27,36 W + 10,55 W = 37,91 W;

4) Projeto refeito: $6,97 \mathrm{~W}+14,84 \mathrm{~W}=21,81 \mathrm{~W}$.

Analisando-se os resultados acima, nota-se que mesmo com o aumento da perda magnética decorrente da troca dos ímãs, a alteração do enrolamento do estator propicia uma redução da perda resistiva, resultando a soma de ambas menor que a do protótipo, aproximadamente $33,14 \%$. 


\section{Capítulo 5}

\section{Conclusões e Continuidade do Trabalho}

Observou-se que as curvas da tensão induzida, obtidas experimentalmente e calculadas pelo software FEMM, possuem a mesma forma de onda e que os seus valores eficazes são bem próximos um do outro. Portanto, a geometria da máquina e os seus materiais foram corretamente configurados no programa computacional baseado no método dos elementos finitos.

Através da análise dos gráficos de cores referentes ao protótipo, notou-se que a densidade de fluxo magnético não ultrapassou 1,2 T, possibilitando a alteração do material dos ímãs, pois os valores da indução magnética não superaram o limite de saturação do material ferromagnético.

A primeira mudança realizada foi a redução do tamanho do entreferro de $1,35 \mathrm{~mm}$ para $0,76 \mathrm{~mm}$, aumentando o fluxo magnético, resultando em um maior valor de torque eletromagnético.

A alteração dos ímãs de ferrita pelos de $\mathrm{NdFeB}$ (Bonded), mantendo-se as demais características e geometria do MTIPR, teve como conseqüência o aumento em torno de $38 \%$ do torque eletromagnético, sendo que a densidade de fluxo magnético nos dentes não ultrapassou 1,5 T. 
Como comprovou-se que os ímãs de terras-raras não saturaram o material ferromagnético da máquina, foi realizado um novo projeto do MTIPR utilizando-se esse tipo de ímã. O número de espiras e a bitola dos fios do enrolamento do estator foram recalculados, para que a máquina fornecesse um valor de torque eletromagnético próximo ao do protótipo. Com isso, houve uma redução em torno de $292,36 \%$ das perdas no cobre e um aumento aproximadamente de $64,55 \%$ das perdas magnéticas, e a soma de ambas ficou inferior cerca de 33,14\% em relação ao protótipo.

Portanto, através da análise do campo magnético, utilizando-se uma programa computacional baseado no método dos elementos finitos, melhorias como, por exemplo, o aumento do torque eletromagnético podem ser comprovadas diminuindo-se o tamanho do entreferro e trocando-se o material do ímã por outro de maior energia. Além disso, o projeto pode ser refeito objetivando-se determinadas características, como a redução das perdas resistivas.

A importância deste tipo de estudo é a possibilidade de observação do comportamento magnético da máquina, como a densidade de fluxo magnético e a tensão induzida, que são conseqüências da geometria e dos materiais selecionados para o projeto.

Uma análise interessante que deve ser feita, futuramente, em elementos finitos é a temporal, que possui uma formulação diferente da apresentada neste trabalho e possibilita o cálculo instântaneo e refinado das perdas magnéticas.

Diferentes materiais ferromagnéticos, comumente chamados de aços elétricos, e um novo projeto de estator, devem ser estudados, no sentido de melhorar o desempenho da máquina. 


\section{Referências Bibliográficas}

ABELE, M. G. Structures of Permanent Magnets - Generation of Uniform Fields. First Edition. New York: John Wiley \& Sons, Inc, 1993.

ALCANTARA JÚNIOR, N. P. As Determinações dos Mapas das Densidades de Fluxo em Máquinas Elétricas, pelo Método dos Elementos Finitos. 1984. 192f. Dissertação - Escola de Engenharia de São Carlos, Universidade de São Paulo, São Carlos, 1984.

ALCANTARA JÚNIOR, N. P. Localização e Verificação das Dimensões dos Componentes da Armadura em Estruturas de Concreto Armado Utilizando Campos Magnetostáticos Superficiais e Redes Neurais Artificiais. 2003. 157f. Tese (Livre Docência) - Faculdade de Engenharia, Universidade Estadual Paulista, 2003.

CIBAS - Permanent Magnets \& Magnetic Devices. Disponível em: 〈http://www.cibas.it> Acesso em: 17 de maio de 2006.

CHUNG, T. K.; KIM, S. K.; HAHN, S. Y. Optimal Pole Shape Design for the Reduction of Cogging Torque of Brushless DC Motor Using Evolution Strategy. IEEE Transactions on Magnetics. Korea, v. 33, No. 2, p. 1908-1911, March 1997.

COULOMB, J. L. A Methodology for the Determination of Global Electromechanical Quantities From a Finite Element Analysis and its Application to the Evaluation of Magnetic Forces, Torques and Stiffness. IEEE Transactions on Magnetics. v. 19, No. 6, p. 25142519, November 1983.

FARIA R. N.; LIMA, L. F. C. P. Introdução ao Magnetismo dos Materiais. Primeira Edição. São Paulo: Editora Livraria da Física, 2004.

GIERAS, J. F.; WING, M. Permanent Magnet Motor Technology. First Edition. New York: Marcel Dekker, Inc, 2002. 
GONELlA, M. C. Acionamento e Controle Sensorless para Motores Brushless DC Aplicados a Compressores Herméticos para Refrigeração Doméstica. 2006. 115 f. Dissertação - Escola de Engenharia de São Carlos, Universidade de São Paulo, São Carlos, 2006.

GUCKELBERGER, D.; BRADLEY, B. Setting a New Standard for Efficiency: Brushless DC Motors. Trane Engineers Newsletter, v. 33-4, 2004.

HENDERSHOT JÚNIOR, J. R.; MILLER, T. J. E. Design of Brushless Permanent-Magnet Motors. First Edition. New York: Oxford University Press, 1994.

JANG, G. H.; YOON, J. W.; RO, K. C.; PARK, N. Y.; JANG, S. M. Performance of a Brushless DC Motor due to the Axial Geometry of the Permanent Magnet. IEEE Transactions on Magnetics, Korea, v. 33, No. 5, p. 4101-4103, September 1997.

JIN, J., The Finite Element Method in Electromagnetics. First Edition. New York: John Wiley \& Sons, Inc., 1993.

KENJO, T.; NAGAMORI, S. Permanent-Magnet and Brushless DC Motors. First Edition. New York: Oxford University Press, 1984.

KIM, C. G.; LEE, J. H.; KIM, H. W.; YOUN, M. J. Study on Maximum Torque Generation for Sensorless Controlled Brushless DC Motor with Trapezoidal Back EMF. IEE Proc. Electr. Power Appl. Republic of Korea, v. 152, No. 2, p. 277-291, March 2004.

KRAUS, J. D.; FLEISCH, D. A. Electromagnetics with Applications. Fifth Edition. New York: McGRAW-HILL BOOK COMPANY, Inc, 1999.

KRISHNAN, R. Electric motor drives: modeling, analysis and control. New Jersey, USA: Prentice Hall, 2001.

Lua - The Programming Language. Disponível em: 〈http://www.lua.org>. Acesso em: 17 de julho de 2006.

McFee, S.; WEBB, J. P.; LOWTHER, D. A. A Tunable Volume Integration Formulation for Force Calculation in Finite Element Based Computational Magnetostatics. IEEE Transactions on Magnetics, v. 24, No. 1, p. 439-442, January 1988. 
MEDEIROS, L. H.; REYNE, G.; MEUNIER. Comparison of Global Force Calculations on Permanent Magnets. IEEE Transactions on Magnetics. Grenoble (France), v. 34, No. 5, p. 3560-3563, September 1998.

MEDEIROS, L. H.; REYNE, G.; MEUNIER, G. About the distribution of forces in permanent magnets. IEEE Transactions on Magnetics. Grenoble (France), v. 35, No. 3, p. 1215-1218, May 1999.

MEEKER, D. Finite Element Method Magnetics - User's Manual. Fourth Version. Walthan (MA): disponível em: <http://femm.foster-miller.net>. Acesso em: 10 fev. 2006.

MILLER, T. J. E. Brushless Permanent-Magnet and Reluctance Motor Drives. First Edition. London: Oxford University Press, 1989.

MIZIA, J.; KDAMIAK, K.; EASTHAM, A. R.; DAWSON G. E. Finite Element Force Calculation: Comparison of Methods for Electric Machines. IEEE Transactions on Magnetics. Canada and Poland, v. 24, No. 1, p. 4447-450, January 1988.

MONTEIRO, J. R. B. A. Estratégias de Acionamento e Controle em Máquinas CA de Ímã Permanente com Fluxo Não Senoidal. 1997. 120f. Dissertação - Escola de Engenharia de São Carlos, Universidade de São Paulo, São Carlos, 1997.

MONTEIRO, J. R. B. A. Transformação DQ Não Senoidal para Máquinas Síncronas com Ímã Permanente no Rotor. 2002. 108f. Tese - Escola de Engenharia de São Carlos, Universidade de São Paulo, São Carlos, 2002.

NASAR, S. A.; BOLDEA, I. Electric Machines: Steady-State Operation. First Edition. New York: Hemisphere Publishing Corporation, 1990.

NASAR, S. A.; BOLDEA, I.; UNNEWEHER, L. E. Permanent Magnet, Relutance, and Self Synchronous Motors. CRC Press, 1993.

NEOMAX AMERICA, INC. Disponível em: <http://www.neomaxamerica.com> Acesso em: 20 de junho de 2006.

PAN, Z. Y.; LUO, F. L. Novel Resonant Pole Inverter for Brushless DC Motor Drive System. IEEE Transactions on Power Electronics. Singapore, v. 20, No 1, p. 173-181, January 2004. 
PILLAY, P.; KRISHNAN, R. Modeling of Permanent Magnet Motor Drives. IEEE Transactions on Industry Electronics. Virginia, v. 35, No. 4, p. 537-541, November 1988.

PILLAY, P.; KRISHNAN, R. Modeling, Simulation, and Analysis of Permanent-Magnet Motor Drives, Part II: The Brushless DC Motor Drive. IEEE Transactions on Industry Applications. Virginia, v. 25, No. 2, p. 274-279, March/April 1989.

RASHID, M. H. Eletrônica de Potência: circuitos, dispositivos e aplicações. Primeira Edição. São Paulo: MAKRON Books, 1999.

SALEM, T.; HASKEW, T. A. Simulation of the Brushless DC Machine. 27th Southeastern Symposium on System Theory. Tuscaloosa, p. 18-22, March 1994.

SILVESTER, P. P.; FERRARI, R. L. Finite Elements for Electrical Engineers. First Edition. Cambridge: Cambridge University Press, 1983.

SLEMON, G. R.; LIU, X. Core Losses in Permanent Magnet Motors. IEEE Transactions on Magnetics. Toronto, v. 26, No. 5, p. 1653-1655, September 1990.

STILL, A.; SISKIND, C. S. Elements of Electrical Machine Design. Third Edition. New York: McGRAW-HILL BOOK COMPANY, Inc, 1954.

SYKULSKI, J. K. Computational Magnetics. First Edition. London: Chapman \& Hall, 1994.

TEIXEIRA, F. H. P. Metodologia para projeto, Construção e Ensaios em Máquina Síncrona de Imã Permanente - MSIP. 2006. 103 f. Dissertação - Escola de Engenharia de São Carlos, Universidade de São Paulo, São Carlos, 2006.

USS - Nonoriented Sheet Steel for Magnetic Application. USA: United States International, Inc, 1978.

WAGNER, D. Introduction to the Theory of Magnetism. First Edition. New York: Pergamon Press Ltd., 1972. 


\section{APÊNDICE A - Materiais Magnéticos}

As propriedades magnéticas de um meio são caracterizadas por um fenômeno chamado polarização (equação 38), que ocorre quando um momento de dipolo magnético é induzido na presença de um campo magnético externo em um dado meio (ABELE, 1993).

$$
\vec{B}=\mu_{0} \vec{H}+\vec{M}_{P}
$$

Onde:

$\vec{M}_{P}$ é o vetor de densidade de polarização magnética [T];

$\mu_{0}$ é a permeabilidade magnética do vácuo $\left[\mathrm{H} \cdot \mathrm{m}^{-1}\right]$.

No espaço livre e em materiais não magnéticos o vetor de densidade de polarização magnética é igual a zero (ABELE, 1993). Este vetor consiste na soma do vetor de polarização permanente (resultado do processo de magnetização) com o vetor de polarização induzida pelo campo magnético.

$$
\vec{M}_{P}=\vec{M}_{0}+\vec{M}_{m}
$$

Onde:

$\vec{M}_{m}$ é o vetor de densidade de polarização magnética induzida pelo campo magnético [T];

$\vec{M}_{0}$ é o vetor de densidade de polarização magnética devido a polarização permanente [T]. 
A polarização induzida (para meios isotrópicos) é proporcional ao campo magnético aplicado (equação 40), enquanto a polarização permanente é independente da intensidade do campo magnético (também referenciada como remanência).

$$
\vec{M}_{m}=\mu_{0} \cdot \chi_{m} \cdot \vec{H}
$$

Sendo:

$$
\chi_{m}=\mu_{r}-1
$$

Onde:

$\chi_{m}$ é a susceptibilidade magnética;

$\mu_{\mathrm{r}}$ é a permeabilidade relativa.

Substituindo-se a equação (41) na equação (40), tem-se:

$$
\vec{M}_{m}=\mu_{0} \mu_{r} \vec{H}-\mu_{0} \vec{H}
$$

Substituindo-se a equação (42) na equação (38), pode-se escrevê-la da seguinte forma:

$$
\vec{B}=\vec{M}_{0}+\mu_{0} \mu_{r} \vec{H}=\vec{M}_{0}+\mu \vec{H}
$$

A polarização permanente é resultado do processso de magnetização do campo externo, que consiste no alinhamento dos momentos magnéticos, gerando um campo magnético. 
Esse campo gerado pode ser pequeno, tendendo a reduzir o campo aplicado (materiais diamagnéticos), ou somar-se ao campo externo (materiais paramagnéticos), e pode ser elevado (materiais ferromagnéticos). Assim, existem três tipos básicos de materiais magnéticos: diamagnéticos, paramagnéticos e ferromagnéticos.

\section{A.1 Materiais Diamagnéticos}

A classe dos materiais diamagnéticos é a maior de todas, abrangendo todas as moléculas orgânicas, todos os gases nobres, os metais nobres (bismuto, zinco, mercúrio e outros) e não metais como o enxofre e o iodo (WAGNER, 1972).

Os materiais diamagnéticos não apresentam um momento magnético externo e, quando submetidos a um campo magnético, produzem o seu próprio campo de polaridade oposta (magnetismo negativo).

"O diamagnetismo é resultado do movimento orbital dos elétrons que, circulando ao redor do núcleo, formam um anel eletrônico de corrente e produzem um campo magnético". (FARIA, 2005, p. 20). Para cada órbita têm-se dois elétrons circulando em direções opostas, por isso não há a geração de um campo magnético externo ao material.

$\mathrm{Na}$ presença de um campo magnético externo, o emparelhamento de dois elétrons girando em sentidos opostos é desbalanceado, por isso o momento magnético não é mais nulo. De acordo com a lei de Lenz, no sentido de evitar qualquer mudança no campo magnético produzido pelo átomo, haverá uma mudança de velocidade dos elétrons como reação contrária ao campo magnético externo.

"O diamagnetismo é uma propriedade de todos os materiais, mas como é um efeito relativamente fraco, ele só pode ser facilmente observado nos materiais que não sejam também paramagnéticos.” (FARIA, 2005, p. 21). 
A susceptibilidade magnética dos materiais diamagnéticos é negativa $\left(\chi_{\mathrm{m}}<0\right)$ e a permeabilidade magnética relativa é pouco menor que a unidade $\left(\mu_{\mathrm{r}}<1\right)$.

\section{A.2 Materiais Paramagnéticos}

Os materiais paramagnéticos possuem os elétrons de seus átomos desemparelhados (número ímpar de elétrons). Por isso, mesmo na ausência de um campo magnético externo, eles possuem um momento magnético.

Existem átomos com um número atômico elevado e com um número ímpar de elétrons, que apresentam diamagnetismo ao invés de paramagnetismo, como o bismuto.

Na presença de um campo magnético externo, os elétrons desemparelhados produzirão o seu próprio campo magnético, devido ao seu movimento de rotação (spin) e ao seu momento angular orbital. No sentido de evitar qualquer mudança do campo magnético, tentando manter os dipolos atômicos dispostos aleatoriamente, a agitação térmica dos átomos se opõe ao campo aplicado.

Exemplos de substâncias paramagnéticas: ar, sódio, alumínio, lítio, neodímio e outros.

A permeabilidade magnética relativa dos materiais paramagnéticos é pouco superior a unidade $\left(\mu_{\mathrm{r}}>1\right)$, e a susceptibilidade magnética é positiva $\left(\chi_{\mathrm{m}}>0\right)$ e diminui com a temperatura. 


\section{A.3 Materiais Ferromagnéticos}

Em decorrência ao desemparelhamento dos elétrons, os materiais paramagnéticos e ferromagnéticos possuem um momento magnético externo, mas apenas os ferromagnéticos apresentam a formação de domínios magnéticos, que são regiões em que há o predomínio de apenas um alinhamento magnético (figura A.1).

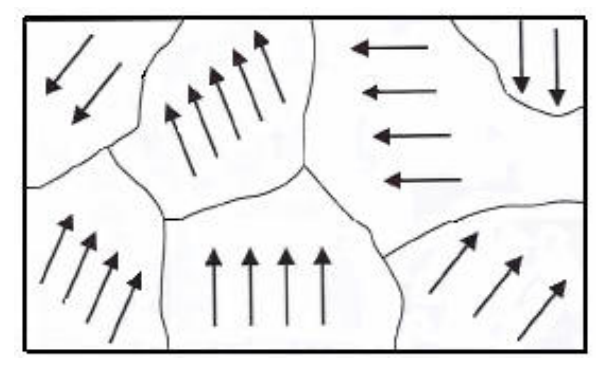

Figura A.1. Representação da estrutura dos domínios magnéticos dispostos aleatoriamente em um material policristalino. Neste caso cada grão monocristalino contém um único domínio magnético. Nesta condição o material está desmagnetizado, ou seja, não produz um campo magnético externo (FARIA, 2005).

Conforme o alinhamento dos momentos magnéticos atômicos, os materiais ferromagnéticos podem existir tanto no estado magnetizado quanto no desmagnetizado (FARIA, 2005). Quando todos os momentos magnéticos dos domínios estão alinhados na mesma direção do campo magnético externo, tem-se a densidade de fluxo magnético saturada.

Conhecendo-se a estrutura cristalina do material, pode-se calcular a magnetização de saturação. Sabendo-se que a densidade do ferro $\left(\rho\left[\mathrm{Kg} \mathrm{m}^{-3}\right]\right)$ é $7,86 \times 10^{3}$ e a sua massa atômica $(Z[\mathrm{Kg}])$ é igual a $55,85 \times 10^{-3}$, tem-se (FARIA, 2005):

$$
n=\frac{N_{A} \cdot \rho}{Z}=\frac{\left(6,02 \times 10^{23}\right) \cdot\left(7,86 \times 10^{3}\right)}{\left(55,85 \times 10^{-3}\right)}=8,47 \times 10^{28}{\text { átomos } \mathrm{m}^{-3}}^{-3}
$$

Onde:

$n$ é o número de átomos por unidade de volume [átomos $\cdot \mathrm{m}^{-3}$ ];

$N_{A}$ é o número de Avogrado [mol $\left.{ }^{-1}\right]$. 
O momento de dipolo magnético de um elétron na primeira órbita é chamado de magnéton de $\operatorname{Bohr}\left(\mu_{B}\left[\mathrm{Am}^{2}\right]\right)$ e é dado por (FARIA, 2005):

$$
\mu_{B}=\frac{e \cdot h}{4 \cdot \pi \cdot m_{e}}=\frac{\left(1,6 \times 10^{-19}\right) \cdot\left(6,63 \times 10^{-34}\right)}{4 \cdot \pi \cdot\left(9,11 \times 10^{-31}\right)}=9,27 \times 10^{-24} \mathrm{Am}^{2}
$$

Onde:

$e$ é a carga do elétron $[\mathrm{C}]$;

$h$ é a constante de Planck [J s];

$m_{e}$ é a massa do elétron $[\mathrm{Kg}]$.

Como o número de magnétons de Bohr por átomo $\left(n_{B}\right)$ é igual a 2,2 no caso do ferro, a magnetização de saturação $\left(M_{S}[\mathrm{~A} / \mathrm{m}]\right)$ é então dada por (FARIA, 2005):

$$
M_{S}=n \cdot n_{B} \cdot \mu_{B}=\left(8,47 \times 10^{28}\right) \cdot(2,2) \cdot\left(9,27 \times 10^{-24}\right)=1,73 \times 10^{6} \quad \mathrm{~A} / \mathrm{m}
$$

Se a densidade do fluxo magnético do ferro exceder aproximadamente 1,6-1,7 $\mathrm{T}$ a permeabilidade magnética decresce rapidamente (HENDERSHOT; MILLER, 1994). A densidade do fluxo magnético de saturação $\left(B_{S}[\mathrm{~T}]\right)$, correspondente à magnetização do ferro, é dada por:

$$
B_{S}=\mu_{0} \cdot M_{S}=\left(4 \pi \times 10^{-7}\right) \cdot 1,73 \times 10^{6}=2,18 \mathrm{~T}
$$

Em 2,1 T a permeabilidade magnética do ferro é praticamente a permeabilidade do ar (HENDERSHOT; MILLER, 1994). Os projetos de máquinas elétricas devem assegurar que a densidade de fluxo magnético não exceda 1,6 - 1,7 T. 
Outras razões para limitar a densidade do fluxo magnético no ferro são as perdas causadas por correntes parasitas e por histerese, que crescem rapidamente com o seu aumento.

Exemplos de substâncias ferromagnéticas: ferro fundido, ferro puro, ferro silício, níquel, cobalto e outros.

Os materiais ferromagnéticos acima de uma temperatura crítica, chamada temperatura de Curie, comportam-se como uma substância paramagnética, pois há uma redução na intensidade de magnetização.

A susceptibilidade magnética e a permeabilidade magnética relativa dos materiais ferromagnéticos são bem superiores à unidade $\left(\chi_{\mathrm{m}} \gg 1\right.$ e $\left.\mu_{\mathrm{r}} \gg>1\right)$.

Relacionados ao ferromagnetismo existem outros dois comportamentos magnéticos: antiferromagnetismo e ferrimagnetismo. No primeiro caso, os momentos magnéticos assumem orientações antiparalelas, apresentando um magnetismo externo praticamente zero. Um exemplo de uma substância antiferromagnética é o óxido de manganês. No segundo caso, existem íons magnéticos desiguais que também se orientam antiparalelamente, mas devido à diferença entre eles a magnetização resultante não é nula. Esses materiais apresentam uma baixa condutividade, quando comparados aos ferromagnéticos. Um exemplo de um material ferrimagnético é a ferrita.

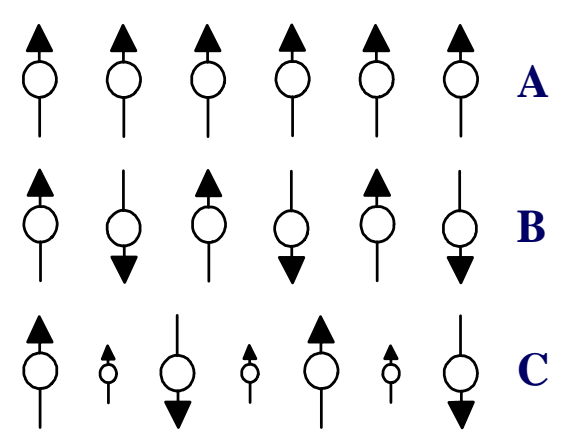

Figura A.2. Representação ilustrativa das orientações dos momentos de dipolo magnético: (A) ferromagnetismo, (B) antiferromagnetismo e (C) ferrimagnetismo (FARIA, 2005). 


\section{A.3.1 Curva de Histerese Magnética}

Aplicando-se um campo magnético $\left(H_{m}\left[\mathrm{~A} \mathrm{~m}{ }^{-1}\right]\right)$ em um material ferromagnético até a sua saturação e, em seguida retirando-se esse campo, observa-se que a densidade de fluxo magnético não decresce tão rapidamente quanto aumentou na magnetização inicial (figura A.3). Quando a intensidade do campo magnético se anula, ainda há a existência de uma densidade residual, ou remanência $\left(B_{r}[\mathrm{~T}]\right)$.

Para anulá-la, deve-se aplicar um campo desmagnetizante, que é chamado de força coercitiva $\left(-H_{C}\left[\mathrm{~A} \mathrm{~m}^{-1}\right]\right)$. Aumentando-se o campo desmagnetizante, obtém-se uma curva de magnetização com polaridade oposta à inicial, e o processo repete-se originando uma curva fechada, conhecida como curva de histerese.

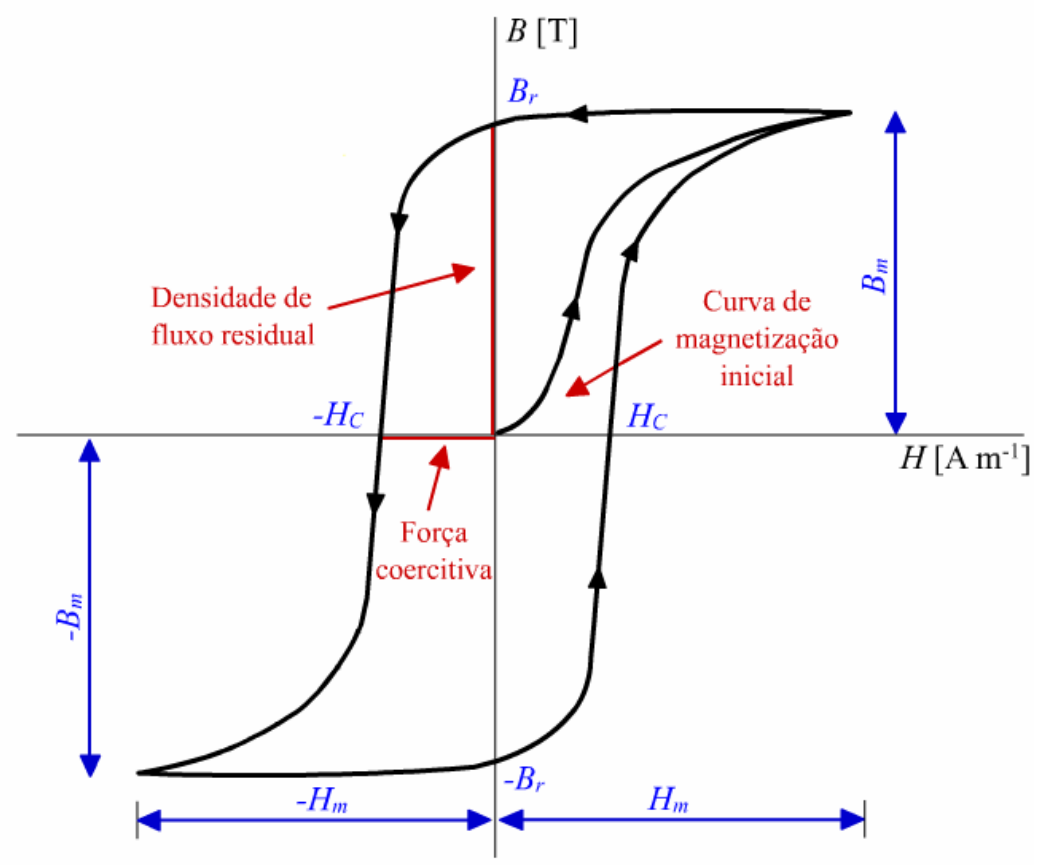

Figura A.3. Ciclo de histerese.

Os materiais que possuem uma alta coercividade são denominados materiais magneticamente duros, como os ímãs permanentes, e os que possuem uma baixa coercividade são denominados materiais magneticamente moles, como o ferro. 


\section{A.3.2 Ímãs Permanentes}

Alguns materiais ferromagnéticos, após serem submetidos a um campo magnético, permanecem magnetizados, mesmo se esse campo for retirado.

\section{A.3.2.1 Remanência}

Aplicando-se um campo magnético em um material até atingir a saturação, e em seguida, retirando-o, a densidade de fluxo magnético não se anula, restando a densidade de fluxo residual ou a remanência. Quanto maior for essa propriedade magnética, maior será o campo magnético produzido pelo ímã.

\section{A.3.2.2 Coercividade Intrínseca}

A coercividade intrínseca representa a resistência de desmagnetização de um material. Por isso, quanto maior for essa propriedade de um ímã permanente, maior será a dificuldade em desmagnetizá-lo.

"A coercividade está intimamente relacionada com a movimentação das paredes do domínio no material magnético. Para os domínios crescerem, as paredes devem se mover, de tal forma que, os domínios orientados favoravelmente na direção do campo aplicado, se expandam. 
Os ímãs permanentes devem ser preparados com uma microestrutura que impeça o movimento das paredes de domínio magnético ou que dificulte o aparecimento de domínios reversos. O processo mais antigo para adequar a microestrutura foi o de trabalho a frio dos aços magnéticos, por meio do qual o endurecimento com tensões introduz discordâncias que imobilizam ou bloqueiam as paredes do domínio. Com isto, obtinha-se uma alta remanência, assim como um campo coercitivo elevado (FARIA, 2005, p. 63)".

\section{A.3.2.3 Produto de Energia}

O produto da densidade de fluxo magnético pela intensidade de campo magnético (produto $\mathrm{BH}$ ) tem dimensões da densidade de energia. Através da curva de desmagnetização indutiva $(B \times H)$ (figura A.4) obtém-se o produto BH para qualquer ponto $P$ através do cálculo da área do retângulo sombreado. $\mathrm{O}$ valor máximo do produto $\mathrm{BH}$ determina a qualidade do ímã, pois quanto maior for o seu valor, menor será o volume deste material para a produção de um certo campo magnético.

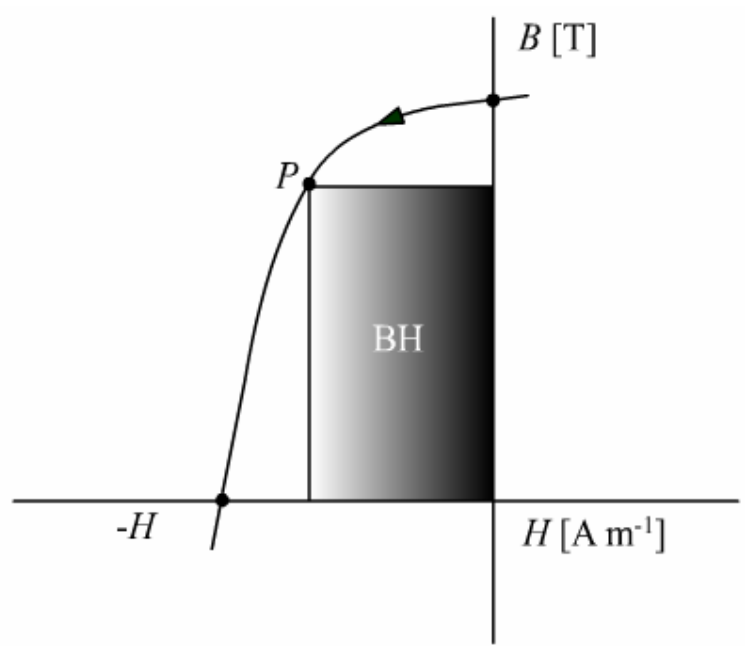

Figura A.4. Curva de desmagnetização. 


\section{A.3.2.4 Fator de Quadratura}

O fator de quadratura (FQ) é um indicador da estabilidade de um ímã permanente face à desmagnetização (FARIA, 2005). Ele é obtido através do segundo quadrante da curva de desmagnetização intrínseca (figura A.5) e é calculado através da equação (48).

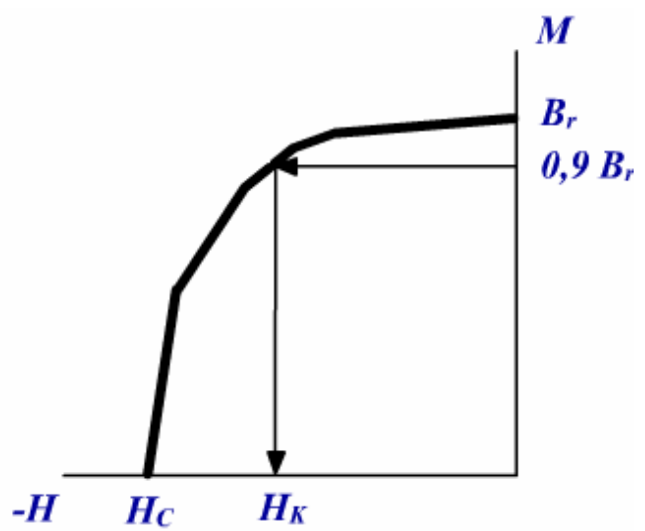

Figura A.5. Determinação do campo $H_{K}$ a partir de uma curva de desmagnetização intrínseca (FARIA, 2005).

$$
F Q=\frac{H_{K}}{H_{C}}
$$

Onde:

$H_{C}$ é a coercividade intrínseca $\left[\mathrm{A} \mathrm{m} \mathrm{m}^{-1}\right]$

$H_{K}$ é intensidade do campo magnético responsável pela redução de $10 \%$ da remanência $\left[\mathrm{A} \mathrm{m}^{-1}\right]$.

Quanto mais próximo da unidade estiver o fator de quadratura, maior a estabilidade de um ímã quando submetido a um campo desmagnetizante. Fisicamente, este fator representa o número de grãos magnéticos que compõe o ímã permanente, que já reverteu sua magnetização devido à aplicação do campo desmagnetizante. Desta forma, um ímã ideal seria aquele no qual os grãos reverteriam concomitantemente sua magnetização para um dado valor do campo magnético reverso (FARIA, 2005). 


\section{A.3.2.5 Tipos de Ímãs Permanentes}

Os materiais magnéticos avançaram tecnologicamente a partir da década de 30:

1930: foram desenvolvidas as ligas do tipo alumínio-níquel-cobalto (Alnico);

1952: foram desenvolvidas as ferritas de bário;

1970: foram desenvolvidas as ligas de cobalto e terras-raras;

1983: surgiu a liga neodímio-ferro $(\mathrm{NdFe})$, que posteriormente foi aperfeiçoada com a introdução do boro (B), formando a liga magnética NdFeB.

Esses avanços tecnológicos possibilitaram a fabricação dos ímãs permanentes que estão inseridos em diferentes aplicações. Existem basicamente quatro tipos deles: alnico, ferrita, samário-cobalto e neodímio-ferro-boro.

\section{A.3.2.5.1 Alnico}

Os ímãs de alnico são resistentes à corrosão e podem ser utilizados em aplicações que encontram-se em elevadas temperaturas $\left(550{ }^{\circ} \mathrm{C}\right)$. São fabricados pelo processo de fundição e possuem uma geometria simplificada.

As propriedades magnéticas do alnico são mostradas na tabela A.1.

Tabela A.1 - Propriedades magnéticas do alnico.

\begin{tabular}{|c|c|c|c|c|}
\hline Material & $\begin{array}{c}\text { Remanência } \\
{[\mathrm{T}]}\end{array}$ & 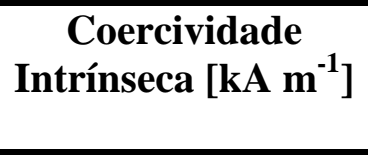 & $\begin{array}{c}\text { Produto de } \\
\text { Energia Máximo } \\
{\left[\mathrm{kJ} \mathrm{m}^{-3}\right]}\end{array}$ & $\begin{array}{c}\text { Temperatura } \\
\text { de Curie } \\
{\left[{ }^{\circ} \mathrm{C}\right]}\end{array}$ \\
\hline Alnico & $0,65-1,28$ & $43,80-121,00$ & $11,10-42,10$ & 890,00 \\
\hline
\end{tabular}




\section{A.3.2.5.2 Ferrita}

Os ímãs de ferrita também são conhecidos como cerâmicos (não metálicos). São formados sinterizando misturas de óxidos metálicos $\left(K \mathrm{O} \times 6 \mathrm{Fe}_{2} \mathrm{O}_{3}\right)$, podendo $K$ ser estrôncio $(\mathrm{Sr})$, bário $(\mathrm{Ba})$ ou chumbo $(\mathrm{Pb})$. São resistentes à corrosão, aos ácidos, aos sais e aos gases. Apresentam uma alta resistividade elétrica e possuem a temperatura máxima de trabalho de $250{ }^{\circ} \mathrm{C}$. São os ímãs de menores custos comparados aos demais.

As propriedades magnéticas da ferrita dependem da sua constituição e do seu tratamento térmico, são mostradas na tabela A.2.

Tabela A.2 - Propriedades magnéticas da ferrita.

\begin{tabular}{ccccc}
\hline Material & $\begin{array}{c}\text { Remanência } \\
{[\mathbf{T}]}\end{array}$ & $\begin{array}{c}\text { Coercividade } \\
\text { Intrínseca }\left[\mathbf{k A ~ m}^{-\mathbf{1}}\right]\end{array}$ & $\begin{array}{c}\text { Produto de } \\
\text { Energia Máximo } \\
{\left[\mathbf{k J ~ m}^{-3}\right]}\end{array}$ & $\begin{array}{c}\text { Temperatura } \\
\text { de Curie } \\
{\left[{ }^{\mathbf{0}} \mathbf{C}\right]}\end{array}$ \\
\hline Ferrita & $0,20-0,44$ & $132,00-382,00$ & $6,40-35,00$ & 450,00 \\
\hline Fonte: CIBAS (2006). & & &
\end{tabular}

A densidade do fluxo magnético produzida no entreferro $\left(B_{g}[\mathrm{~T}]\right)$, por ímãs de ferrita em motores síncronos, pode ser estimada pela equação (49) (GIERAS; WING, 2002).

$$
B_{g} \approx(0,3 \ldots 0,7) \cdot B_{r}
$$

\section{A.3.2.5.3 Samário-Cobalto e Neodímio-Ferro-Boro}

Os ímãs de Samário-Cobalto $\left(\mathrm{SmCo}_{5}\right)$ formam a primeira geração de ímãs à base de terras-raras e de metais de transição. Já a segunda foi desenvolvida com os compostos do tipo $\mathrm{Sm}_{2} \mathrm{Co}_{17}$, com adições de ferro e cobre (FARIA, 2005). A terceira é constituída pelos ímãs à base de neodímio-ferro-boro, que foram desenvolvidos sem a adição do cobalto, que na década de 70 tinha um alto custo. 
As propriedades magnéticas desses ímãs são mostradas na tabela A.3.

Tabela A.3 - Propriedades magnéticas do samário-cobalto e do NdFeB.

\begin{tabular}{|c|c|c|c|c|}
\hline Material & $\begin{array}{c}\text { Remanência } \\
{[\mathrm{T}]}\end{array}$ & $\begin{array}{c}\text { Coercividade } \\
\text { Intrínseca }\left[\mathrm{kA} \mathrm{m}^{-1}\right]\end{array}$ & $\begin{array}{l}\text { Produto de Energia } \\
\text { Máximo }\left[\mathrm{kJ} \mathrm{m}^{-3}\right]\end{array}$ & $\begin{array}{c}\text { Temperatura } \\
\text { de Curie } \\
{\left[{ }^{\circ} \mathrm{C}\right]}\end{array}$ \\
\hline $\begin{array}{c}\text { SmCo } \\
\mathbf{N d}_{15} \mathrm{Fe}_{77} \mathbf{B}_{8}\end{array}$ & $\begin{array}{l}0,95-1,14 \\
1,04-1,46\end{array}$ & $\begin{array}{l}420,00-1592,00 \\
807,60-2388,00\end{array}$ & $\begin{array}{l}159,00-256,00 \\
207,00-406,00\end{array}$ & $\begin{array}{l}770,00 \\
310,00\end{array}$ \\
\hline
\end{tabular}

Fonte: CIBAS (2006).

\section{A.3.3 Ligas Magnéticas de Ferro-Silício}

As ligas magnéticas de ferro-silício são utilizadas na fabricação dos rotores e dos estatores das máquinas elétricas, pois a adição do silício ao ferro aumenta a resistividade elétrica, causando a diminuição de perdas por correntes de Foucault e por histerese.

Essas ligas contêm até 6,5\% de silício e algumas impurezas (carbono, enxofre, fósforo e manganês) associadas ao ferro.

As propriedades magnéticas e a resistividade elétrica das ligas de ferro-silício ( $\mathrm{Fe}-\mathrm{Si}$ ) dependem de suas constituições e dos tratamentos térmicos a que foram submetidas.

Na tabela A.4 são apresentadas as propriedades magnéticas da liga Fe-Si.

Tabela A.4 - Propriedades magnéticas da liga Fe-Si.

\begin{tabular}{cccc}
\hline Material & $\begin{array}{c}\text { Permeabilidade } \\
\text { Relativa Inicial }\end{array}$ & $\begin{array}{c}\text { Perdas por Histerese } \\
\text { para B } \text { máx }_{\text {matização }}\end{array}$ & $\begin{array}{c}\text { Magnetiza } \\
\text { de Saturação [T] }\end{array}$ \\
\hline Fe-3\% Si & 500 & 200 & 2 \\
Fe-3\% Si - Grão orientado & 15000 & 50 & 2 \\
\hline
\end{tabular}

Fonte: CIBAS (2006) 


\section{APÊNDICE B - Campos Magnéticos Estáticos e o Método dos Elementos Finitos}

A Lei de Ampère associa a corrente elétrica com a intensidade de campo magnético, e a sua equação diz que a integral de linha da componente tangencial da intensidade de campo magnético sobre um percurso $\ell$ fechado é igual à corrente envolvida por esse caminho.

$$
\oint_{\ell}(\vec{H} \cdot \overrightarrow{d \ell})=I
$$

Onde:

$\overrightarrow{d \ell}$ é um elemento infinitesimal do caminho percorrido [m];

$\vec{H}$ é o vetor de intensidade de campo magnético $\left[\mathrm{A} \mathrm{m}^{-1}\right]$;

I é a corrente elétrica $[\mathrm{A}]$;

$\ell$ é o caminho total percorrido [m].

Aplicando-se o Teorema de Stokes ao primeiro membro da equação (50), tem-se:

$$
\int_{S}(\vec{\nabla} x \vec{H}) \cdot d \vec{S}=\int_{S} \vec{J} \cdot d \vec{S}
$$

Onde:

$d \vec{S}$ é um elemento infinitesimal de área $\left[\mathrm{m}^{2}\right]$;

$\vec{J}$ é a densidade de corrente $\left[\mathrm{A} \mathrm{m}^{-2}\right]$;

$S$ é a área delimitada pelo caminho fechado $\ell\left[\mathrm{m}^{2}\right]$.

Pode-se escrever a Lei de Ampère na forma vetorial:

$$
\vec{\nabla} \times \vec{H}=\vec{J}
$$


A intensidade de campo magnético depende apenas da corrente e é independente do meio. O campo de forças associado a $\vec{H}\left[\mathrm{~A} \mathrm{~m}^{-1}\right.$ ] é a densidade de fluxo magnético $\vec{B}$ [T], que é dado por:

$$
\vec{B}=\mu \cdot \vec{H}
$$

e tendo-se:

$$
v=1 / \mu
$$

tem-se:

$$
\vec{\nabla} \times(\vec{B} v)=\vec{J}
$$

Onde:

$B$ é a densidade de fluxo magnético [T];

$v$ é a relutividade $\left[\mathrm{m} \mathrm{H}^{-1}\right]$;

$\mu$ é a permeabilidade magnética $\left[\mathrm{H} \mathrm{m}^{-1}\right]$.

O fluxo magnético $(\Phi[\mathrm{Wb}])$ através de uma superfície é definido como:

$$
\Phi=\int_{S} \vec{B} \cdot d \vec{S}
$$

Deve-se observar que as linhas do fluxo magnético são percursos fechados, sem um ponto inicial ou final. Isto contrasta com o fluxo elétrico que se origina nas cargas positivas e termina nas negativas. Portanto, os campos $\vec{B}$ não possuem fontes ou sorvedouros, o que é matematicamente expresso por:

$$
\vec{\nabla} \cdot \vec{B}=0
$$


Sabe-se do cálculo vetorial que para qualquer função vetorial $\Phi$, pode-se escrever:

$$
\vec{\nabla} \cdot(\vec{\nabla} \times \Phi)=0
$$

Portanto, uma vez que o divergente de $\vec{B}$ é nulo, deve existir uma função vetorial $\vec{A}$ tal que:

$$
\vec{\nabla} \times \vec{A}=\vec{B}
$$

Pois tem-se:

$$
\vec{\nabla} \cdot(\vec{\nabla} \times \vec{A})=0
$$

qualquer que seja $\vec{A}$.

Substituindo-se a equação (59) na equação (55), tem-se:

$$
\vec{\nabla} \times(v(\vec{\nabla} \times \vec{A}))=\vec{J}
$$

Na prática, pode-se considerar que as componentes x e y do vetor potencial magnético ( $\left.\vec{A}\left[\mathrm{~Wb} \mathrm{~m}^{-1}\right]\right)$ e do vetor densidade de corrente são nulas na maior parte do domínio, existindo apenas a componente em z. Também admitir-se-á que $\vec{A}$ não varia na direção z, mas apenas nas direções x e y (JIN, 1993). Desenvolvendo-se os rotacionais da equação (61), tem-se:

$$
\frac{\partial}{\partial x}\left(\frac{v \partial A}{\partial x}\right)+\frac{\partial}{\partial y}\left(\frac{v \partial A}{\partial y}\right)=-J
$$


Com estas simplificações o potencial magnético, inicialmente apresentado como um vetor, passa a ser tratado como uma função escalar, conforme equação (62), conhecida como equação de Poisson não linear.

Se a relação entre B e $\mathrm{H}$ for linear, $v$ independe de A, e por isso pode ser isolada na equação (62), (ALCANTARA, 1985):

$$
\frac{\partial^{2} A}{\partial x^{2}}+\frac{\partial^{2} A}{\partial y^{2}}=-\frac{J}{v}
$$

Se o meio for livre de correntes, a equação (63) se reduz à equação de Laplace:

$$
\frac{\partial^{2} A}{\partial x^{2}}+\frac{\partial^{2} A}{\partial y^{2}}=0
$$

Pode-se obter o valor da densidade de fluxo magnético através do rotacional do potencial magnético $\left(\mathrm{A}\left[\mathrm{Wb} \cdot \mathrm{m}^{-1}\right]\right)$, ou seja, resolvendo-se a equação (62), e como ela não possui solução analítica conhecida, utiliza-se métodos numéricos para a obtenção de soluções aproximadas.

\section{B.1 Energia do Campo Magnético de Circuitos Portadores de Corrente}

Um circuito genérico é mostrado na figura B.1, que compreende um circuito percorrido por uma corrente elétrica $(i[\mathrm{~A}])$ e outro por um conjunto de malhas. 


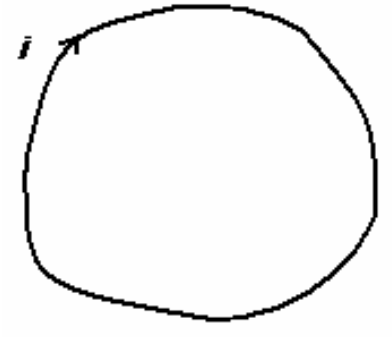

a)

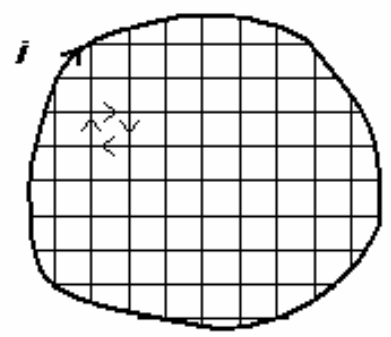

b)

Figura B.1. a) Circuito genérico percorrido pela corrente $i$; b) Conjunto de malhas (ALCANTARA, 1985).

Observando-se a figura B.1 b, nota-se que se cada malha conduzir uma corrente igual à do contorno, não haverá corrente no interior do conjunto de malhas, pois elas se cancelam, restando apenas a do contorno.

As malhas de corrente podem ser aproximadas por dipolos magnéticos, e a energia associada a uma distribuição de corrente pode ser obtida através do cálculo do trabalho para se estabelecer a distribuição de dipolos equivalentes.

O trabalho realizado para girar um dipolo de um ângulo $\delta \theta$, contra o seu binário, é expresso pela equação (65).

$$
\begin{gathered}
\delta W=T \delta \theta \\
\delta W=|\vec{m} \times \vec{B}| \delta \theta=i \cdot \Delta s \cdot B \cdot \operatorname{sen} \theta d \theta
\end{gathered}
$$

Onde:

$\vec{m}$ é o vetor momento magnético $\left[\mathrm{A} \cdot \mathrm{m}^{2}\right]$;

$i$ é a corrente da malha [A];

$T$ é o torque $[\mathrm{Nm}]$;

$W$ é trabalho $[\mathrm{J}]$;

$\Delta \mathrm{s}$ é a área da malha do dipolo elementar $\left[\mathrm{m}^{2}\right]$. 
A energia total é expressa pela equação (67).

$$
\Delta W=i \int \Delta s \cdot B \cdot \operatorname{sen} \theta d \theta=i \cdot \Delta s \cdot B \cdot \cos \theta=i \cdot \Phi
$$

"Calcula-se a energia mais simplesmente por uma maneira semelhante a que é empregada na eletrostática: imaginando-se todos os dipolos, representados por pequenas argolas, reunidos em seus lugares, com orientação correta, mas com todas as correntes mantidas nulas. Evidentemente, não se requer nenhuma energia para se proceder assim. Todas as correntes são então lentamente elevadas aos seus valores finais (ALCANTARA, 1985, p. 21)”.

“Todos os fluxos devem elevar-se em proporção às correntes. Em alguma fase do processo, os fluxos dos dipolos terão valores $h \Phi_{K}$ e as correntes $h i_{K}$, onde $h$ é algum número entre zero e a unidade". (ALCANTARA, 1985, p. 21).

Elevando-se as correntes, aumenta-se a energia:

$$
d W=\sum_{K} h \Phi_{K} \cdot i_{K} d h=h d h \sum_{K} \Phi_{K} i_{K}
$$

Integrando-se em $h$, encontra-se a energia total:

$$
W=\int_{0}^{1} h d h \sum_{K} \Phi_{K} \cdot i_{K}=\frac{1}{2} \sum_{K} \Phi_{K} \cdot i_{K}
$$

Sabendo-se que:

$$
\Phi=\int_{S} \vec{B} \cdot d \vec{S}=\int_{S}(\nabla x \vec{A}) d \vec{S}=\int_{l} \vec{A} d \vec{l}
$$




$$
i_{K}=J_{K} d S
$$

$$
i d l=J d S d l=J d U
$$

Substituindo-se as equações (70), (71) e (72) na (69), tem-se:

$$
W=\frac{1}{2} \sum \oint_{l} \vec{A}_{K} \cdot \vec{J}_{K} d U_{K}
$$

"Desde que o integrando seja zero em todas as porções do espaço não incluídos na equação (73), pode-se estender a região de integração para todo o espaço, pois nenhuma contribuição adicional será acrescentada e, pode-se escrever a equação (73) com uma notação simplificada". (ALCANTARA, 1985, p. 23):

$$
W=\frac{1}{2} \sum \oint_{l} \vec{A} \cdot \vec{J} d U
$$

Da Lei de Ampère, tem-se:

$$
\nabla \times \vec{H}=\vec{J}
$$

Substituindo-se a equação (75) na (74):

$$
W=\frac{1}{2} \int \vec{A} \cdot \nabla \times \vec{H} d U
$$


Utilizando-se a identidade vetorial:

$$
\nabla \cdot(\vec{H} \times \vec{A})=\vec{A} \cdot \nabla \times \vec{H}-\vec{H} \cdot \nabla \times \vec{A}
$$

Tem-se a expressão para a energia:

$$
W=\frac{1}{2} \int \vec{A} \cdot \vec{J} d U=\frac{1}{2} \oint \nabla \cdot(\vec{H} \times \vec{A}) d U+\frac{1}{2} \int \vec{H} \cdot \nabla \times \vec{A} d U
$$

Rearranjando-se a equação (78):

$$
\frac{1}{2} \oint \nabla \cdot(\vec{H} \times \vec{A}) d U=\frac{1}{2} \int \vec{A} \cdot \vec{J} d U-\frac{1}{2} \int \vec{H} \cdot \vec{B} d U
$$

Quando a superfície é estendida a distâncias suficientemente grandes o primeiro termo da equação (79) é nulo:

$$
\frac{1}{2} \int_{V} \vec{A} \cdot \vec{J} d U=\frac{1}{2} \int_{V} \vec{H} \cdot \vec{B} d U
$$

\section{B.2 Funcional de Energia para Campos Magnéticos no Plano}

Devido ao fluxo magnético no entreferro do motor ser bidimensional, o campo magnético também tem o mesmo comportamento (simetria planar). 


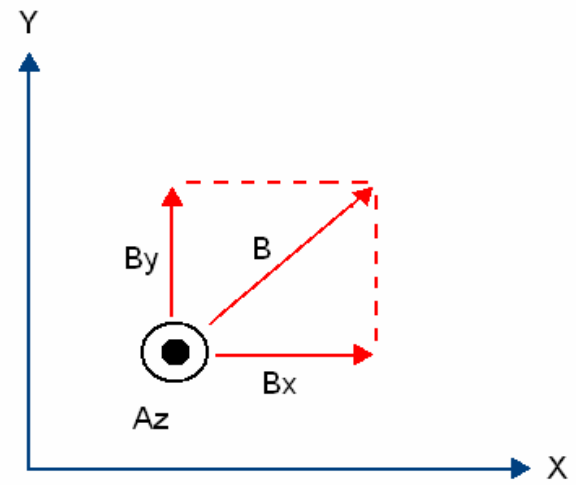

Figura B.2. Representação de um campo magnético bidimensional.

Devido ao comportamento bidimensional do campo magnético, as integrais espaciais da equação (80) podem ser substituídas por integrais no plano:

$$
\frac{1}{2} \int_{S} A \cdot J d S=\frac{1}{2} \int_{S} H \cdot B d S
$$

O termo do lado direito da equação (81) representa a densidade de energia ( $\left.w\left[\mathrm{~J} \mathrm{~m}^{-3}\right]\right)$ e pode ser escrito como:

$$
w=\int_{0}^{B} v B d B
$$

Substituindo-se a equação (82) na (81), obtém-se:

$$
\int_{S}\left(\int_{0}^{B} v B d B\right) d S-\frac{1}{2} \int_{S} A \cdot J d S=0
$$

Subtraindo-se $\left(\frac{1}{2} \int_{S} A \cdot J d S\right)$ de ambos os membros, tem-se:

$$
-\frac{1}{2} \int_{S} A \cdot J d S=\int_{S}\left(\left(\int_{0}^{B} v B d B\right)-A \cdot J\right) d S
$$


Desse modo o funcional de energia $F$ é obtido:

$$
F(A(x, y))=\int_{S}\left(\int_{0}^{B} v B d B-A J\right) d S
$$

A minimização do funcional deve obedecer às condições de contorno. Na figura B.3 está ilustrada a representação de um problema de campo magnético estático.

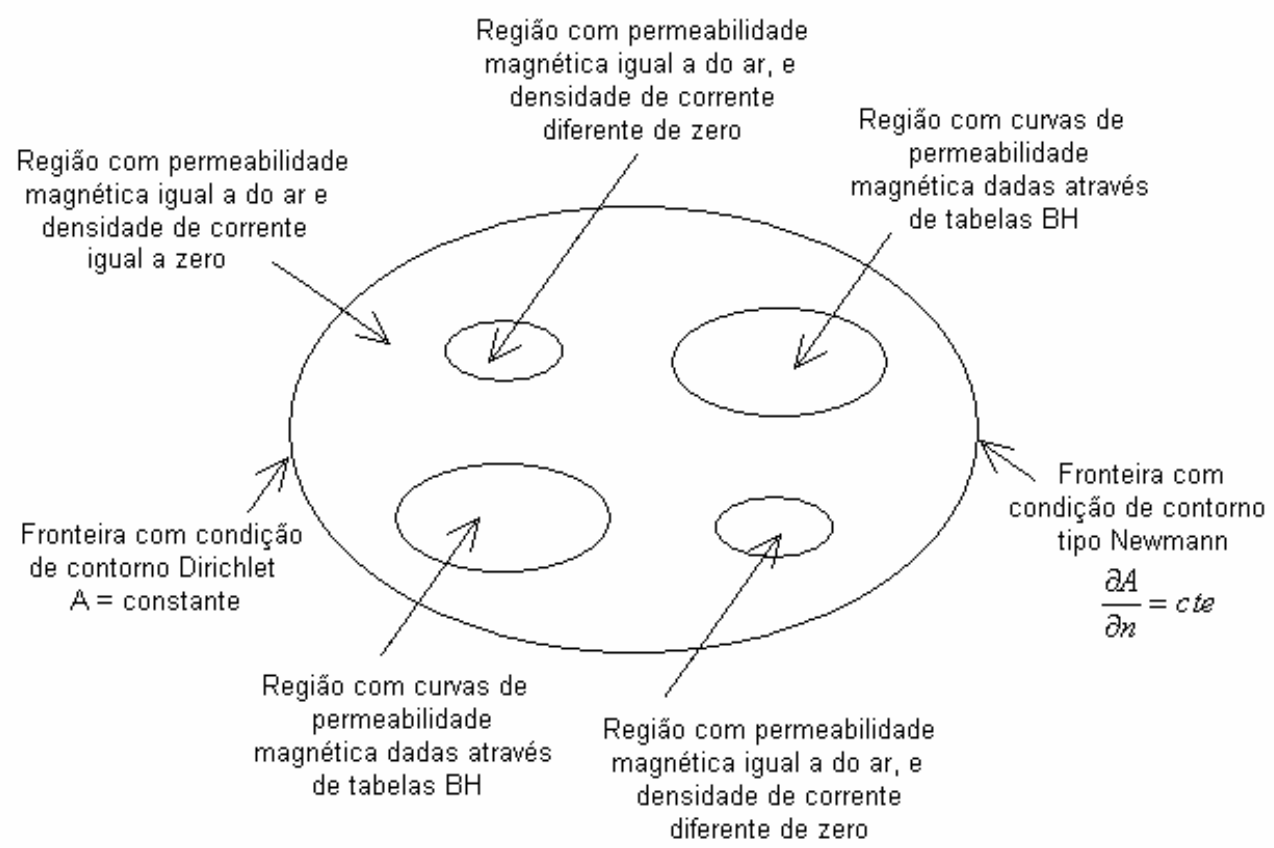

Figura B.3. Representação ilustrativa de um problema de campo magnetostático (ALCANTARA, 2003).

O funcional $F$ encontrado na equação (85) é do tipo:

$$
F=\int I\left(A, A_{x}, A_{y}, x, y\right) d x d y
$$

A equação do integrando é a de Euler-Lagrange:

$$
\frac{\partial I}{\partial A}-\frac{\partial}{\partial x}\left(\frac{\partial I}{\partial A_{x}}\right)-\frac{\partial}{\partial y}\left(\frac{\partial I}{\partial A_{y}}\right)=0
$$


Substituindo-se a equação (85) na equação (87), tem-se:

$$
\frac{\partial}{\partial A}\left(\int_{0}^{B} v B d B-A J\right)-\frac{\partial}{\partial x}\left(\frac{\partial}{\partial A_{x}}\left(\int_{0}^{B} v B d B-A J\right)\right)-\frac{\partial}{\partial_{y}}\left(\frac{\partial}{\partial A_{y}}\left(\int_{0}^{B} v B d B-A J\right)\right)=0
$$

Manipulando-se algebricamente, obtém-se:

$$
\frac{\partial}{\partial A}\left(\int_{0}^{B} v B d B-A J\right)-\frac{\partial}{\partial x} \cdot \frac{\partial}{\partial B}\left(\int_{0}^{B} v B d B-A J\right) \frac{\partial B}{\partial A_{x}}-\frac{\partial}{\partial y} \cdot \frac{\partial}{\partial B}\left(\int_{0}^{B} v B d B-A J\right) \frac{\partial B}{\partial A_{y}}=0
$$

$\mathrm{Ou}$

$$
-J-\frac{\partial}{\partial x} \cdot B \cdot \frac{\partial B}{\partial A_{x}}-\frac{\partial}{\partial y} \cdot B \cdot \frac{\partial B}{\partial A_{y}}=0
$$

Mas:

$$
B \frac{\partial B}{\partial A_{x}}=B \frac{\partial}{\partial A_{x}}\left(\sqrt{A_{x}^{2}+A_{y}^{2}}\right)=A_{x}=\frac{\partial A}{\partial x}
$$

Semelhantemente:

$$
B \frac{\partial B}{\partial A_{y}}=B \frac{\partial}{\partial A_{y}}\left(\sqrt{A_{x}^{2}+A_{y}^{2}}\right)=A_{y}=\frac{\partial A}{\partial y}
$$

A equação Euler-Lagrange se reduz a:

$$
\frac{\partial}{\partial x}\left(\frac{v \partial A}{\partial x}\right)+\frac{\partial}{\partial y}\left(\frac{v \partial A}{\partial y}\right)=-J
$$

Isso comprova que o funcional $F$ encontrado é válido para a resolução do problema de campo magnético no plano. 


\section{B.3 O Método dos Elementos Finitos}

O Método dos Elementos Finitos é um dos métodos numéricos utilizados para se encontrar soluções aproximadas para equações diferenciais a derivadas parciais, dadas as condições de contorno.

Normalmente este método é utilizado em eletromagnetismo para o cálculo e a análise de grandezas, tais como: intensidade de fluxo elétrico, campo elétrico, intensidade de campo magnético, densidade de fluxo elétrico, densidade de fluxo magnético, potencial magnético, torque eletromagnético, indutâncias, resistências, potência elétrica e energia.

A resolução de problemas, utilizando o método acima, engloba os seguintes passos: discretização do domínio da função, seleção da função de interpolação, formulação do sistema de equações e solução do sistema de equações.

\section{B.3.1 Discretização do Domínio da Função}

A discretização do domínio da função consiste em subdividi-lo em inúmeros subdomínios (figura B.4). Estes últimos são denominados elementos, sendo que os mais utilizados para a modelagem eletromagnética são: segmento de reta, triângulo e tetraedro, respectivamente para uma, duas e três dimensões (JIN, 1993).

Os problemas são formulados em termos de uma função desconhecida $\phi$ associada aos nós de cada elemento $(i, j, k)$, ou seja, para um elemento triangular linear há três nós, sendo um em cada vértice. A discretização do domínio $(\Omega)$ é chamada de pré-processamento, pois pode ser executada separadamente e independentemente dos outros passos. 


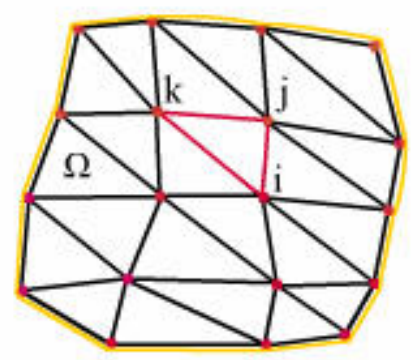

Figura B.4. Representação livre de um domínio subdividido em elementos triangulares (SYKULSKI, 1995).

\section{B.3.2 Seleção da Função de Interpolação}

O segundo passo para a análise, através do método dos elementos finitos, é a seleção da função de interpolação, que irá aproximar o valor da função desconhecida dentro de cada elemento.

Geralmente uma função polinomial é escolhida para ser a função de interpolação. As mais utilizadas são as equações polinomiais de primeira, segunda e terceira ordem. Quanto maior o grau do polinômio, maior a complexidade da formulação, sendo que a mais utilizada é a linear, ou seja, um polinômio de primeira ordem (JIN, 1993).

\section{B.3.3 Formulação do Sistema de Equações}

Um funcional geralmente é uma integral definida, em que o resultado depende da função que define o integrando. Na equação (85) a função é a expressão do potencial magnético $A$ em função de $x$ e $y$.

A solução consiste em encontrar a função $A$ que dá o menor valor para o funcional $F$, ou seja, a minimização do funcional, que é realizada em relação aos valores do potencial magnético nos nós do domínio $(\Omega)$. A função aproximada utilizada é de primeira ordem: 


$$
A(x, y)=\sum_{m=1}^{3} \phi_{m} \cdot A_{m}
$$

Onde:

$A_{m}$ é o potencial magnético em cada nó das malhas dos elementos finitos;

$\phi_{m}$ são as funções de forma.

A minimização do funcional $F$ é feita igualando-se a sua primeira derivada em relação ao potencial magnético em cada nó ( $k$ ) igual a zero (equação 95).

$$
\frac{\partial F}{\partial A_{k}}=0
$$

O potencial magnético é aproximado dentro do elemento triangular por uma função linear:

$$
A^{e}(x, y)=a_{1}+a_{2} x+a_{3} y
$$

Para cada vértice do elemento triangular, o potencial magnético é expresso pela equação (97). 


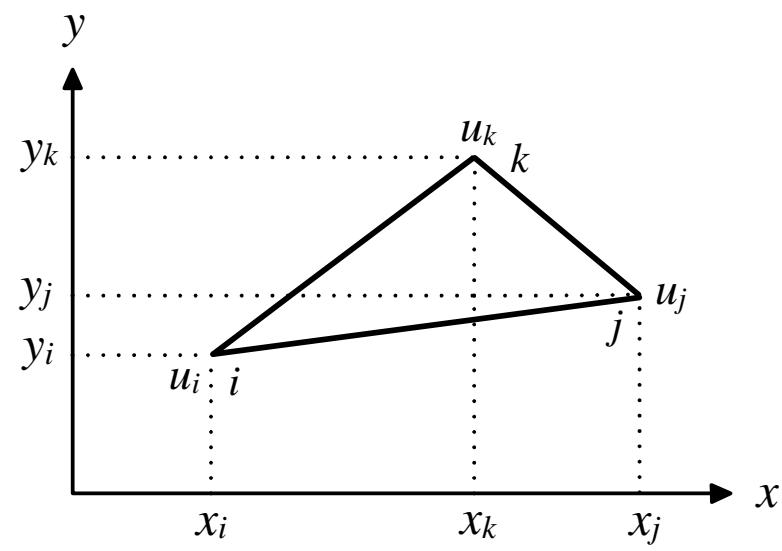

Figura B.5. Elemento triangular.

$$
\begin{aligned}
& A_{i}=a_{1}+a_{2} x_{i}+a_{3} y_{i} \\
& A_{j}=a_{1}+a_{2} x_{j}+a_{3} y_{j} \\
& A_{k}=a_{1}+a_{2} x_{k}+a_{3} y_{k}
\end{aligned}
$$

Resolvendo-se o sistema de equações (97), tem-se:

$$
\begin{aligned}
& a_{1}=\frac{1}{2 \Delta}\left(a_{i} A_{i}+a_{j} A_{j}+a_{k} A_{k}\right) \\
& a_{2}=\frac{1}{2 \Delta}\left(b_{i} A_{i}+b_{j} A_{j}+b_{k} A_{k}\right) \\
& a_{3}=\frac{1}{2 \Delta}\left(c_{i} A_{i}+c_{j} A_{j}+c_{k} A_{k}\right)
\end{aligned}
$$

Sendo:

$$
2 \Delta=\operatorname{det}\left[\begin{array}{ccc}
1 & x_{i} & y_{i} \\
1 & x_{j} & y_{j} \\
1 & x_{k} & y_{k}
\end{array}\right]
$$

Onde:

$\Delta$ é a área do triângulo $\left[\mathrm{m}^{2}\right]$. 


$$
\begin{aligned}
& a_{i}=x_{j} y_{k}-x_{k} y_{j} \\
& b_{i}=y_{j}-y_{k}=y_{j k} \\
& c_{i}=x_{k}-x_{j}=x_{k j}
\end{aligned}
$$

Os coeficientes $a_{j}, b_{j}, \ldots$ são calculados pela permutação cíclica dos subíndices $i, j, k$ (SYKULSKI, 1995):

$$
\begin{aligned}
a_{j} & =x_{k} y_{i}-x_{i} y_{k} \\
b_{j} & =y_{k}-y_{i} \\
c_{j} & =x_{i}-x_{k}, \ldots
\end{aligned}
$$

Substituindo-se a equação (98) na equação (97), tem-se:

$$
\phi_{m}=\frac{a_{m}+b_{m} x+c_{m} y}{2 \Delta} \quad m=i, j, k
$$

Como a densidade de fluxo magnético é igual ao rotacional do vetor potencial magnético (equação 59) e este último é aproximado pela função de primeira ordem (equação 94), a densidade de fluxo magnético pode ser expressa por:

$$
\vec{B}=\frac{1}{2 \Delta} \sum_{i=1}^{3}\left(b_{i} i_{x}+c_{i} i_{y}\right) A_{i}
$$

Sendo o módulo igual a:

$$
|B|=\frac{1}{2 \Delta} \sqrt{\left(b_{1} A_{1}+b_{2} A_{2}+b_{3} A_{3}\right)^{2}+\left(c_{1} A_{1}+c_{2} A_{2}+c_{3} A_{3}\right)^{2}}
$$


Como a aproximação do vetor potencial magnético é definida em termos dos nós dos elementos, a minimização do funcional $F$ será feita igualando-se a sua primeira derivada em relação ao potencial magnético em cada nó igual a zero (equação 105). Por isso, o funcional $F$ deve ser reescrito como sendo um somatório de integrais nos elementos (equação 106).

$$
\begin{gathered}
\frac{\partial F}{\partial A_{k}}=\sum \frac{\partial F_{t}}{\partial A_{k}}=0 \\
F(A(x, y))=\sum F_{t}(A(x, y))
\end{gathered}
$$

Sendo:

$$
F_{t}=\int_{S}\left(-J \cdot A+\int_{0}^{B} v \cdot B d B\right) d x d y
$$

Realizando-se as operações algébricas necessárias, conforme ALCANTARA (1985), tem-se a formulação matemática para cada nó do elemento triangular:

Para o nó 1:

$$
\left(\frac{v}{4 \Delta}\right)\left(\left(b_{1} b_{1}+c_{1} c_{1}\right) A_{1}+\left(b_{1} b_{2}+c_{1} c_{2}\right) A_{2}+\left(b_{1} b_{3}+c_{1} c_{3}\right) A_{3}\right)=\frac{\Delta J}{3}
$$

Para o nó 2:

$$
\left(\frac{v}{4 \Delta}\right)\left(\left(b_{2} b_{1}+c_{2} c_{1}\right) A_{1}+\left(b_{2} b_{2}+c_{2} c_{2}\right) A_{2}+\left(b_{2} b_{3}+c_{2} c_{3}\right) A_{3}\right)=\frac{\Delta J}{3}
$$


Para o nó 3:

$$
\left(\frac{v}{4 \Delta}\right)\left(\left(b_{3} b_{1}+c_{3} c_{1}\right) A_{1}+\left(b_{3} b_{2}+c_{3} c_{2}\right) A_{2}+\left(b_{3} b_{3}+c_{3} c_{3}\right) A_{3}\right)=\frac{\Delta J}{3}
$$

Na forma matricial, tem-se:

$$
\left(\frac{v}{4 \Delta}\right)\left(\begin{array}{lll}
b_{1} b_{1}+c_{1} c_{1} & b_{1} b_{2}+c_{1} c_{2} & b_{1} b_{3}+c_{1} c_{3} \\
b_{2} b_{1}+c_{2} c_{1} & b_{2} b_{2}+c_{2} c_{2} & b_{2} b_{3}+c_{2} c_{3} \\
b_{3} b_{1}+c_{3} c_{1} & b_{3} b_{2}+c_{3} c_{2} & b_{3} b_{3}+c_{3} c_{3}
\end{array}\right)\left(\begin{array}{l}
A 1 \\
A 2 \\
A 3
\end{array}\right)=\left(\frac{\Delta}{3}\right)\left(\begin{array}{l}
J \\
J \\
J
\end{array}\right)
$$

Agrupando-se todas as equações dos elementos, tem-se o seguinte sistema de equação global:

$$
[\mathrm{S}] \cdot[\mathrm{A}]=[\mathrm{R}]
$$

Onde [S] é uma matriz global com informações geométricas e magnéticas, [A] é um vetor contendo o potencial magnético nos nós da malha e [R] é um vetor contendo os valores das correntes nos nós.

A matriz $[\mathrm{S}]$ possui as seguintes características: é altamente esparsa, simétrica, positiva, diagonalmente dominante e singular. A ordem desta matriz é igual ao número de nós na malha de elementos finitos.

Devido a matriz $[\mathrm{S}]$ ser singular (determinante é igual a zero), a equação (112) não possui solução única. Por isso, há a necessidade em impor-se condições de contorno, que normalmente são as de Dirichlet (o valor da função é conhecido no contorno), pois as de Neuman já estão implícitas na formulação variacional (ALCANTARA, 1985).

Além disso, quando duas sub-regiões possuem propriedades magnéticas diferentes é necessário relacionar as soluções dos dois lados da interface (SYKULSKI, 1995). 


\section{B.3.4 Solução do sistema de equações}

Com as condições de contorno impostas ao sistema, ele pode ser resolvido por métodos numéricos que explorem a esparsidade da matriz [S]. Esses métodos podem ser diretos (que fornecem a solução exata do sistema após um número finito de iterações), ou iterativos (que geram uma seqüência de vetores que convergem para a solução do sistema).

\section{B.3.5 Métodos para o Cálculo do Torque}

Um dos principais objetivos em utilizar-se o método dos elementos finitos é o cálculo do torque, que possibilita uma melhor análise do funcionamento da máquina elétrica.

Nas subseções seguintes são apresentados os principais métodos para o cálculo do torque eletromagnético.

\section{B.3.5.1 O Tensor das Tensões de Maxwell}

O torque eletromagnético (equação 113) em uma máquina elétrica pode ser calculado pela integral de superfície da força normal no entreferro, obtida pelo tensor das tensões de Maxwell (equação 114), que é a força por unidade de área produzida pelo campo magnético na superfície (CHUNG; KIM; HAHN, 1997).

$$
\begin{gathered}
\vec{T}_{e l}=\oint_{S} \vec{r} \times \vec{F} d S \\
\vec{F}=\frac{1}{\mu_{0}} \vec{B}(\vec{B} \cdot \vec{n})-\frac{1}{2 \mu_{0}} B^{2} \vec{n}
\end{gathered}
$$


Onde:

$\vec{F}$ é o tensor de Maxwell $\left[\mathrm{N} \mathrm{m}^{-2}\right]$;

$\vec{n}$ é o vetor normal à superfície $\mathrm{S}$;

$r$ é o raio do rotor $[\mathrm{m}]$.

O cálculo do torque, pelo tensor das tensões de Maxwell, pode apresentar resultados imprecisos, se o domínio da função não for discretizado corretamente no local em que se deseja obtê-lo, pois as funções de forma podem não aproximar corretamente os elementos. Erros maiores podem ocorrer nas componentes tangenciais de $\vec{B}$ e $\vec{H}$ em elementos adjacentes às fronteiras entre materiais de diferentes permeabilidades. Erros piores podem ocorrer nos cantos das interfaces, onde a solução exata de $\vec{B}$ é aproximadamente simplificada (MEEKER, 2006).

Para a obtenção de valores mais precisos do torque, pode-se calculá-lo através do Weighted Stress Tensor, que é a versão da integral de volume pelo tensor das tensões de Maxwell. As aproximações para esse cálculo são descritas em (McFee; WEBB; LOWTHER, 1988).

O método baseado no tensor de tensões de Maxwell é um artifício matemático. A densidade de força calculada não é um resultado físico, enquanto que o método baseado no princípio do trabalho virtual apresenta um significado físico (MEDEIROS; REYNE; MEUNIER, 1999). 


\section{B.3.5.2 O Princípio do Trabalho Virtual}

O princípio do trabalho virtual pode determinar o torque pelo cálculo da derivada da energia magnética $(W[\mathrm{~J}])$ em relação a um deslocamento virtual da parte móvel (rotor).

$$
T_{e l}=\frac{\partial W}{\partial \theta_{m}}
$$

\section{B.3.5.3 A Fórmula de Lorentz}

O torque pode ser calculado através da equação (116), sendo $(J \times B)$ a força de Lorentz.

$$
T_{e l}=-\int_{V} a \times(J \times B) d V
$$

Onde:

$a$ é o momento perpendicular ao eixo de rotação e direcionado ao ponto em que a força é calculada. 


\section{APÊNDICE C - Descrição do Programa Computacional de Elementos Finitos FEMM}

O programa FEMM (Finite Element Method Magnetics) é obtido gratuitamente em (MEEKER, 2006), incluindo o seu código fonte. Suas principais características são:

- Utilizar formulação variacional de problemas de campos eletromagnéticos resolvidos pelo método dos elementos finitos (MEEKER, 2006);

- Discretizar o domínio com elementos triangulares de primeira ordem (MEEKER, 2006);

- O algoritmo de triangularização é o de Delaunay (JIN, 1993), com possibilidade de refinamento da malha em regiões onde isto se faz necessário;

- A função de aproximação é de primeira ordem, ou seja, linear (MEEKER, 2006);

- Utilizar o método do Conjugado-Gradiente e o método de Newton-Rapson para a solução do sistema de equações algébricas resultantes da formulação por elementos finitos (MEEKER, 2006).

O programa possui três etapas: pré-processador, processador e o pós-processador. A primeira parte é responsável pela modelagem geométrica, definindo-se materiais, correntes e condições de contorno. A segunda parte executa os cálculos e a terceira visualiza os resultados. Cada etapa é detalhada a seguir. 


\section{C.1 Pré-processador}

Nesta etapa, define-se o tipo de problema, a unidade do desenho e a precisão dos cálculos (figura C.1). Desenha-se o modelo geométrico a ser estudado (figura C.2), define-se as propriedades elétricas e magnéticas dos materiais, selecionando-as na biblioteca (figura C.3), e acrescenta-as através da definição de propriedades (figura C.4). O programa também permite a inclusão de novos materiais (figura C.5).

A última parte dessa etapa é a criação da geometria discretizada com elementos triangulares (figura C.6).

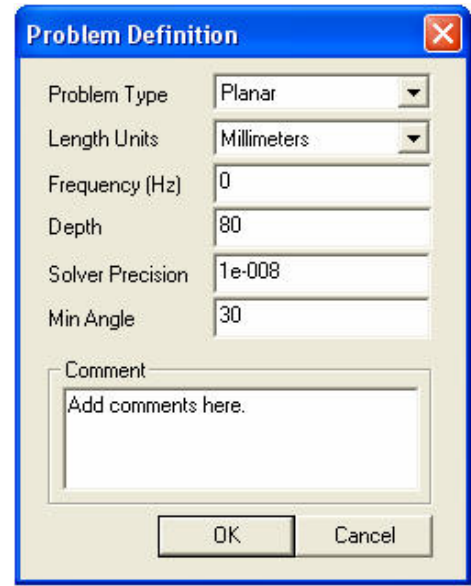

Figura C.1. Definição do problema.

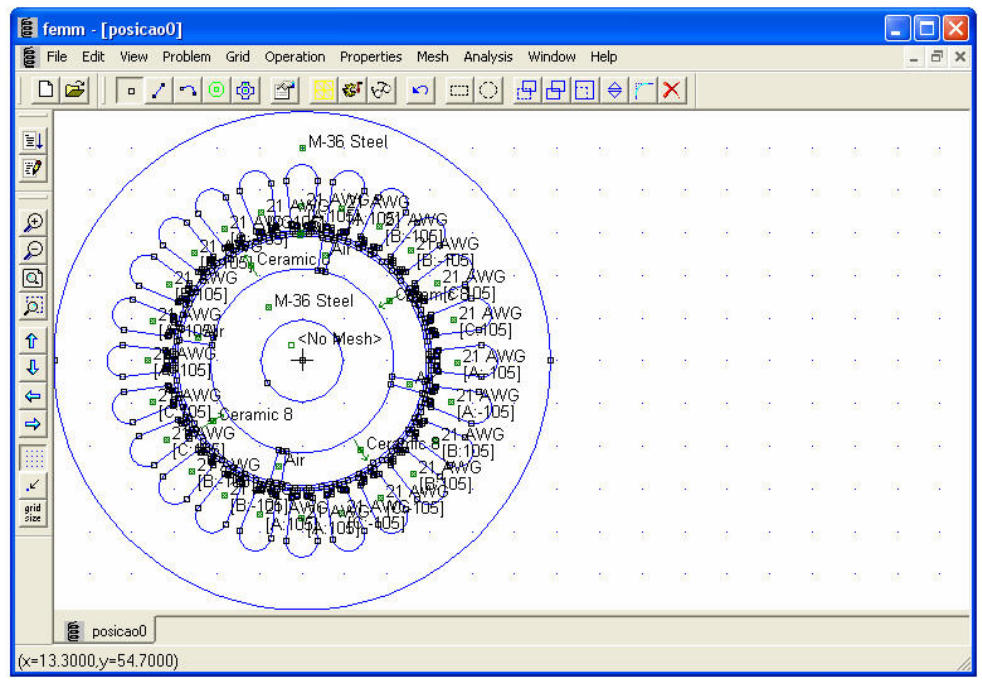

Figura C.2. Desenho da geometria. 


\section{Materials Library}

Library Materials Air

$+\square$ PM Materials

$+\square$ Soft Magnetic Materials

$+\square$ Solid Non-Magnetic Conductors

$+\square$ Copper AWG Magnet Wire

$+\square$ Copper SWG Magnet Wire

$+\square$ Copper Metric Magnet Wire

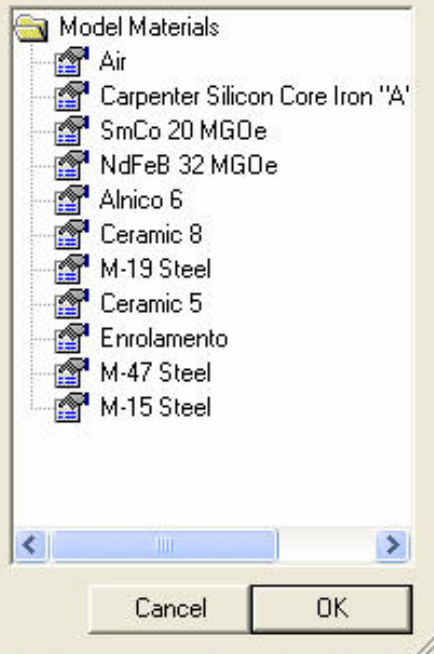

Figura C.3. Biblioteca dos materiais.

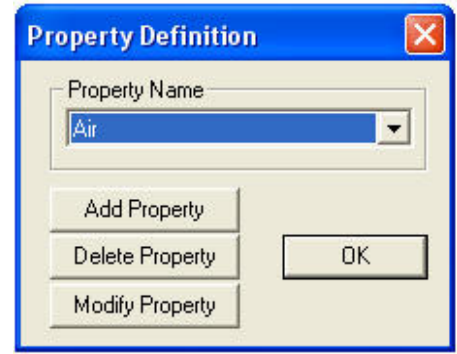

Figura C.4. Definição das propriedades.

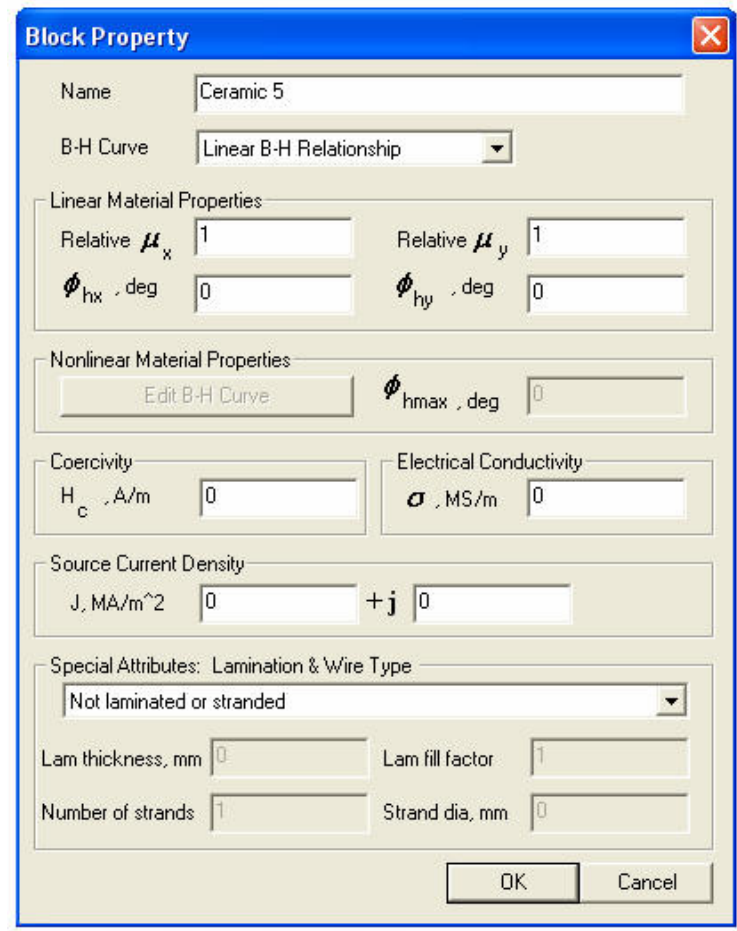

Figura C.5. Edição das características de um dado material. 


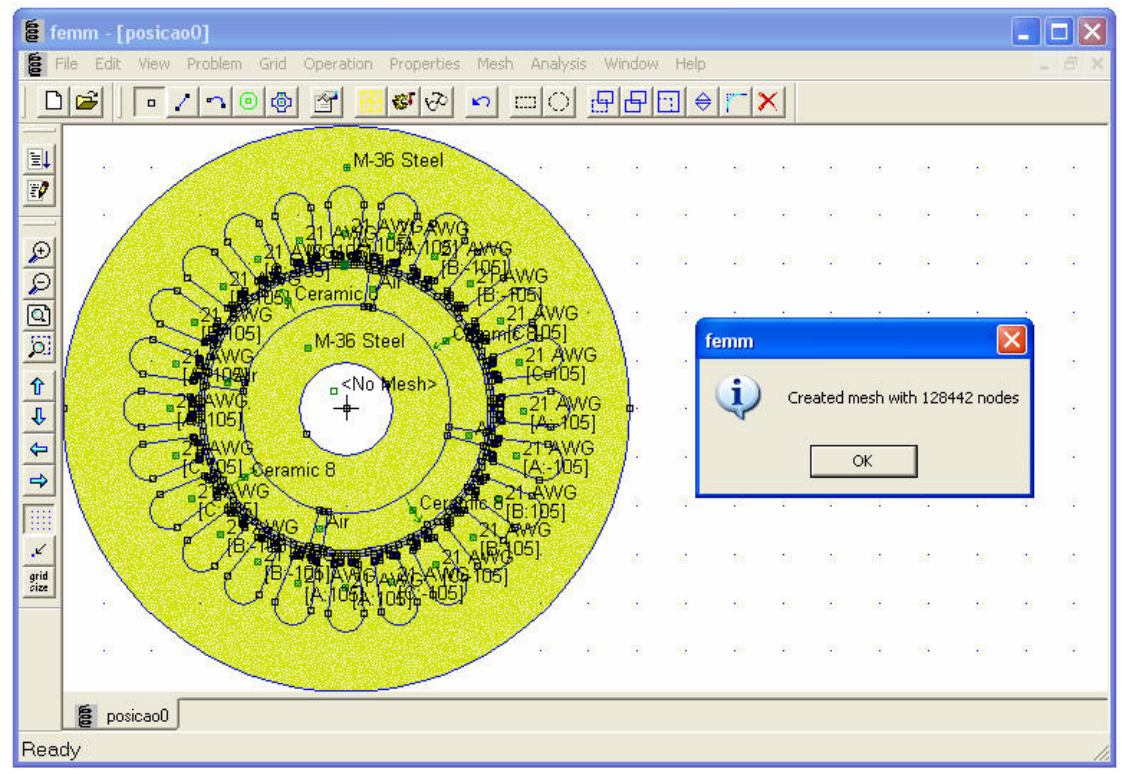

Figura C.6. Discretização da geometria em elementos triangulares de primeira ordem.

\section{C.2 Processador}

Nesta fase, a geometria já está totalmente configurada, os materiais já foram definidos, as condições de contorno impostas e a discretização realizada (MEEKER, 2006). O cálculo é efetuado através das equações geradas utilizando-se métodos numéricos. Pode-se observar essa etapa através da figura C.7.

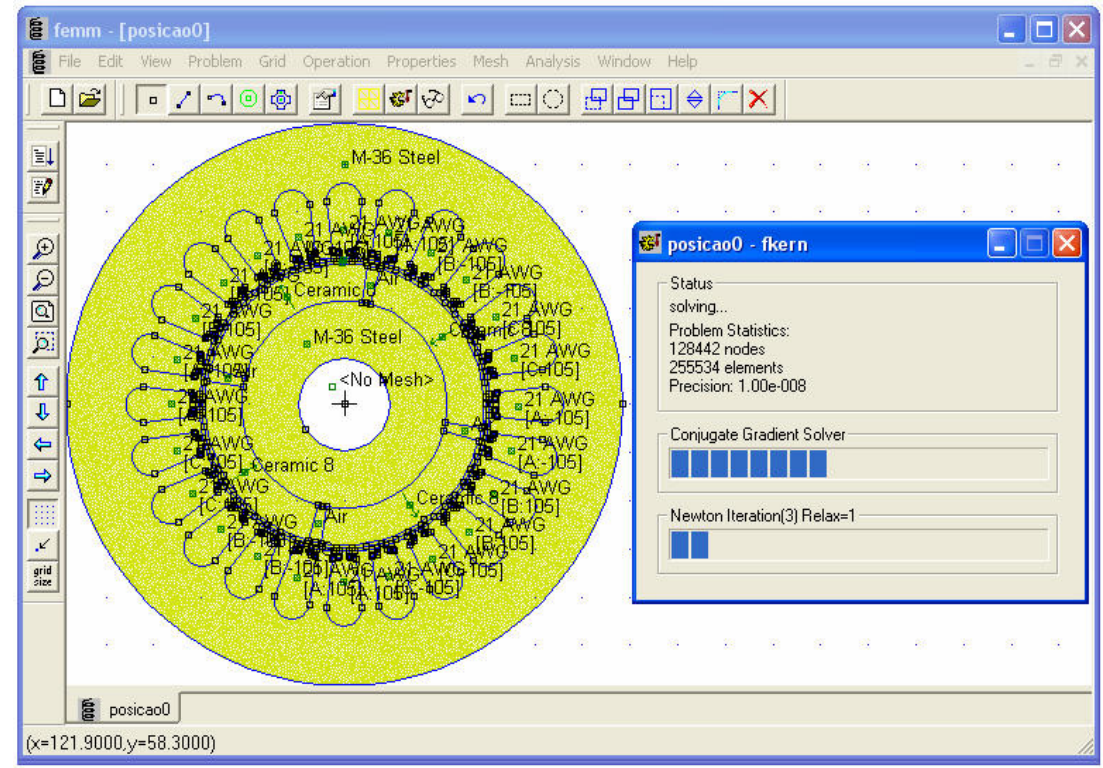

Figura C.7. Execução dos cálculos. 


\section{C.3 Pós-processador}

Nesta etapa, visualiza-se os resultados através dos gráficos de linhas de fluxo (figura C.8), dos gráficos de cores que representam a densidade de fluxo magnético (figura C.9) e dos gráficos da curva de indução magnética (figura C.10). Também é possível gravar resultados numéricos em arquivos do tipo texto durante a fase do pós-processamento. Isso foi muito utilizado durante a execução deste trabalho.

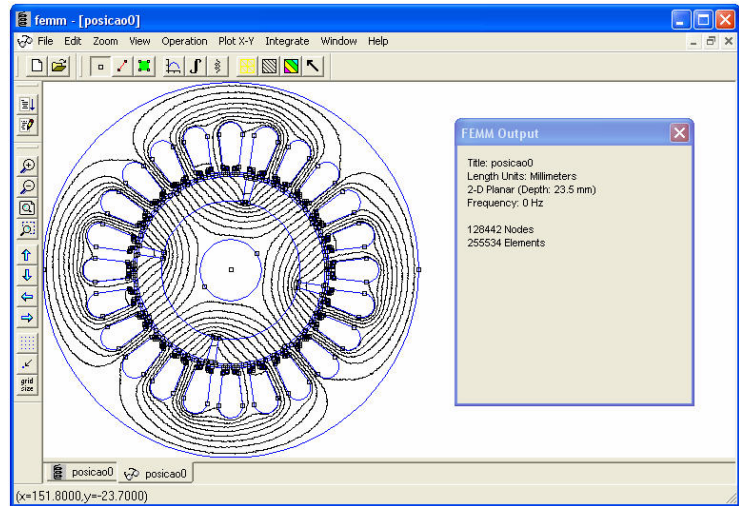

Figura C.8. Gráfico de linhas.

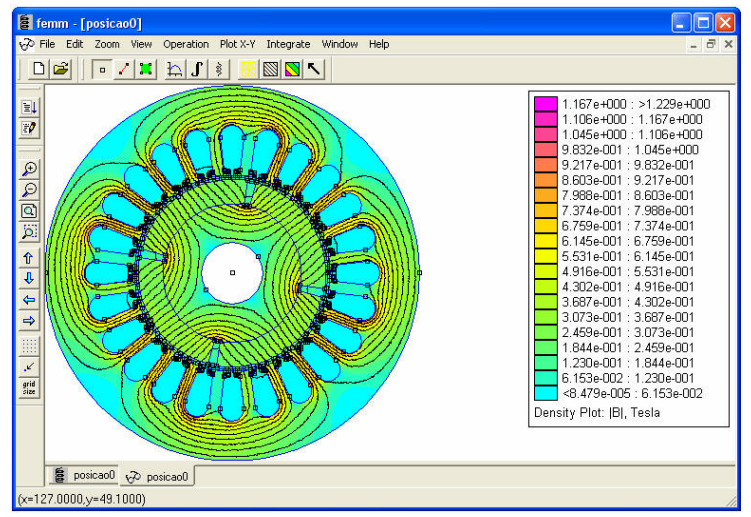

Figura C.9. Gráfico de cores.

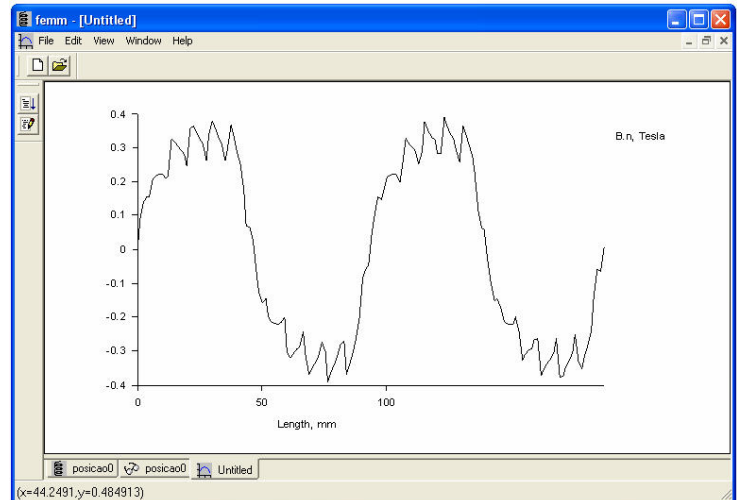

Figura C.10. Gráfico da densidade de fluxo magnético da componente normal. 


\section{C.4 Descrição da Linguagem Lua Scripting}

A linguagem Lua foi projetada e implementada pelo Grupo da Tecnologia de Computação Gráfica (Tecgraf), da Pontifícia Universidade Católica do Rio de Janeiro (PUCRio), por: Roberto Lerusalimschy, Waldemar Celes e Luiz Henrique de Figueiredo. A primeira versão (Lua 1.0) é de julho de 1993 e a versão atual (Lua 4.1.1.) é de junho de 2006. A motivação para a criação dessa linguagem foi a necessidade das aplicações do Tecgraf serem configuradas externamente pelos usuários (LUA, 2006).

A distribuição de Lua é gratuita, incluindo o seu código fonte, que está disponível em (LUA, 2006).

A linguagem Lua Scripting é projetada para estender aplicações e também utilizada como uma linguagem de propósito geral. Possui a grande vantagem de ser interpretada, ou seja, não precisa ser compilada, apenas executada.

Lua é escrita em ANSI C e é implementada como uma pequena biblioteca de funções C. Funciona acoplada a programas hospedeiros em linguagens tradicionais como $\mathrm{C}$ e $\mathrm{C}++$. Combina programação procedural com poderosas construções para descrição de dados, baseados em tabelas associativas e semântica extensível. É considerada uma linguagem segura, pois não é possível acessar serviços não autorizados do programa hospedeiro (LUA, 2006).

"Lua é tipada dinamicamente, interpretada a partir de bytecodes e tem gerenciamento automático de memória com coleta de lixo. Essas características fazem de Lua uma linguagem ideal para configuração, automação (scripting) e prototipagem rápida." (LUA,2006). 